\title{
Molten Salt Reactor Engineering Study for Off-Gas Management
}

\section{Nuclear Technology}

Research and Development

Prepared for

US Department of Energy MSR Campaign

J. McFarlane, ${ }^{(\mathrm{a})}$ B.J. Riley, ${ }^{(\mathrm{b})}$ D.E. Holcomb, (a) A. Lines, (b) H.B. Andrews, ${ }^{(a)}$ S.A. Bryan, ${ }^{(b)}$ A.S. Chapel,(a) N.D.B. Ezell,,(a) H.M. Felmy, , $^{(\mathrm{b})}$ M.S. Greenwood, (a) P.W. Humrickhouse, ${ }^{(\mathrm{c})}$ and K.G. Myhre ${ }^{(\mathrm{a})}$

(a) Oak Ridge National Laboratory (b)Pacific Northwest National Laboratory (c)Idaho National Laboratory August 31, 2020 ORNL/TM-2020/1602, PNNL-30159 


\section{DISCLAIMER}

This information was prepared as an account of work sponsored by an agency of the U.S. Government. Neither the U.S. Government nor any agency thereof, nor any of their employees, makes any warranty, expressed or implied, or assumes any legal liability or responsibility for the accuracy, completeness, or usefulness, of any information, apparatus, product, or process disclosed, or represents that its use would not infringe privately owned rights. References herein to any specific commercial product, process, or service by trade name, trade mark, manufacturer, or otherwise, does not necessarily constitute or imply its endorsement, recommendation, or favoring by the U.S. Government or any agency thereof. The views and opinions of authors expressed herein do not necessarily state or reflect those of the U.S. Government or any agency thereof. 


\section{SUMMARY}

In previous work published by the current team, the waste processing and waste form options were summarized for molten salt reactors (MSR) (Riley et al., 2018b; Riley et al., 2019). The primary types of waste from an MSR are summarized in Figure S1 and include (1) off-gas streams, (2) salt waste streams, (3) separated salt streams, (4) metal waste streams, (5) carbon waste streams, (6) decommissioning and decontaminating (D\&D) waste streams, and (7) operating waste streams, or those that are generated from maintenance procedures. The primary focus of this report will be on management of the off-gas stream as it represents the pressure boundary for fuel-salt MSRs and, thus, is required for fission product confinement during reactor operation and reduction of the source term during a reactor accident.

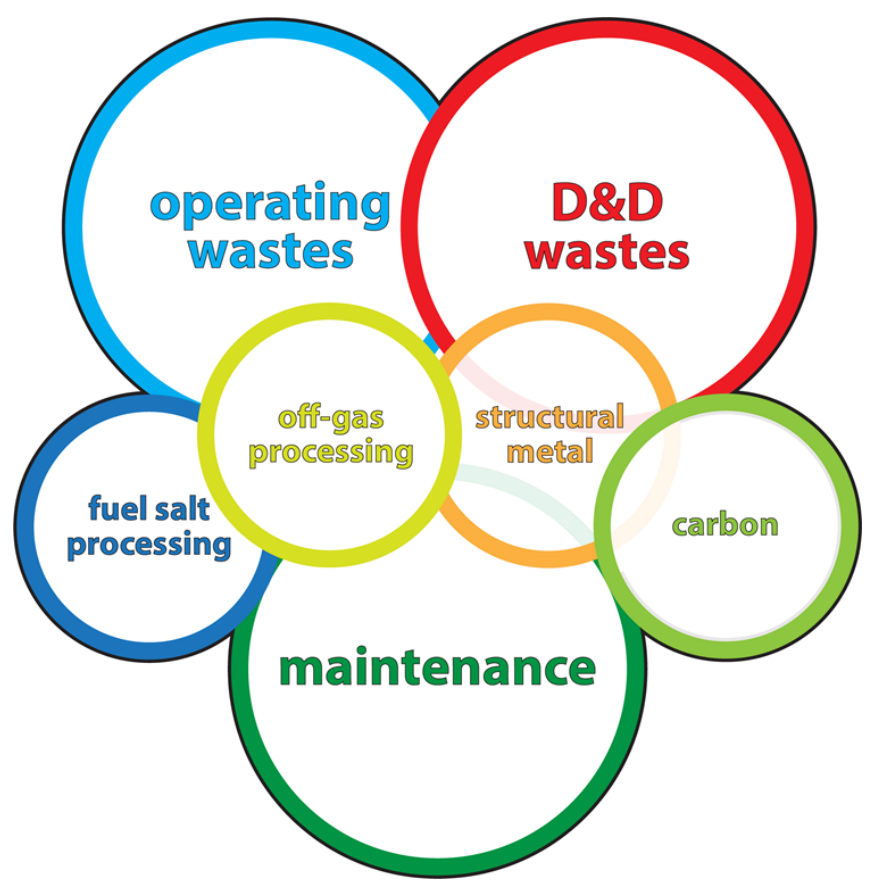

Figure S1. Summary of waste management categories for molten salt reactor program including the upper level (i.e., fuel salt processing, off-gas processing, structural metal, and carbon) and the lower level signifying when materials become wastes (i.e., operating wastes, decontamination and decommissioning wastes, and maintenance). (Modified from Riley et al., 2018)

The goals of this report are to accomplish the following:

- To draft the requirements of an off-gas system for a generic MSR type for (1) normal operation, (2) an off-gas rupture accident, and (3) during a station blackout event

- To consider three different off-gas types: (1) a minimal release configuration that serves to retain fission products within the reactor vessel; (2) a system that relies on physical trapping that includes a decay tank, mechanical filtration, and activated carbon beds; (3) physical and chemical scrubbing including a caustic scrubber

- To take models of actinides, fission products, and activation products within a fuel salt and to determine their chemical speciation and release into the headspace of an MSR and to identify likely decay products that would accumulate in the off-gas system

- To review the components of an end-to-end off gas system for a molten salt; their functionality in removal of radionuclides, acidic gases, and salt mist; and design readiness 
- To review methods of online monitoring to ensure off-gas performance during normal operation, loss of external power, and off-gas rupture events

- To develop a set of design drawings for a caustic scrubber and to discuss how it could be incorporated into a complete off-gas system

- To give the parameters for a thermal analysis of an off-gas system and its components, assuming the transportation and deposition of fission products from long-burnup reactor fuel

- To identify which parts of the off-gas system are well understood and in commercial production, and which need more research and development to increase their technical readiness level

- To report procedures that will be needed for regular maintenance of an off-gas system and planned mitigation for off-normal events such as leakage, and to suggest actions in the event of a station blackout or major off-gas system rupture event

- To suggest end-of-life decommissioning and waste form development of off-gas system components. 


\section{CONTENTS}

SUMMARY .iii

FIGURES vi

TABLES .vii

ABBREVIATIONS AND ACRONYMS viii

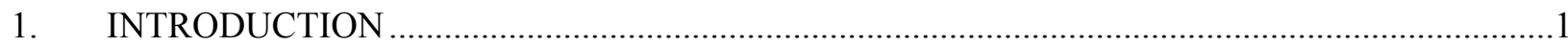

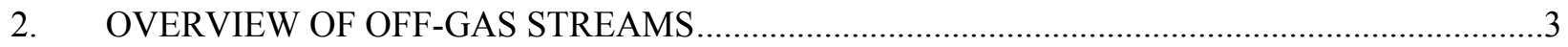

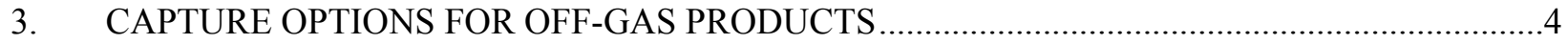

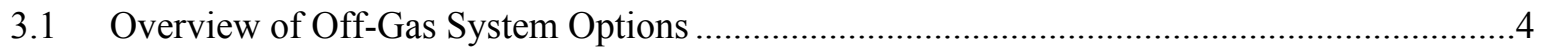

3.2 Particulates, Mists, Aerosols, and Reactive Gases.............................................................

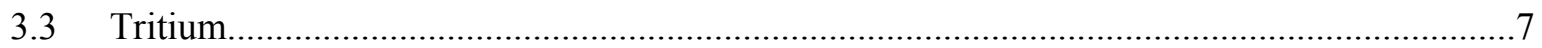

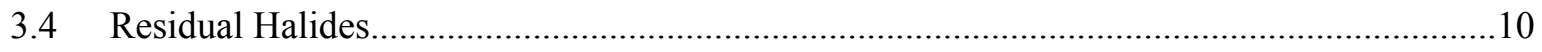

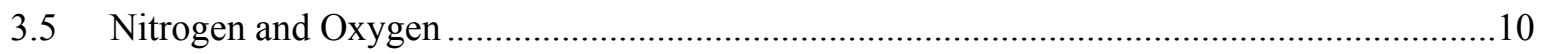

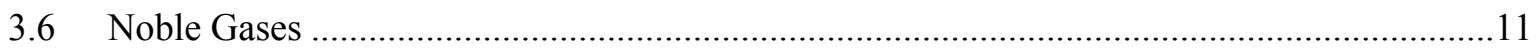

3.6.1 Cryogenic Distillation for Noble Gas Capture..........................................................11

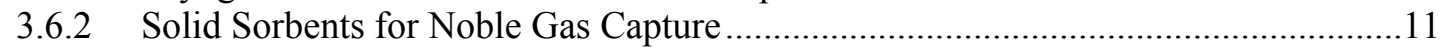

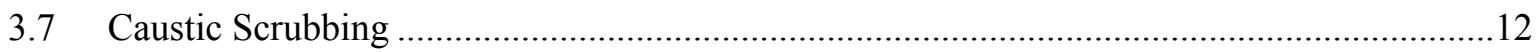

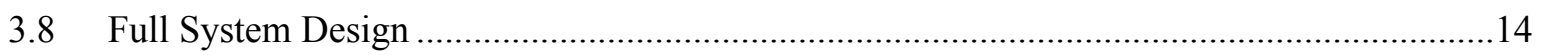

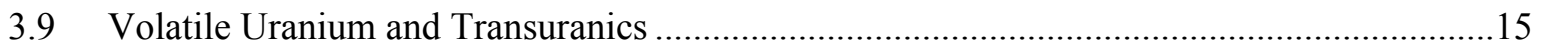

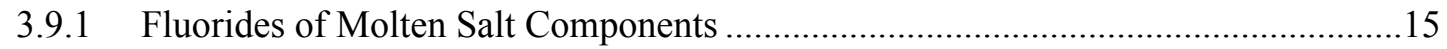

3.9.2 Separations Methods Based on Fluoride Volatility .................................................16

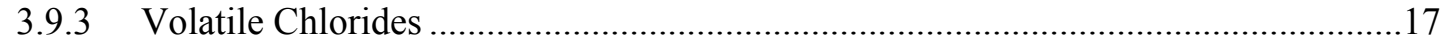

3.9.4 Separations Methods Based on Chloride Volatility ................................................... 18

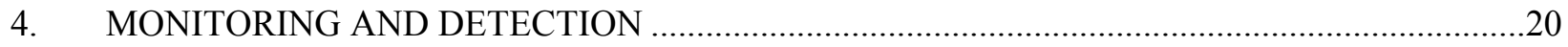

4.1 Online Chemical Composition Analysis for Molten Salt Reactor Off-Gas Treatment

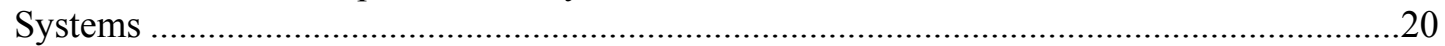

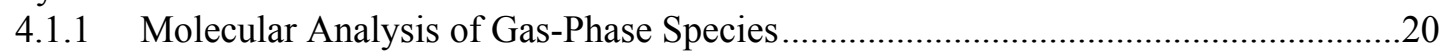

4.1.2 Elemental Analysis of Gaseous Species ...............................................................26

4.1.3 Online Monitoring Applied to Non-Gas-Phase Portions of Off-Gas

Treatment Systems .....................................................................................28

4.2 Online Monitoring beyond Chemical Composition for MSR Off-Gas Treatment

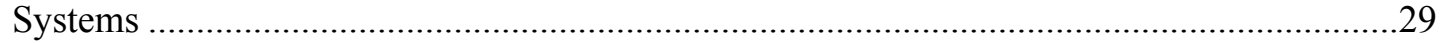

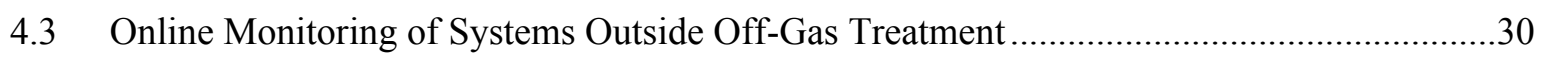

5. AN OFF-GAS SYSTEM AND COMPUTER-AIDED DESIGN …...............................................33

6. THERMAL AND MASS ACCOUNTANCY ANALYSIS INCLUDING DECAY HEAT CALCULATIONS. 
7. CONSIDERATIONS FOR NORMAL OPERATION AND MAINTENANCE, OFFNORMAL EVENTS AND COVER GAS SYSTEM RUPTURE

8. LIFECYCLE OF OFF-GAS COMPONENTS AND WASTE FORMS …..................................40

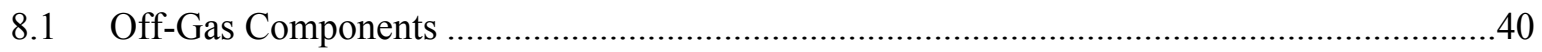

8.2 Waste Forms and Treatment Options for Salt Streams ......................................................40

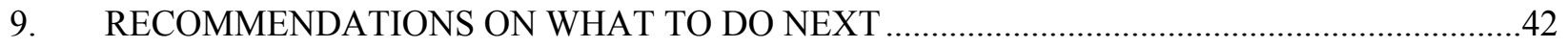

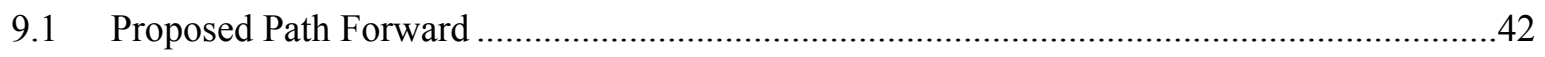

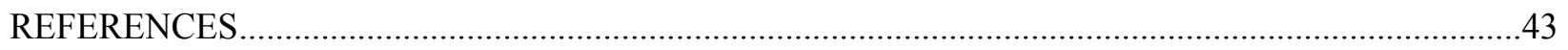

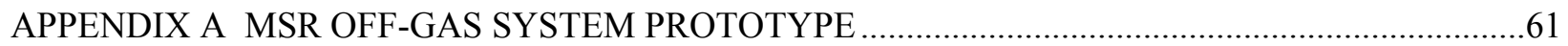

\section{FIGURES}

Figure 3-1. Schematic flow diagram of MSBR off-gas system (Robertson, 1971a)................................4

Figure 3-2. Lithium and beryllium activation and decay schemes associated with tritium........................8

Figure 3-3. Schematic of the overall off-gas system for a commercial MSR based on the MSRE experience (Riley et al., 2018a). .13

Figure 3-4. LiOH-NaOH-KOH ternary diagram from Reshetnikov and Vilutis (1959).

Figure 4-1. (a) Raman spectra of gaseous $I_{2(g)}$ in a sealed quartz reference cell from $532 \mathrm{~nm}$ and $671 \mathrm{~nm}$ Raman systems with a 0.5 second integration time.

Figure 4-2. (a) Spectrum of lowly tritiated gas sample with all six hydrogen isotopologues measured (Fischer et al., 2011).

Figure 4-3. (a) Schematic of probe inserted into gas line and (b) schematic of monitoring setup maximizing distancing between probe within the hazardous environment and instrument/operator in safe environment.

Figure 4-4. (a) Infrared spectra of $\mathrm{ICl}$ at $25^{\circ} \mathrm{C}$ and various pressures ( 0 to 6.91 Torr); inset: closeup view of low-frequency $\mathrm{HCl}$ features.

Figure 4-5. FTIR absorbance measurements of variable pressure $\mathrm{ICl}$ collected at $25^{\circ} \mathrm{C}, 35^{\circ} \mathrm{C}$, $50^{\circ} \mathrm{C}$, and $70^{\circ} \mathrm{C}$ (a)-(d), respectively; (e) PLS model results for the prediction of ICl pressure based on FTIR absorbance data.

Figure 4-6. Schematic of the sampling chamber used for performing LIBS measurements on an aerosol stream such as what would be expected to be present under certain conditions in the off-gas system of MSRs. The same sampling chamber could be used to deploy other optical spectroscopy techniques, such as Raman, in tandem with LIBS

(McFarlane et al., 2019a)......

Figure 4-7. Concentration of $\mathrm{Gd}, \mathrm{Nd}$, and $\mathrm{Sm}$ as a function of time measured in real time using PLS regression analysis of LIBS data collected on a room-temperature aerosol of a water solution containing dissolved lanthanide metal salts to simulate a molten salt aerosol stream containing lanthanide fission products.

Figure 4-8. Cyclic voltammograms of $\mathrm{LiCl}-\mathrm{KCl}-\mathrm{UCl}_{3}$ at a glassy carbon electrode at $755 \mathrm{~K}$. 
Figure 4-9. (a) The absorption spectra of (a) $\mathrm{UO}_{2}{ }^{2+}$, (b) $\mathrm{UO}_{2}{ }^{+}$, (c) $\mathrm{U}^{4+}$, (d) $\mathrm{U}^{3+}$ in $\mathrm{LiCl}-\mathrm{RbCl}$ eutectic melt at $400^{\circ} \mathrm{C}$ (Nagai et al., 2013).

Figure 5-1. Summary of off-gas constituents and planned path forward for capture, immobilization, disposal, and/or release. .....

Figure 5-2. CAD drawing of molten hydroxide eutectic scrubber.

Figure 6-1. Schematic for fission product transport from the condensed molten salt phase to the cover gas.

Figure 6-2. TRANSFORM platform for a reactor systems model that includes the off-gas.

Figure 8-1. Summary of waste management categories for MSR program including the upper level (i.e., fuel salt processing, off-gas processing, structural metal, and carbon) and the lower level signifying when materials become wastes (i.e., operating wastes, D\&D wastes, and maintenance) (modified from Riley et al., 2018).

Figure 8-2. Overview of (a) chloride salt partitioning options and final products targeting alkalis $\left(\mathrm{A}^{+}\right)$, alkaline earths $\left(\mathrm{AE}^{2+}\right)$, rare earths $\left(\mathrm{RE}^{3+}\right)$, actinides $\left(\mathrm{An}^{3+}\right)$, and halides $\left(\mathrm{Ha}^{-}\right)$ where the product(s) listed are those resulting from the partitioning process ( $\mathrm{FP}=$ fission product, USHYZ = ultrastable H-Y zeolite, $\mathrm{SAP}=$ silica aluminophosphate).

\section{TABLES}

Table 1-1. Examples of different types of MSRs designs. TRISO = tristructural isotropic.

Table 3-1. Summary of volatile off-gas waste components that will or could require capture and/or immobilization. This table was taken from Riley et al. (2018b; 2019). WF = waste form, HEPA = high-efficiency particulate air, $\mathrm{AgZ}=$ silver mordenite, $\mathrm{HZ}=$ hydrogen mordenite.

Table 3-2. Source of tritium production $2250 \mathrm{MW}_{\text {th }}$ MSR (Briggs and Korsmeyer, 1970).......................8

Table 3-3. Summary of solid sorbent options in the literature for noble gas capture...............................12

Table 3-4. Examples of actinide solubilities in salt mixtures.

Table 3-5. Selected fluorides that can be made from LWR used nuclear fuel (UNF), along with boiling temperature $\left(T_{\mathrm{b}}\right)$ and the typical amount found in LWR UNF.

Table 3-6. Summary of vapor pressures and boiling temperatures $\left(T_{\mathrm{b}}\right)$ for various chloride species.

Table 4-1. Optical spectroscopic techniques capable of analyzing the following examples of potential molecular off-gas species. FTIR denotes Fourier transform infrared spectroscopy.

Table 4-2. Examples of species expected to be trapped by molten hydroxide scrubber and the optical techniques capable of analysis. 


\section{ABBREVIATIONS AND ACRONYMS}

$3 \mathrm{D}$

A

$\mathrm{AC}$

$\mathrm{AE}$

$\mathrm{Ag}^{0}$-aerogel

AgZ

An

CAD

CG

$\mathrm{CV}$

D\&D

DOAS

DOE

FHR

FLiBe

FY

FP

FTIR

GBS

Ha

HEPA

HZ

IAEA

ISA

LIBS

LiDAR

LWR

MOF

MSBR

MSR three-dimensional

alkali

activated carbon

alkaline earth

silver-functionalized silica aerogel

silver mordenite

actinoids (or actinides) (i.e., ${ }_{89} \mathrm{Ac} \rightarrow{ }_{103} \mathrm{Lr}$ )

computer-aided design

chalcogels (chalcogen-based aerogels)

cyclic voltammogram (voltammetry)

decontamination (or decontaminating) and decommissioning

differential optical absorption spectroscopy

US Department of Energy

fluoride-salt-cooled high-temperature reactor

$\mathrm{LiF}-\mathrm{BeF}_{2}$ salt (i.e., typically $2{ }^{7} \mathrm{LiF} \cdot \mathrm{BeF}_{2}$ )

fiscal year

fission product

Fourier transform infrared (spectroscopy)

glass-bonded sodalite (waste form)

halide

high-efficiency particulate air (filter)

hydrogen mordenite

International Atomic Energy Agency

integrated safety assessment

laser-induced breakdown spectroscopy

light detection and ranging

light water reactor

metal-organic framework

molten salt breeder reactor

molten salt reactor 


$\begin{array}{ll}\text { MSRE } & \text { molten salt reactor experiment } \\ \text { NDA } & \text { nondestructive assay } \\ \text { NIR } & \text { near-infrared } \\ \text { ORNL } & \text { Oak Ridge National Laboratory } \\ \text { PLS } & \text { partial least-squares } \\ \text { RE or REs } & \text { rare earth (element); lanthanoids (or lanthanides) }+\mathrm{Sc}+\mathrm{Y} \\ \text { SAP } & \text { silica aluminophosphate (waste form) } \\ \text { SDB } & \text { 4,4-sulfonyldibenzoate } \\ \text { TF } & \text { tritium fluoride } \\ \text { TRISO } & \text { tristructural isotopic (fuel) } \\ \text { UNF } & \text { used nuclear fuel } \\ \text { USHYZ } & \text { ultrastable H-Y zeolite (waste form) } \\ \text { UV } & \text { ultraviolet (light) } \\ \text { Vis } & \text { visible (light) } \\ \text { WF } & \text { waste form } \\ \text { ZIT } & \text { zinc-in-titania (waste form) }\end{array}$





\section{INTRODUCTION}

The Department of Energy Office of Nuclear Energy's (DOE NE's) advanced reactor technology program seeks to develop and demonstrate technologies that would decrease the risk for private developers to deploy advanced reactors. Molten salt reactors (MSRs), one of these advanced reactor concepts, are subdivided into liquid-salt-fueled and liquid-salt-cooled solid-fueled variants, the latter generally being referred to as a fluoride-salt-cooled high-temperature reactor (FHR). Liquid-salt-fueled MSRs are further subdivided into chloride and fluoride fuel salt types (although less-common mixed fluoride-chloride salts may have advantageous features). The MSR concept is being considered because of its potential for superior economics, readily understandable passive safety, high exergy (and consequent potential to participate in energy markets beyond electricity), high thermodynamic efficiency, greater fissile material utilization, and reduced high-level-waste generation. As MSRs can maintain low-pressure even under accident conditions and the primary circuit fluids have low volatility, the potential for a catastrophic accident involving overpressure is very unlikely. The goal for operating these reactors is to be able to be "walk away" safely.

However, MSRs present challenges in terms of developing an adequate understanding of the chemistry of the salt and the configuration of the fuel, particularly in the case of salt-fueled reactors. (Holcomb et al. 2020) One means of understanding fission product behavior is to develop online instrumentation to determine the chemistry of the fission products that will inform their transport, deposition, and in some cases, the redox state of the salt in the core. Molten-salt-fueled reactors will evolve fission gas during operation. The release of these radionuclides to the headspace of a reactor will require monitoring and ongoing inventory control (Riley et al., 2019) and there will be commonalities in approach across reactor types. Although many fission products are highly soluble in the salt (lanthanides for example), fission gases such as xenon and krypton will readily escape the salt. Acidic gases may accumulate in the headspace as a result of radiolysis. Interhalogens that include fission product iodine may also have significant volatility. However, our knowledge of their speciation is limited to observations during MSRE and we lack detailed understanding of the thermodynamics and transport of these species. Tritium is formed by neutron interactions with light elements in the salt (especially ${ }^{6} \mathrm{Li}$ and ${ }^{7} \mathrm{Li}$ ) and is a ternary fission product. Thus, the off-gas or cover gas system of a molten salt can be considered a radionuclide boundary and a primary means for preventing quantification of radionuclide release. Proper cover gas management during normal operation can mitigate possible fission product release should a breach occur in the off-gas system.

This report considers the lifecycle of the off-gas system, including waste stream. The volatile effluent from an MSR can also be considered a waste stream. Management of waste streams generated from MSRs will be a key element of design and operations. The primary types of waste that can result from MSR operation include (1) used fuel salt waste streams, (2) off-gas streams or volatile effluent, (3) salt processing waste streams, (4) metal component waste streams, (5) carbon waste streams, (6) activated secondary coolant waste streams, and (7) decommissioning and decontaminating (D\&D) waste streams. Some potential solutions were provided recently for managing these wastes (Riley et al., 2018b; Riley et al., 2019); however, many of the available solutions for managing these waste streams have not yet been demonstrated at full scale with actual radionuclides. The goal of this current report is a more in-depth focus of the off-gas management than has been provided in previous studies.

The specific streams coming off the reactor will depend on several variables, including the following:

- Reactor type, e.g., salt cooled, thermal spectrum fluoride salt fueled, and fast spectrum chloride salt fueled

- Salt type, e.g., chloride salts may evolve $\mathrm{Cl}_{2(\mathrm{~g})}$ and volatile species such as $\mathrm{UCl}_{4}$ and fluoride salts may evolve $\mathrm{F}_{2(\mathrm{~g})}$ and volatile species such as $\mathrm{UF}_{6}$.

- Reactor spectrum, fissile and fertile material types, and fuel processing strategy result in different fission product distributions. 
- Real-time separations technologies, e.g., pathways for fission product removal, could introduce other gases and volatiles.

Liquid salt fuel provides a very wide set of potential designs. Four major heat transfer classes are possible, including: (1) loop design where the fuel salt circulates outside of the reactor vessel to transfer heat to a coolant; (2) integral design where the heat transfer to a secondary coolant occurs within vessel; (3) in-core heat transfer where the core itself is configured as a heat exchanger transferring heat from fuel salt to a nonfueled coolant; and (4) direct heat exchange where the heat exchange fluid is intermixed with the fuel salt, acquires heat, and subsequently inherently separates from the fuel salt. An example of the latter is the use of $\mathrm{Pb}$ as the heat exchange fluid, (Sierchula et al., 2019) which is immiscible with the salt and so can be being separated by gravity. $\mathrm{AlCl}_{3}$ can be volatilized and reused as a heat transfer fluid. (Blander et al., 1959) Additionally, in some designs the coolant also serves as a breeding material (producing additional fissile material during operation) or moderator ( $\mathrm{NaOH}$ proposed as coolant). Thermal spectrum reactors require moderation. The moderator or its coating/cladding needs to be chemically compatible with the fuel salt as well as tolerant of high levels of neutron fluence. Graphite is chemically compatible with actinide-bearing fluoride salts, so it is typically used as the moderator. However, graphite has a limited lifetime in high fastneutron flux environments, so it may need to be replaced periodically, generating a high-volume waste stream.

Regarding reactor type listed above, Table 1-1 below provides examples of MSR designs that could be implemented by vendors. Here, molten salts can be used as the coolant or both the primary coolant and the fuel. In addition, the fuel salt can be partitioned into separate streams where one stream is for the fissile components and the other is for the fertile components (i.e., two fluid), or the fissile and fertile components can be combined into a single salt (i.e., single fluid). This report focuses on the salt-fueled reactor type, as the salt cooled system will just have a small fraction of off-gassed components in comparison.

Table 1-1. Examples of different types of MSRs designs. TRISO = tristructural isotropic.

\begin{tabular}{|c|c|c|}
\hline Type & Fuel components & Secondary Coolant \\
\hline FHR & $\begin{array}{l}\text { Solid TRISO fuel } \\
\text { (e.g., } 19.8 \% \text { UCO) }\end{array}$ & $2^{7} \mathrm{LiF}-\mathrm{BeF}_{2}(\mathrm{FLiBe})$ \\
\hline $\begin{array}{l}\text { Thermal Spectrum Fluoride Salt } \\
\text { Fueled }\end{array}$ & 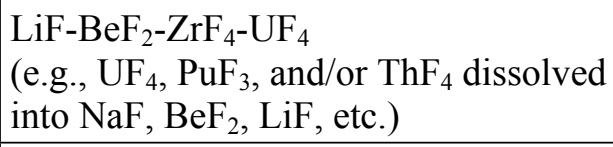 & $\begin{array}{l}\text { LiF-NaF-KF } \\
(\mathrm{FLiNaK})\end{array}$ \\
\hline $\begin{array}{l}\text { Fast Spectrum Chloride Salt } \\
\text { Fueled }\end{array}$ & $\mathrm{PuCl}_{3}-\mathrm{NaCl}$ & $\mathrm{Pb}, \mathrm{MgCl}_{2}-\mathrm{NaCl}$ \\
\hline
\end{tabular}

Regarding the salt type described in the bullet list above, several different salt types have been proposed for MSR concepts. These include an array of actinide fuels (e.g., thorium, uranium, plutonium, or mixed transuranics) dissolved in binary or ternary halide salt mixtures (chloride and/or fluoride). The choice of salt will affect the off-gas chemistry that is evolved either from fission product generation (e.g., noble gases, halides) or acidic gas generation (e.g., $\mathrm{F}_{2(\mathrm{~g})}, \mathrm{Cl}_{2(\mathrm{~g})}, \mathrm{HCl}_{(\mathrm{g})}, \mathrm{HF}_{(\mathrm{g})}$ ). Regarding fuel type listed above, the fission product abundance will change based on the fissile isotope and reactor spectrum.

Regarding real-time separations technologies listed above, this is the aspect of the reactor concept in which certain fission product poisons (e.g., noble gases, lanthanides) and corrosion-inducing species (e.g., Te, $\mathrm{HCl}$, $\mathrm{HF}$ ) could be removed from the reactor in real-time. Having the option to perform real-time separations is one of the most attractive benefits for an MSR. In some cases, the off-gases could be removed from the reactor salt matrix through gas sparging (e.g., with He). Removing lanthanide fission products would be more difficult and will be discussed in a subsequent section; any processing technology, however, has the potential to introduce additional contaminants into the system (e.g., $\left.\mathrm{O}_{2(\mathrm{~g})}, \mathrm{Bi}\right)$. 
Off-gas management for MSRs will be a significant element of reactor operations. A summary of online monitoring techniques to be used to monitor the reactor will also be provided in the next section. As well as being important for waste handling, about $95 \%$ of the ${ }^{135} \mathrm{Xe}$ production in thermal reactors is from ${ }^{135} \mathrm{I}$ $\left(t_{1 / 2}=6.57 \mathrm{~h}\right)$ decay, making understanding iodine motion and removal important to achieving efficient fuel utilization. 


\section{OVERVIEW OF OFF-GAS STREAMS}

Depending on the variables between different MSR concepts (described in Section 1), the off-gas streams generated from the reactor will vary. However, the main types of off-gas streams will be consistent across the different reactor concepts. Fission gases, mists, and other chemical components will be released from the fuel salt into the cover gas. Radioactive decay of volatile fission products, xenon and krypton, will occur in the cover gas stream, generating low-volatility daughters directly in the gas. Based on the experience from the Molten Salt Reactor Experiment (MSRE), the following wastes and contaminants are expected from a commercial MSR (fluoride or chloride systems alike):

- Mists, aerosols, and particles, e.g., pyrolysis products, salt residues, graphite debris for graphitemoderated fluoride systems, noble metals (e.g., $\mathrm{Ru}, \mathrm{Pd}, \mathrm{Rh}$ )

- Volatile species, e.g., $\mathrm{Kr}, \mathrm{Xe},{ }^{3} \mathrm{HF}, \mathrm{HF}, \mathrm{H}_{2} \mathrm{O}, \mathrm{O}_{2}, \mathrm{~F}_{2}, \mathrm{Cl}_{2}, \mathrm{Br}_{2}, \mathrm{I}_{2}$, Ar, interhalogens (e.g., $\mathrm{ICl}_{1} \mathrm{IF}_{5}$, $\mathrm{IF}_{7}$ ), volatile halides, and the decay products (e.g., $\mathrm{Cs}, \mathrm{Ba}, \mathrm{Rb}, \mathrm{Sr}, \mathrm{La}, \mathrm{Br}, \mathrm{I}, \mathrm{Se}, \mathrm{Te}$ ) (Ostvald et al., 2009)

- Tritium, e.g., ${ }^{3} \mathrm{H}_{2(\mathrm{~g})},{ }^{3} \mathrm{HH}_{(\mathrm{g})},{ }^{3} \mathrm{HF}_{(\mathrm{g})},{ }^{3} \mathrm{HF}_{(\mathrm{l})}$, and possibly ${ }^{3} \mathrm{HHO}_{(\mathrm{g})}$ and/or ${ }^{3} \mathrm{H}_{2} \mathrm{O}_{(\mathrm{g})}$

- Short-lived volatile radionuclides and their daughters, e.g., ${ }^{139} \mathrm{Xe} t_{1 / 2}=39.5 \mathrm{~s},{ }^{90} \mathrm{Kr} t_{1 / 2}=32.3 \mathrm{~s},{ }^{137} \mathrm{Xe}$ $t_{1 / 2}=3.83 \mathrm{~min},{ }^{135 \mathrm{~m} X e ~} t_{1 / 2}=15.3 \mathrm{~min},{ }^{89} \mathrm{Kr} t_{1 / 2}=3.18 \mathrm{~min},{ }^{135} \mathrm{Xe} t_{1 / 2}=9.1 \mathrm{~h},{ }^{88} \mathrm{Kr} t_{1 / 2}=2.84 \mathrm{~h},{ }^{133 \mathrm{~m} X e ~} t_{1 / 2}=$ $2.19 \mathrm{~d},{ }^{133} \mathrm{Xe} t_{1 / 2}=5.25 \mathrm{~d}$

- Longer-lived radionuclides, e.g., ${ }^{85} \mathrm{Kr} t_{1 / 2}=10.7 \mathrm{y},{ }^{36} \mathrm{Cl} t_{1 / 2}=3 \times 10^{5} \mathrm{y},{ }^{79} \mathrm{Se} t_{1 / 2}=6.5 \times 10^{4} \mathrm{y}$, ${ }^{129} \mathrm{I} t_{1 / 2}=1.57 \times 10^{7} \mathrm{y}$

Additionally, some nonradioactive streams fall into the list of off-gas streams including the following:

- Water vapors

- Non-noble gases, e.g., $\mathrm{N}_{2(\mathrm{~g})}, \mathrm{O}_{2(\mathrm{~g})}$

- Nonradioactive noble gases, e.g., He cover gas

Elements and compounds transported into the cover gas, and thus the off-gas system of an MSR, will span a wide range of thermochemical and thermophysical properties. Many of these will experience decay, as noted above, changing which capture methods will work best as the radionuclides transit through off-gas components. Section 3 describes each category of off-gas component, with recommendations for capture or holdup. Section 4 describes online monitoring in the off-gas system, measuring heat load, flow characteristics, and performance of off-gas components. Section 5 discusses how a complete system can be configured to meet the required functionality to reduce the risk of radionuclide release. Subsequent sections discuss transport calculations and modeling (Section 6), operations and maintenance (Section 7), and waste from the off-gas (Section 8) and identify where we have uncertainties in off-gas design and testing that require more investigation (Section 9). 


\section{CAPTURE OPTIONS FOR OFF-GAS PRODUCTS}

\subsection{Overview of Off-Gas System Options}

An MSR's cover gas system will contain the radionuclides emerging from the free surface above the fuel salt as well as any sweep or sparging gases used. About half of fission products are noble gases (B. Betzler, private communication 2018). Because each megawatt-day of thermal power requires the fission of approximately 1 gram of actinide material, a large MSR $(1 \mathrm{GWe})$ would produce slightly more than a kilogram of noble fission gas per day or about $19 \mathrm{~L}$ of noble gas per day at reactor operating temperature and atmospheric pressure. About $15 \%$ of the gaseous fission products are sufficiently short lived that they will decay in the fuel salt system. Direct production of fission gases essentially stops when the reactor becomes subcritical; however, continuous decay processes in the gas stream will result in low volatility material suspended in the gas stream that may deposit on duct or vessel surfaces or be carried along by the gas stream. Consequently, the passive decay heat removal capacity of the cover gas removal system used in the event of loss of active cooling needs to have enough capacity to remove the decay heat of the previously produced fission gases currently in the system and those recently produced.

The most advanced MSR off-gas system design available was that for the Molten Salt Breeder Reactor (MSBR), which was described in its conceptual design report in 1971 (Smith, 1971). The basic component layout and system performance requirements employed in this report stem from the historic MSBR design effort. The off-gas total decay heat production for a large MSR (the MSBR) was estimated to be $21.3 \mathrm{MW}$ with roughly $9 \%$ entrained as aerosols or mists, almost $80 \%$ of the gaseous heat load generated in the first hour following release, and well less than $1 \%$ of decay heat remaining in the gas stream after 2 days (Smith and Bell, 1969). The MSBR planned to use a helium carrier stream flowing at a rate of $312 \mathrm{~L} / \mathrm{m}$. Figure 3-1 shows an example off-gas system concept for the MSBR.

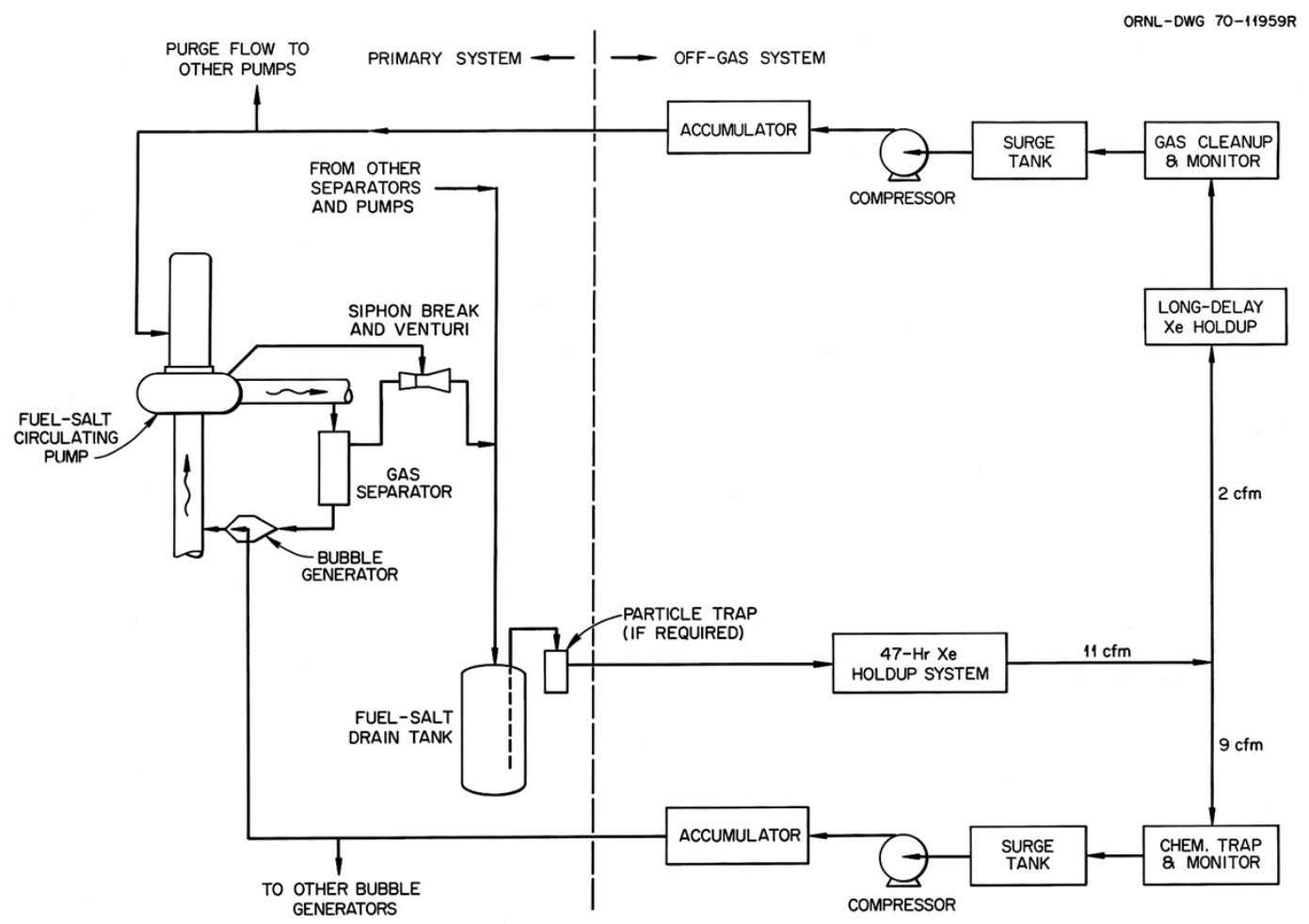

Figure 3-1. Schematic flow diagram of MSBR off-gas system (Robertson, 1971a). 
MSRs have two primary cover gas system design variants. For the first of these, the fission gases are removed from the reactor vessel after a period of decay to avoid pressurization of the fuel salt circuit. Gas holdup can be accomplished by providing a tortuous gaseous escape path within the reactor vessel (e.g., through a multi-chamber pathway). Delaying removal of the gaseous fission products significantly reduces the decay heat removal requirements for the emerging fission gases. The principal design alternative is to remove gases from the reactor vessel as rapidly as possible. This design slows the buildup of neutron poisons in the salt and reduces the quantity of releasable radionuclides within the vessel. The removed radionuclides entrained in the cover gas handling system increase its decay heat removal requirements as well as the consequences from a cover gas system leak. The MSBR planned to use its drain tank as a 2hour delay tank to take advantage of its required cooling system as well as preheating the vessel to minimize any thermal shock resulting from draining. Two alternative methods have been proposed to delay and treat the emerging gas stream: (1) a combination of mechanical filters, a 2 hour delay tank, and a series of activated carbon beds or (2) a caustic scrubber followed by one or more activated carbon beds. The longlived ${ }^{85} \mathrm{Kr}\left(\mathrm{t}_{1 / 2}=10.76 \mathrm{y}\right)$ would be contained for decay or recirculated through the cover gas.

The nonvolatile components in the off-gas stream for the reference MSBR were described as being mists or smokes (particles) at relatively low concentration (probably between 100 and $1000 \mathrm{ppm}$ by volume) divided into three groups (McNeese, 1974):

1) Fuel salt particles, generated in the pump bowl and the bubble separator, having potential sizes ranging from 1 to $10 \mu \mathrm{m}$.

2) An estimated $1 \%$ to $50 \%$ of the noble metal $\left({ }^{41} \mathrm{Nb}\right.$ through $\left.{ }^{52} \mathrm{Te}\right)$ fission products as particles ranging in size from 0.01 to $10 \mu \mathrm{m}$. For a $2250 \mathrm{MW}(\mathrm{t})$ reactor, the mass flow rate could be as high as 300 grams per day.

3) Nonvolatile fission product daughters of krypton and xenon. The assumption is made that noble gas daughters which are born in the salt will be retained in the salt as fluorides. For a $2200 \mathrm{MW}(\mathrm{t})$ reactor, and assuming a 2-hour gas holdup volume, an estimated 140 grams per day of noble-gas daughters will accumulate in the holdup tank. It is likely that many of these will deposit on the walls of the tank but their chemical form is not known definitively.

A summary of potential options for processing various streams is presented in Table 3-1. Below Table 3-1, these different families of species are described in more detail within subsections. Much of the discussion in this section is based on experience gained during the MSRE, with citations to literature on the topic. 
Table 3-1. Summary of volatile off-gas waste components that will or could require capture and/or immobilization. This table was taken from Riley et al. $(2018 \mathrm{~b} ; 2019)$. WF $=$ waste form, HEPA $=$ highefficiency particulate air, $\mathrm{AgZ}=$ silver mordenite, $\mathrm{HZ}=$ hydrogen mordenite.

\begin{tabular}{|c|c|c|c|}
\hline Waste type & Capture method & Immobilization method & Reference \\
\hline All & Decay Tank & $\begin{array}{l}\text { Increase residence time in } \\
\text { off-gas to reduce activity }\end{array}$ & Robertson (1971a) \\
\hline \multirow{3}{*}{$\begin{array}{l}\text { Aerosols - salt } \\
\text { mists and } \\
\text { splashes, } \\
\text { particulates, } \\
\text { condensed } \\
\text { daughters of } \\
\text { noble gases }\end{array}$} & Molten $\mathrm{NaOH}$ & $\begin{array}{l}\text { Ceramic or glass waste forms } \\
\text { (WF) }\end{array}$ & Smith (1956) \\
\hline & Particle traps, charcoal beds & Solids & $\begin{array}{l}\text { Greenwood et al. } \\
\text { (2018), Zagnit'ko and } \\
\text { Chuvilin (2009), } \\
\text { Robertson (1971c) }\end{array}$ \\
\hline & $\begin{array}{l}\text { HEPA filters } \\
(\geq 300 \mathrm{~nm} \text { diameter })\end{array}$ & $\begin{array}{l}\text { Size reduction and } \\
\text { decontamination }\end{array}$ & IAEA (1987) \\
\hline Reactive gases & Molten $\mathrm{NaOH}$ & Ceramic or glass WF & Smith (1956) \\
\hline \multirow{2}{*}{$\begin{array}{l}\text { Tritium } \\
\text { (i.e., }{ }^{3} \mathrm{H}_{(\mathrm{g})},{ }^{3} \mathrm{H}_{2} \mathrm{O} \text { ) }\end{array}$} & $\begin{array}{l}\text { Separated from low-volume } \\
\text { gas streams (e.g., desiccant, } \\
\text { molecular sieve, carbon) }\end{array}$ & $\begin{array}{l}\text { Low-water cement in high- } \\
\text { integrity containers }\end{array}$ & Vienna et al. (2015) \\
\hline & $\begin{array}{l}\text { Oxidize to water by } \\
\text { contacting with heated } \\
\text { copper oxide }\end{array}$ & Capture in molecular sieve & Robertson (1971c) \\
\hline \multirow{5}{*}{$\begin{array}{l}\text { Residual } \\
\text { gaseous halides } \\
\text { [e.g., } \mathrm{F}_{2(\mathrm{~g})}, \mathrm{Cl}_{2(\mathrm{~g})}, \\
\left.\mathrm{I}_{2(\mathrm{~g})}, \mathrm{ICl}_{(\mathrm{g})}\right]\end{array}$} & Silver mordenite (AgZ) & As AgI in composite WF & Bruffey et al. (2016) \\
\hline & $\begin{array}{l}\mathrm{Ag}^{0} \text {-functionalized silica } \\
\text { aerogel }\end{array}$ & As AgI in composite WF & Matyáš et al. (2011a) \\
\hline & $\begin{array}{l}\mathrm{Ag}^{+/ 0}-\text { loaded } \\
\text { aluminosilicate aerogels }\end{array}$ & As AgI in composite WF & Riley et al. (2017a) \\
\hline & Sulfide aerogel (chalcogel) & Chalcogenide glass (possibly) & $\begin{array}{l}\text { Riley et al. (2013a); } \\
\text { Riley et al. (2015) }\end{array}$ \\
\hline & Molten $\mathrm{NaOH}$ & Ceramic or glass WF & Smith (1956) \\
\hline $\begin{array}{l}\text { Other gases } \\
\mathrm{N}_{2}, \mathrm{O}_{2}^{\dagger}\end{array}$ & $\begin{array}{l}\text { Activated carbon, magnetic } \\
\text { separation, cryogenic }\end{array}$ & Released & Baker et al. (2007) \\
\hline \multirow{4}{*}{$\begin{array}{l}\text { Noble gases } \\
\text { (e.g., Xe on short } \\
\text { time frame, later } \\
\text { primarily Kr) }\end{array}$} & Cryogenic distillation & Storage as compressed gas & Liu et al. (2014) \\
\hline & \begin{tabular}{|l} 
Solid sorbents (AgZ, HZ, \\
activated charcoal)
\end{tabular} & Storage as compressed gas & Vienna et al. (2015) \\
\hline & Metal-organic frameworks & Storage as compressed gas & Liu et al. (2014) \\
\hline & Sulfide aerogel (chalcogel) & Storage as compressed gas & $\begin{array}{l}\text { Subrahmanyam et al. } \\
(2017)\end{array}$ \\
\hline
\end{tabular}

*Full salt composition from splashes, or condensation of volatile daughters.

${ }^{\dagger}$ Note that the isotopes generated from a fluoride salt are ${ }^{16} \mathrm{O},{ }^{17} \mathrm{O}$, and ${ }^{18} \mathrm{O}$ for oxygen and ${ }^{15} \mathrm{~N}$ for nitrogen, which are all stable; thus, these could be released. 


\subsection{Particulates, Mists, Aerosols, and Reactive Gases}

Particulates from structural materials, salt mists, and aerosols from condensed noble gas daughters could be generated in several ways during reactor operation. The main driver for removing the particulates, mists, and aerosols is to prevent plugging of the cover gas piping. Replacing filters and screens would place an operational burden on the plant. A gravitational wet scrubber that has a large surface area and low pressure drop (Kim et al., 2001) could reduce the maintenance requirements.

Mists and aerosols were generated by the fuel salt through splashing or volatilization. During the MSRE, it was estimated that $<1 \%$ of the salt became airborne (Compere et al., 1975); this did contain some noble metals, while the main constituents of this airborne fraction consisted of salts containing daughters of krypton and xenon (i.e., $\mathrm{Cs}, \mathrm{Ce}, \mathrm{Ba}, \mathrm{Rb}, \mathrm{Sr}, \mathrm{Y}$ ), barium, as well as fission product iodine and iodine from the decay of tellurium, bromine, and selenium.

In the MSRE, pressurized helium (5 psig) was used to sparge the salt and push fission gases toward a series of metal filters and charcoal beds, which were then vented to the atmosphere (Thoma, 1971; Compere et al., 1975). The system did not work well as it was prone to plugging. It was discovered that many of the plugging issues were the result of carbon deposits in the system nearly entirely from pump oil pyrolysis.

As described in more detail later (Section 3.7), a molten hydroxide scrubber could be used to capture particulates, mists, aerosols, and reactive gases. A submerged-bed aqueous hydroxide scrubber would work as well. However, the high heat load on the scrubber and the safety implications of having large volumes of potentially pressurizing and reactive materials (e.g., water) near MSR containment are challenges to the adoption of aqueous systems. Mitigation efforts could include an anti-siphon vessel and drying to remove residual water vapor from the cover gas. Either approach can be used to simultaneously neutralize acidic streams [see Equations (3-1) through (3-3)] while removing particulates that could plug system components.

Molten hydroxide scrubber:

$$
\begin{aligned}
\mathrm{HF}_{(\mathrm{g})}+\mathrm{NaOH}_{(\text {liq })} & \rightleftharpoons \mathrm{Na}_{(\text {soln })}^{+}+\mathrm{F}_{(\text {soln })}^{-}+\mathrm{H}_{2} \mathrm{O}_{(\mathrm{g})} \\
\mathrm{HCl}_{(\mathrm{g})}+\mathrm{NaOH}_{(\text {liq })} & \rightleftharpoons \mathrm{Na}_{(\text {soln })}^{+}+\mathrm{Cl}_{(\text {soln })}^{-}+\mathrm{H}_{2} \mathrm{O}_{(\mathrm{g})} \\
\mathrm{HI}_{(\mathrm{g})}+\mathrm{NaOH}_{(\text {liq })} & \rightleftharpoons \mathrm{Na}_{(\text {soln })}^{+}+\mathrm{I}_{(\text {soln })}^{-}+\mathrm{H}_{2} \mathrm{O}_{(\mathrm{g})}
\end{aligned}
$$

\subsection{Tritium}

Tritium $\left({ }^{3} \mathrm{H}\right.$ or $\left.\mathrm{T}\right)$ is a radionuclide by-product that is produced by neutron interactions within fuel salt (Table 3-2). Tritium shortly after creation will be present in the fuel salt mainly as tritium fluoride (TF) and also to a small extent as dissolved molecular $\mathrm{T}_{2}$. The ratio of the two states depends on the redox potential of the fuel salt (Forsberg et al., 2017). Metallic beryllium contact has been shown to effectively reduce TF to atomic tritium in FLiBe (Petti et al., 2006). Providing excess beryllium in the salt will keep the FLiBe TF concentration below 20 parts per trillion in FLiBe (Simpson et al., 2006). For MSRE, beryllium was used to control the $\mathrm{U}(\mathrm{IV}) / \mathrm{U}(\mathrm{III})$ ratio, which would have effectively shifted the $\mathrm{TF} / \mathrm{T}_{2}$ equilibrium to $\mathrm{T}_{2}$. However, the mass balance of tritium was not closed at MSRE, with much of the excess thought to have infiltrated graphite structures (Thoma, 1971). Tritium gas has a very low solubility in FLiBe, with the equilibrium partial pressure of tritium gas over FLiBe with $1 \mathrm{ppm} \mathrm{T}_{2}$ being $10^{5} \mathrm{~Pa}$ (Fukada, 2013), so any production of $\mathrm{T}_{2}$ will promote transfer of tritium into the gas phase. An equilibrium condition will not be achieved with tritium because the diffusion and release mechanisms are very slow; rather, a steady release rate will be achieved during reactor operation. The actual release rate would be driven by any gas bubbling system - effectively creating a larger surface area for diffusion. For instance, Engel et al. (1980) estimated that about $18-19 \%$ of the tritium would be released into the cover gas stream via bubbling, but this will depend on bubble gas parameters such as the rate of generation and size distribution. 
Table 3-2. Source of tritium production $2250 \mathrm{MW}_{\text {th }}$ MSBR (Briggs and Korsmeyer, 1970, Briggs, 1972).

\begin{tabular}{|l|r|}
\hline Contribution & TBq/d \\
\hline Ternary Fission & 1.15 \\
\hline${ }^{6} \mathrm{Li}(\mathrm{n}, \alpha){ }^{3} \mathrm{H}$ & 44.77 \\
\hline${ }^{7} \mathrm{Li}(\mathrm{n}, \alpha \mathrm{n}){ }^{3} \mathrm{H}$ & 43.29 \\
\hline${ }^{19} \mathrm{~F}\left(\mathrm{n},{ }^{17} \mathrm{O}\right){ }^{3} \mathrm{H}$ & 0.33 \\
\hline Total & $\mathbf{8 9 . 5 4}$ \\
\hline
\end{tabular}

Tritium production will vary substantially with fuel salt composition. In reactors that include lithium in the fuel salt, tritium will be produced at a rate of $\sim 0.037 \mathrm{TBq} / \mathrm{MW}_{\mathrm{th}} /$ day if $99.99 \%$ enriched in ${ }^{7} \mathrm{Li}$ (Briggs, 1972). MSRs that do not include lithium in their core will produce much less tritium. The mass of tritium produced per day in a large MSR with lithium-bearing salt would be $\sim 250 \mathrm{mg}$ knowing that the specific activity of tritium is $363 \mathrm{TBq} / \mathrm{g}$.

Enrichment in ${ }^{7} \mathrm{Li}$ mitigates what would otherwise be a significantly larger tritium production rate, given the high $(940 \mathrm{~b})$ thermal cross section for the ${ }^{6} \mathrm{Li}(\mathrm{n}, \alpha)^{3} \mathrm{H}$ reaction, as can be seen in Table 3-2 that was calculated for an enrichment of $99.99 \%{ }^{7} \mathrm{Li}$. Regardless of the level of enrichment, a small amount of ${ }^{6} \mathrm{Li}$ will always be present because ${ }^{9} \mathrm{Be}$ also has a small $(\mathrm{n}, \alpha)$ cross section that results in the production of ${ }^{6} \mathrm{Li}$. However, the cross-section threshold of $\sim 667 \mathrm{keV}$ limits its impact for thermal reactors. The activation and decay paths associated with tritium production for lithium and beryllium are shown in Figure 3-2.

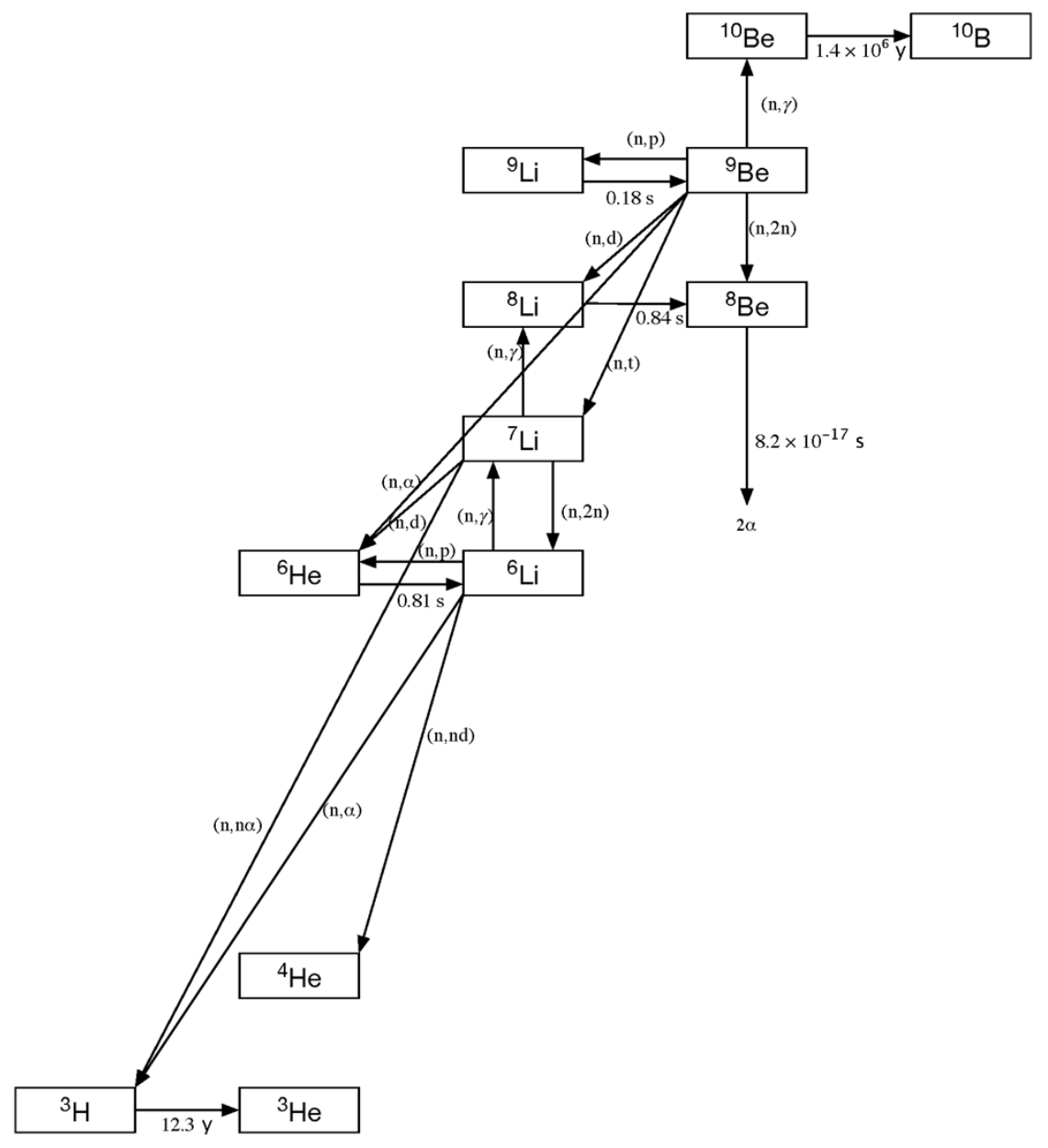

Figure 3-2. Lithium and beryllium activation and decay schemes associated with tritium. 
The ${ }^{3} \mathrm{H}$ production in an MSR with lithium in its fuel salt is substantially more than that produced in a light water-cooled reactor (LWR) while less than that produced by a heavy-water moderated reactor (Phillips and Easterly, 1980). The location/disposition of the tritium will vary substantially based upon the fuel salt treatment scheme selected. In systems that elect to sparge the fuel salt with inert gas, a significant fraction of the tritium will migrate to the gas bubbles and be carried into the off-gas system.

Tritium, likely in the form of $\mathrm{T}_{2}$, will diffuse into and through the surrounding materials. Of particular concern is the primary heat exchanger with its large surface area of thin-walled features, providing a potential pathway for escape. Tritium diffusion through high-temperature alloys is exponentially temperature dependent (Schmidt et al., 1985). Above 300-400 ${ }^{\circ} \mathrm{C}$, tritium has a sufficiently large diffusion coefficient to result in permeation though high-temperature alloys. Thus, both the high rate of generation and the high temperature of the salt contribute to tritium escape through heat exchangers, causing much more concern for MSRs than for water-cooled reactors.

Tritium permeation through metallic alloys involves a sequence of steps: (1) adsorption onto the alloy surface and decomposition if in fluoride form, (2) permeation through the alloy, and (3) reemergence at the opposite surface. The transport of tritium can be blocked at any of these steps. The permeation process step has an Arrhenius-type temperature relationship. Equation (3-4) describes the steady-state permeation flux, $J$, of tritium through unoxidized metals (Bell et al., 1979), where $D_{0}$ is a constant related to diffusivity of tritium through the metal, $K_{0}$ is a constant related to the solubility of tritium in the metal, $E$ is the activation energy for permeation (the sum of the enthalpy of solution for tritium in the metal and the energy of activation for diffusion), $k$ is the Boltzmann constant, $T$ is the absolute temperature, $t$ is the wall thickness, and $P_{2}$ and $P_{1}$ are the tritium partial pressures on opposite sides of the wall:

$$
J=\frac{D_{0} K_{0}}{t} e^{\frac{-E}{k T}}\left(P_{2}^{1 / 2}-P_{1}^{1 / 2}\right)
$$

Several alternate methods have been proposed to reduce the tritium migration into the power cycle. The tritium release prevention methods are conveniently grouped into three categories: (1) absorption, (2) stripping, or (3) barriers. Absorption schemes include introducing removable absorption material (such as activated carbon) into the fuel salt and chemically binding tritium into the secondary or tertiary coolant. The presumption employed by the MSBR program was that any tritium and/or tritium fluoride that reached a graphite surface was retained by the graphite. The MSBR proposed limiting tritium transport to the steam system based on an isotopic exchange of tritium with a hydrogenous impurity in the reactor secondary coolant salt (sodium fluoroborate eutectic). The tritium could also be trapped in a tertiary nitrate heat transfer salt (Robertson, 1971b).

Sparging the fuel salt with small $(\sim 0.5 \mathrm{~mm}$ diam.) inert gas bubbles was a primary tritium removal mechanism planned for the MSBR (Briggs, 1972). The tritium gas would diffuse into the high surface area provided by the small sparging bubbles. Window-based methods, such a placing a high tritium-permeability target in the reactor coolant system, have also been proposed to remove tritium selectively from flowing salt streams (Holcomb and Wilson, 2017). As the diffusion coefficient for tritium in FLiBe is small, both absorption-bed and window-based systems depend on turbulent motion to transport the tritium to the active surface for efficient separation (Fukada and Mitshishi, 1988).

Barrier-based methods generally rely on incorporating a very low diffusivity material into the heat exchanger. The heat exchanger itself could be composed of a material such as molybdenum, with low tritium permeability, along with adequate salt compatibility and mechanical strength, such as molybdenum. Alternately, separate ceramic materials layers could be employed as diffusion barriers. However, oxide layer barriers would dissolve in fluoride salts, and uranium fluoride would chemically attack nearly all carbides (forming uranium carbide), significantly limiting potential barrier materials. The barrier layer would also need to have adequate thermal expansion matched to the structural material to avoid cracking/chipping. No barrier-based tritium blocking system has yet reached high technology readiness levels (Sherman and Adams, 2008). A mixed absorption/barrier method was recommended in a 2013 
technology review (Holcomb et al., 2013). The recommended method was based upon incorporating yttrium into the heat exchanger tube alloy or via co-extrusion of a yttrium layer in multi-layer tubes. Tritium reaching the yttrium would tend to form a stable hydride, preventing further diffusion (van Mal, 1976).

Another option to minimize ${ }^{3} \mathrm{H}$ release is to use an overpressure of ${ }^{1} \mathrm{H}_{2(\mathrm{~g})}$ (nonradioactive hydrogen) in the secondary coolant. This approach can largely restrict diffusion of tritium by requiring it to diffuse into a much higher concentration of hydrogen (Lecocq, 1976). Note, however, that adding hydrogen could increase tritium escape from the secondary system by increasing the fraction of tritium in a chemical state capable of diffusing through structural materials (Korsmeyer, 1971) such as in the form of HT.

The demands of the off-gas system for capturing and immobilizing tritium is dependent upon which of these methods of tritium control are adopted.

\subsection{Residual Halides}

The category of residual halides covers halogens and interhalogen compounds (e.g., ICl) that come from contaminants in the salts (e.g., Br), fission products (e.g., ${ }^{129} \mathrm{I},{ }^{131} \mathrm{I}$ ), and products from MSR salt decomposition [e.g., $\mathrm{Cl}_{2(\mathrm{~g})}, \mathrm{F}_{2(\mathrm{~g})}$ ]. For the gaseous capture of halide gases, readers are directed to a series of recent literature reviews on this topic (Riley et al., 2016; Huve et al., 2018; Riley and Chong, 2020); some of these are summarized in Table 3-1. The literature is inconclusive on the efficacy of either solid sorbents or liquid scrubbing methods. While many of the papers include sorption of iodide species, a lot of these options would likely work for other halides as well.

Solid sorbent options include porous functional silica-based aerogels (Matyáš et al., 2011b; Riley et al., 2017a), porous-metal-exchanged/impregnated zeolites (e.g., faujasite, Linde type A, mordenite) (Thomas et al., 1978; Jubin, 1981; Wilhelm and Puppe, 1989; Riley and Chong, 2020), $\mathrm{AgNO}_{3}$-impregnated silica (Mineo et al., 2002; Mineo et al., 2003), and $\mathrm{AgNO}_{3}$-impregnated alumina (Tanabe et al., 2010). Additives without metal getters include sulfide-based aerogels (chalcogels) (Riley et al., 2011; Riley et al., 2013b; Riley et al., 2014), graphene aerogels (Scott et al., 2015), graphene powders (Scott et al., 2015), granular activated carbon (Jubin, 1988), and metal-organic frameworks (MOFs) (Sava et al., 2011; Sava et al., 2012; Sava et al., 2013).

Liquid scrub options include aqueous and nonaqueous approaches. Aqueous approaches include caustic scrubbing solutions (Trevorrow et al., 1983b), electrolytic scrubbing (Mailen and Horner, 1975; Horner et al., 1977), Mercurex (Collard et al., 1980; Trevorrow et al., 1983b), and Iodox (Trevorrow et al., 1983b). One of the most promising nonaqueous scrubbing options is a molten hydroxide scrubber being developed at Oak Ridge National Laboratory (ORNL). This will be discussed more in Section 3.7.

\subsection{Nitrogen and Oxygen}

Gases such as $\mathrm{O}_{2(\mathrm{~g})}$ and $\mathrm{N}_{2(\mathrm{~g})}$ could be present in the salts or helium purge gas as minor contaminants. Oxygen buildup in the fluoride or chloride salt is a problem because as an electronegative impurity it shifts the redox state of the salt, promoting formation of $\mathrm{CrF}_{3}$ or $\mathrm{CrCl}_{3}$, respectively, i.e., corroding the container. While oxygen can contaminate and change the redox chemistry of the salt, nitrogen and oxygen can react with structural metals, resulting in unwanted changes to the properties of these materials.

It is likely that these gases could be removed using a helium purge gas in the same way that oxygen was minimized to $<1 \mathrm{ppm}$ during the MSRE using a helium purge. Oxygen and water can be removed from the purge gas using a heated titanium sponge and molecular sieve, respectively, as was done with the MSRE; these were done to keep oxygen at $\leq 1 \mathrm{ppm}$. Nonstable isotopes of oxygen and nitrogen have half-lives less than a few minutes. Thus, after passing through the off-gas system, these gases could be vented to the atmosphere. 
Robertson (1965) estimated that having only $1 \mathrm{ppm}$ of $\mathrm{O}_{2}$ in the helium stream would result in $5.5 \mathrm{~g}$ of precipitated $\mathrm{ZrO}_{2}$ per year from the fuel salt. Thus, the formation of $\mathrm{ZrO}_{2}$ could be used to follow the redox chemistry of the salt, as it becomes more oxidized through burnup. Solid $\mathrm{ZrO}_{2}$ may be readily filtered from the salt (along with precipitated fission products and graphite fines), helping to maintain redox control. The change of salt composition through the loss of $\mathrm{ZrF}_{4}$ through the formation of $\mathrm{ZrO}_{2}$ at the slow rate of $5.5 \mathrm{~g} /$ year, as seen for MSRE, would be considered trivial, as $\mathrm{ZrF}_{4}$ represented $5 \mathrm{~mol} \%$ of the initial MSRE salt composition.

\subsection{Noble Gases}

Radioactive isotopes of xenon and krypton will be present in a variety of radionuclides with a range of halflives $\left(t_{1 / 2}\right)$ including ${ }^{139} \mathrm{Xe}\left(t_{1 / 2}=39.5 \mathrm{~s}\right),{ }^{90} \mathrm{Kr}\left(t_{1 / 2}=32.3 \mathrm{~s}\right),{ }^{137} \mathrm{Xe}\left(t_{1 / 2}=3.83 \mathrm{~min}\right),{ }^{135 \mathrm{~m}} \mathrm{Xe}\left(t_{1 / 2}=15.3 \mathrm{~min}\right),{ }^{89} \mathrm{Kr}$ $\left(t_{1 / 2}=3.18 \mathrm{~min}\right),{ }^{135} \mathrm{Xe}\left(t_{1 / 2}=9.1 \mathrm{~h}\right),{ }^{88} \mathrm{Kr}\left(t_{1 / 2}=2.84 \mathrm{~h}\right),{ }^{133 \mathrm{~m}} \mathrm{Xe}\left(t_{1 / 2}=2.19 \mathrm{~d}\right),{ }^{133} \mathrm{Xe}\left(t_{1 / 2}=5.25 \mathrm{~d}\right)$, and ${ }^{85} \mathrm{Kr}\left(t_{1 / 2}\right.$ $=10.76 \mathrm{y})$. Because most of these have fairly short half-lives, it is believed that they will decay either in the reactor or in the graphite moderator, but this will be undesirable for core neutronics. The goal of noble gas removal is to reduce the neutron poison load in the core, primarily through the removal of ${ }^{135} \mathrm{Xe}$ to a mole fraction of $<0.005$ (Rosenthal et al., 1972). Adding a pyrolytic coating to the graphite will reduce the rate of xenon stripping by the graphite and allow more of the fission gas to diffuse to gas interfaces (e.g., the cover gas and sparged gas bubbles). The purpose of a gas sparge is to increase the gas-liquid interfacial area in the salt, thus increasing the fission gas removal rate so it is competitive with stripping by the graphite surfaces (Gabbard, 1972; Rosenthal et al., 1972). The size of the introduced bubbles is an important parameter. A venturi-type bubble generator that generates bubbles has been assessed for noble gas removal, but the derived correlations will need experimental validation before developing a full-scale device for an MSR cover gas system (Gabbard, 1972).

Noble gas separation can be combined with an initial hold up in a decay tank with a residence time of 1-2 hours, where entrained salt combined with fines can be removed along with many of the short-lived xenon isotopes. The gas is held up for a further 47 hours to achieve decay of most of the ${ }^{135} \mathrm{Xe}$, before being cleaned and recirculated to the reactor purge gas system (Rosenthal et al., 1972). An overall off-gas confinement of $90 \mathrm{~d}$ will provide 17 times the half-life of ${ }^{133} \mathrm{Xe}$ and so could provide a low activity release to the environment.

\subsubsection{Cryogenic Distillation for Noble Gas Capture}

Noble gas capture has been investigated for many decades, and options for this approach are described below. Krypton solidification was demonstrated through the incorporation into zeolite type 5A, copper metal, and SiC (Jubin and Bruffey, 2016; Bruffey and Jubin, 2017).

One of the most often pursued options is cryogenic distillation, which is a commercially available technology that uses liquid nitrogen as the typical medium (Laser et al., 1973; Baetsle and Broothaerts, 1977; Chesne et al., 1977; Yarbro et al., 1977; Henrich and von Ammon, 1985). This technology has limitations. In particular, gases that condense at $\geq 77 \mathrm{~K}$ require removal prior to the process or they can result in unwanted pressure buildups in the system. Another limitation is the production of reactive gases through radiolysis (e.g., ozone production from $\mathrm{O}_{2}$ ). Following removal of more condensable gases, xenon and krypton can be dissolved in liquid nitrogen, removed in a stripping column, and separated downstream in purification columns.

\subsubsection{Solid Sorbents for Noble Gas Capture}

Solid sorbents for noble gas capture include zeolites, activated carbon, MOFs, and chalcogels and are summarized in Table 3-3. Many of these have been thoroughly investigated in the laboratory but have not been tested on a larger scale.

Trevorrow et al. (1983a) demonstrated that mordenites (Z-type zeolites) could be used to separate krypton and xenon using different temperature conditions. Here, silver mordenite (AgZ) was used at room 
temperature to remove xenon. After this, the stream was chilled and run through hydrogen mordenite (HZ) at $-80^{\circ} \mathrm{C}$ to remove krypton, which was concentrated on a separate $\mathrm{HZ}$ stream at $60^{\circ} \mathrm{C}$, and then removed to a cold trap. They demonstrated that the xenon bed could be regenerated after a heat treatment of 200$250^{\circ} \mathrm{C}$. In studies in the Farrusseng laboratory (Daniel et al., 2013; Deliere et al., 2016), Ag-exchanged ZSM-5 zeolites showed promise for noble gas capture and separation and performed better than several MOFs evaluated head-to-head along with the zeolites.

Table 3-3. Summary of solid sorbent options in the literature for noble gas capture. AgZ and HZ denote silver and hydrogen mordenites, respectively; AC denotes activated carbon/charcoal; MOF denotes metalorganic framework; SDB denotes 4,4 -sulfonyldibenzoate; CG denotes chalcogels.

\begin{tabular}{|c|c|c|c|}
\hline Class & Type & Notes & Reference(s) \\
\hline \multirow[b]{2}{*}{ Zeolite } & $\begin{array}{l}\text { Mordenites for } \\
\mathrm{Xe} / \mathrm{Kr}\end{array}$ & $\begin{array}{l}\mathrm{AgZ} \text { for } \mathrm{Xe}\left(25^{\circ} \mathrm{C}\right) ; \mathrm{HZ} \text { for } \mathrm{Kr}\left(80^{\circ} \mathrm{C}\right) \\
\text { regenerated at } 200-250^{\circ} \mathrm{C}\end{array}$ & Trevorrow et al. (1983a) \\
\hline & ZSM-5 & $\begin{array}{l}\text { Ag-ZSM-5 showed Xe and } \mathrm{Kr} \text { capacities of } \\
35 \pm 3 \times 10^{-5} \text { and } \sim 50 \times 10^{-8} \mathrm{~mol} \mathrm{~g}^{-1} \text {, respectively; } \\
\mathrm{Xe} / \mathrm{Kr} \text { selectivity of }>100\end{array}$ & $\begin{array}{l}\text { Daniel et al. (2013), } \\
\text { Deliere et al. (2016) }\end{array}$ \\
\hline \multirow[b]{2}{*}{$\mathrm{AC}$} & SorboNorit B3 & Comparable properties to zeolites tested & Bazan et al. (2011) \\
\hline & - & $\begin{array}{l}\text { Delay beds can be used to allow short-lived } \\
\text { radionuclides to decay }\end{array}$ & - \\
\hline \multirow{2}{*}{ MOF } & $\begin{array}{l}\text { SBMOF-1 (Ca- } \\
\text { SDB) }\end{array}$ & Very high $\mathrm{Xe} / \mathrm{Kr}$ selectively & Banerjee et al. (2016) \\
\hline & $\begin{array}{l}\mathrm{Ni} / \mathrm{DOBDC} \\
\mathrm{FMOF}-\mathrm{Cu}\end{array}$ & $\begin{array}{l}\text { Two-bed approach with } \mathrm{Ni} / \mathrm{DOBDC} \text { for } \mathrm{Xe} \\
\text { removal and FMOF-Cu for } \mathrm{Kr} \text { removal }\end{array}$ & Liu et al. (2014) \\
\hline CG & S-based & $\begin{array}{l}\left(\mathrm{NH}_{4}\right)_{0.03} \mathrm{MoS}_{4}, \mathrm{Na}_{0.3} \mathrm{Sb}_{2} \mathrm{~S}_{3}, \mathrm{~K}_{0.15} \mathrm{Na}_{0.3} \mathrm{Sb}_{2} \mathrm{~S}_{2.5}, \\
\text { and } \mathrm{Na}_{0.1} \mathrm{Sb}_{2} \mathrm{~S}_{3} \text { showed } 0.29-0.69 \mathrm{mmol} \mathrm{g}{ }^{-1} \\
\text { Xe and } 0.16-0.28 \mathrm{mmol} \mathrm{g}{ }^{-1} \mathrm{Kr} \text { capacities } \\
\end{array}$ & $\begin{array}{l}\text { Subrahmanyam et al. } \\
(2017)\end{array}$ \\
\hline
\end{tabular}

For activated carbon/charcoal, Bazan et al. (2011) evaluated SorboNorit B3 along with zeolites (Koestrolith $13 \mathrm{X}-\mathrm{K} 2$ and Koestrolith $4 \mathrm{AK}$ ) as sorbents for the capture efficiency of xenon and krypton as well as $\mathrm{O}_{2}$ and argon. All sorbents evaluated showed the same order of capacities, i.e., $\mathrm{Xe}>\mathrm{Kr}>\mathrm{O}_{2}>$ Ar. Activated charcoal delay beds can also be used to temporarily capture and delay the transport of short-lived radioisotopes while they decay; these species will emerge from these beds with the helium carrier gas and stable gaseous species, e.g., argon and $\mathrm{H}_{2} \mathrm{O}$. Delay beds such as these are currently in use at commercial boiling water reactor power stations.

MOFs are composed of organic moieties interlinked by metal ions or clusters forming a three-dimensional (3D) crystal structure with long-range order. These 3D networks form with predictable pore sizes that can act as molecular sieves. Modeling efforts have been pursued to determine the optimal pore sizes and chemistries required for the selective capture of particular species of interest (Nouar et al., 2008; Wang et al., 2013; Lu et al., 2014). In a paper by Banerjee et al. (2016), a Xe/Kr selectively of $\sim 16$ was documented for SBMOF-1 (also called Ca-SDB). In a study by Liu et al. (2014), a two-bed approach was evaluated in which a Ni/DOBDC MOF was used to pull xenon out of a stream of 400 ppm xenon and 40 ppm krypton in dry air followed by the use of a FMOF-Cu MOF to pull krypton out of the stream.

Chalcogels are chalcogen-based aerogels that have recently been demonstrated to have $\mathrm{Xe} / \mathrm{Kr}$ selectivity. Here, Subrahmanyam et al. (2017) studied four chalcogels including $\left(\mathrm{NH}_{4}\right)_{0.03} \mathrm{MoS}_{4}, \mathrm{Na}_{0.3} \mathrm{Sb}_{2} \mathrm{~S}_{3}$, $\mathrm{K}_{0.15} \mathrm{Na}_{0.3} \mathrm{Sb}_{2} \mathrm{~S}_{2.5}$, and $\mathrm{Na}_{0.1} \mathrm{Sb}_{2} \mathrm{~S}_{3}$. The selectivities of $\mathrm{Xe} / \mathrm{Kr}$ were up to a factor of $\sim 6$. The sorbents showed capacities of $0.29-0.69 \mathrm{mmol} \mathrm{g}^{-1}$ for xenon and $0.16-0.28 \mathrm{mmol} \mathrm{g}^{-1}$ for krypton. 


\subsection{Caustic Scrubbing}

Caustic scrubbers are liquid-based sorption beds that are designed to do several very important things simultaneously:

(1) Act as a trap for particulates, mists, aerosols, and potential corrosive/reactive gases (e.g., $\mathrm{HF}_{(\mathrm{g})}, \mathrm{HCl}_{(\mathrm{g})}$, $\mathrm{HI}_{(\mathrm{g})}, \mathrm{F}_{2(\mathrm{~g})}, \mathrm{Cl}_{2(\mathrm{~g})}$, and $\left.\mathrm{I}_{2(\mathrm{~g})}\right)$

(2) Neutralize any acidic species

(3) Combine the benefits of a gravitational scrubber with those of a chemical scrubber

Caustic scrubbers can either be aqueous hydroxide mixtures or nonaqueous molten hydroxide mixtures. For MSRs, the less water introduced into the secondary systems, the better, so the molten hydroxide scrubber would likely be the preferred choice if a caustic scrubber is desired. Plus, molten hydroxide scrubbers should have a higher efficiency than an aqueous-based caustic scrubber. An example of such a system incorporated into a full system for off-gas management is shown in Figure 3-3.

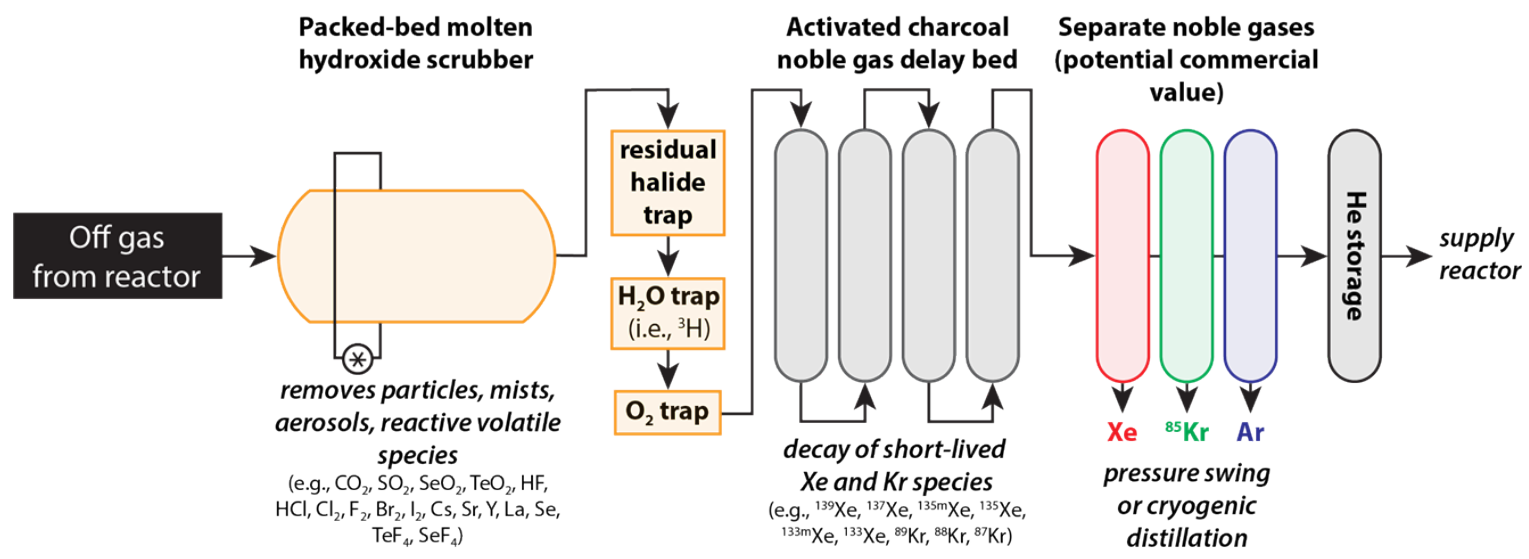

Figure 3-3. Schematic of the overall off-gas system for a commercial MSR based on the MSRE experience (Riley et al., 2018a). All components shown, except the molten hydroxide packed-bed scrubber, are commercially available.

Instead of using pure alkali hydroxides (e.g., $\mathrm{NaOH}, \mathrm{KOH}$ ), mixtures such as $\mathrm{LiOH}-\mathrm{NaOH}-\mathrm{KOH}$ and other mixtures are used since they have much lower melting temperatures; e.g., a LiOH-NaOH-KOH ternary phase diagram is provided in Figure 3-4. Additionally, the boiling temperatures of alkali hydroxide mixtures are quite high, (e.g., $\mathrm{Na} / \mathrm{K} / \mathrm{Li} 2 / 2 / 1$ is around $1300^{\circ} \mathrm{C}$ ). The viscosities and densities of molten alkali hydroxide mixtures are quite low and similar to aqueous mixtures (i.e., $\eta<2.5 \mathrm{mPa} \cdot \mathrm{s}$ and density, $\rho<1.8$ $\mathrm{g} / \mathrm{cm}^{3}$ near melting temperatures) (Janz, 1988). Containment for the scrubber could be fabricated from highnickel alloys, which are compatible with molten $\mathrm{NaOH}$ (i.e., $T \leq 560^{\circ} \mathrm{C}$ ) (Davies, 2019); the operating temperature is expected to be in the range of $150-300^{\circ} \mathrm{C}$ (Craig and Anderson, 1997).

An off-gas system that includes a caustic scrubber will need continuous monitoring for caustic flow, pressure drop, and scrubber efficiency. For the latter, indicative species should be monitored, for instance iodine that will indicate a chemical change when passing through the molten hydroxide. The molecular speciation can be determined by molecular spectroscopy that is sensitive to the chemical form, such as Raman, Infrared (IR), or UV-Visible. Noble gases that are unlikely to be retained in the scrubber will respond to laser induced breakdown spectroscopy. These methods are discussed in more detail in Section 4. 


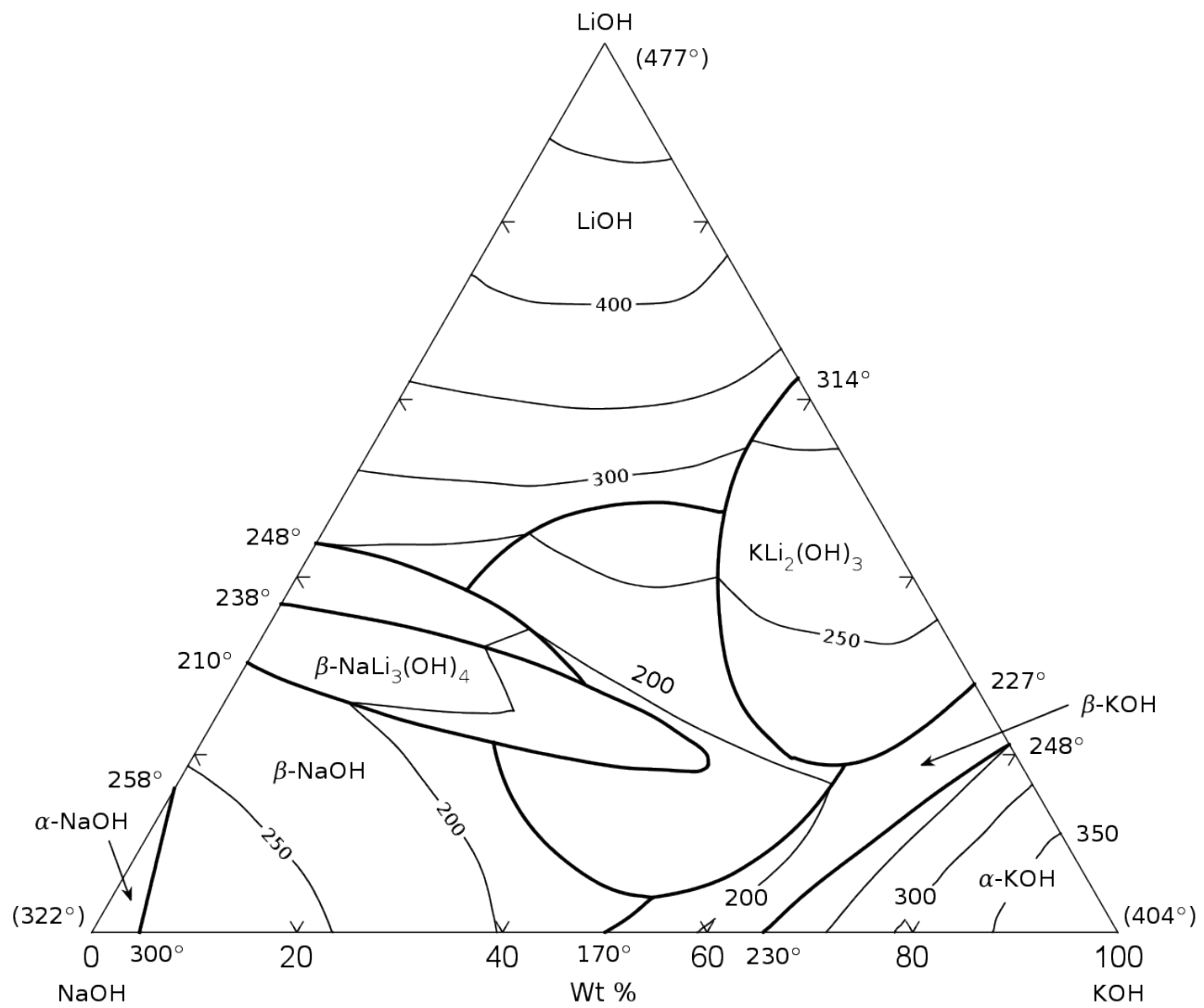

Figure 3-4. LiOH-NaOH-KOH ternary diagram from Reshetnikov and Vilutis (1959) with temperatures in ${ }^{\circ} \mathrm{C}$.

\subsection{Full System Design}

The primary components of the conceptual full system design shown in Figure 3-3 are described below (see Table 3-1 and Table 3-3 for more information).

1. Hydroxide scrubber. The molten hydroxide scrubber will be the initial system contacting the off-gas stream from the reactor. In one design, this scrubber will be composed of a molten hydroxide mixture over a packed bed of Ni-201 Raschig rings. This should behave as a non-pluggable filter. It will be used to trap insolubles (e.g., noble metals), trap alkaline species, and neutralize acidic species (e.g., $\mathrm{CO}_{2}$, $\mathrm{SO}_{2}, \mathrm{SeO}_{2}, \mathrm{TeO}_{2}, \mathrm{HF}, \mathrm{HCl}$ ). Permanent or noncondensable gases will pass through the trap, e.g., $\mathrm{O}_{2}$, $\mathrm{Ar}, \mathrm{He}, \mathrm{Kr}$, and $\mathrm{Xe}$.

2. Residual halide trap. This trap will include a sorbent bed for the removal of long-lived halide radionuclides (e.g., ${ }^{36} \mathrm{Cl}$ and ${ }^{129} \mathrm{I}$ ) and can be composed of a commercially available halide sorbent (e.g., AgZ).

3. Tritium trap. Tritium is likely to remain in the hydroxide scrubber as an ion (i.e., $\left.{ }^{3} \mathrm{HO}^{-}\right)$. If released, it will likely be in the form of water (i.e., ${ }^{3} \mathrm{HHO}$ or ${ }^{3} \mathrm{H}_{2} \mathrm{O}$ ), which could be captured in a molecular sieve.

4. Oxygen/nitrogen trap. Both $\mathrm{O}_{2(\mathrm{~g})}$ and $\mathrm{N}_{2(\mathrm{~g})}$ could be removed from the system using a getter (Naito et al., 1974; Wang et al., 2017), e.g., Ti-sponge.

5. Noble gases. The activated charcoal delay beds will allow for the short-lived noble gas isotopes to decay. Eventually ${ }^{85} \mathrm{Kr}$ as well as stable isotopes of $\mathrm{Ar}, \mathrm{Kr}$, and $\mathrm{Xe}$ will emerge from these delay beds with helium (i.e., carrier gas) (NUCON Technical Bulletin 11B10, 2012; Stockinger, 2012). Here, the 
noble gases can be separated from the carrier gas using cryogenic distillation or pressure-swing adsorption (IAEA, 1980). It is possible that ${ }^{85} \mathrm{Kr}\left(t_{1 / 2}=10.73 \mathrm{y}\right)$ could be released, or it will have to remain in a long-term decay storage environment (IAEA, 1980). It is also possible that commercial applications might exist for these noble gases.

6. Recycle carrier gas. It is likely that the helium carrier gas can be returned to the reactor.

\subsection{Volatile Uranium and Transuranics}

Solubilities of uranium and transuranic elements in molten salts have been studied to determine the range of compositions that can be used for homogeneous-fueled MSR operation. Solubility has also been a key consideration for developing fuel cycles to recycle actinide and prepare waste forms, using methods such as fractional crystallization. Some examples of solubility are given in Table 3-4. Zhang (2014) reviewed what is known about the solution chemistry of actinides in molten salts in 2014. Research continues on measurement and modeling of these correlations, and a database of the Gibbs free energies of molten salt mixtures is under development (McMurray et al., 2019).

As MSRs will not be operated above the solubility limit of their constituent actinides, it can be assumed that the actinides in an operating MSR will primarily become airborne as aerosolized material or mists. However, when one considers the complete fuel cycle, including processes to achieve actinide separation through volatility or distillation, gaseous species will be produced and thus require a specialized off-gas system. Processes that produce volatile uranium fluorides and chlorides are considered in this section. The thermochemistry of actinide and fission product fluorides and chlorides has been reviewed in Riley et al. (2018b) and is briefly summarized here.

Table 3-4. Examples of actinide solubilities in salt mixtures as a function of temperature in ${ }^{\circ} \mathrm{C}$.

\begin{tabular}{|c|c|c|c|}
\hline Species in Salt & Major salt components & Solubility & References \\
\hline $\mathrm{UF}_{4}$ & $\mathrm{NaF} \mathrm{ZrF}_{4}(0.52: 0.48 \mathrm{~mol}$ ratio $)$ & $0.099 \mathrm{t}-45.11 \mathrm{~mol} \%$ & Seregin et al. (2011) \\
\hline $\mathrm{ThF}_{4}$ & $\mathrm{NaF} \mathrm{ZrF} \mathrm{rF}_{4}(0.52: 0.48 \mathrm{~mol}$ ratio $)$ & $0.0384 \mathrm{t}-18.562 \mathrm{~mol} \%$ & Seregin et al. (2011) \\
\hline $\mathrm{CeF}_{3}$ & $\mathrm{NaF} \mathrm{ZrF} \mathrm{rF}_{4}(0.52: 0.48 \mathrm{~mol}$ ratio $)$ & $0.0069 \mathrm{t}-2.718 \mathrm{~mol} \%$ & Seregin et al. (2011) \\
\hline $\mathrm{PuF}_{3}$ & $2 \mathrm{LiF}-\mathrm{BeF}_{2}$ & $\begin{array}{l}0.31 \mathrm{~mol} \%, 550^{\circ} \mathrm{C} \\
0.84 \mathrm{~mol} \%, 650^{\circ} \mathrm{C}\end{array}$ & Ponomarev et al. (2016) \\
\hline $\mathrm{PuF}_{3}$ & $\begin{array}{l}\text { LiF-NaF-KF (46.5:11.5:42 } \\
\text { mol\%) }\end{array}$ & $33 \mathrm{~mol} \%, 700^{\circ} \mathrm{C}$ & Ponomarev et al. (2016) \\
\hline $\mathrm{UF}_{4}$ & $\begin{array}{l}\text { LiF-NaF-KF (46.5:11.5:42 } \\
\text { mol\%) }\end{array}$ & $45 \mathrm{~mol} \%, 700^{\circ} \mathrm{C}$ & Ponomarev et al. (2016) \\
\hline $\mathrm{AmF}_{3}$ & $\begin{array}{l}\text { LiF-NaF-KF (46.5:11.5:42 } \\
\text { mol\%) }\end{array}$ & $43 \mathrm{~mol} \%, 700^{\circ} \mathrm{C}$ & Ponomarev et al. (2016) \\
\hline
\end{tabular}

\subsubsection{Fluorides of Molten Salt Components}

A list of the actinide and fission product fluorides, their boiling points $\left(T_{\mathrm{b}}\right)$, and a typical concentration (mass\%) of the metal in LWR used nuclear fuel (UNF) is given in Table 3-5. The concentrations expected for MSRs will depend on the type of fuel, the burnup, and the redox state. Of the actinides, $\mathrm{U}, \mathrm{Np}$, and $\mathrm{Pu}$ can form volatile hexafluorides. While $\mathrm{UF}_{6}$ and $\mathrm{NpF}_{6}$ are stable, $\mathrm{PuF}_{6}$ is thermally and radiolytically unstable. Thorium and the transuranic elements form nonvolatile fluorides (e.g., $\mathrm{ThF}_{4}, \mathrm{PuF}_{4}, \mathrm{AmF}_{3}, \mathrm{AmF}_{4}$, $\mathrm{CmF}_{3}$ ) and will remain in solution during processing. Of the fission products, the rare earths, alkalis, and alkaline earths (e.g., Cs, Sr) all form nonvolatile fluorides and so will also remain in solution (Hightower and McNeese, 1968). The noble-metal fission products (i.e., Mo, Tc, Ru, Rh) have limited solubility and will precipitate in the metallic state (Kedl, 1972). However, they and some of the other fission products (i.e., $\mathrm{Sb}, \mathrm{I}, \mathrm{Br}, \mathrm{Cl}, \mathrm{S}, \mathrm{Nb}, \mathrm{Se}$, and $\mathrm{Te}$ ) can form volatile fluorides and oxyfluorides under treatment with $\mathrm{F}_{2}$ 
and will be released to the processing headspace along with any residual krypton and xenon. Separations by fluorine volatility are discussed in the next section. Fluorination of structural materials can produce $\mathrm{FeF}_{3}$, which becomes volatile at $T>450^{\circ} \mathrm{C}, \mathrm{ZrF}_{4}$ at $T>600^{\circ} \mathrm{C}$, and $\mathrm{CrF}_{3}$ at $T>650^{\circ} \mathrm{C}$ (HSC Chemistry, Outotec). Depending on the processing conditions, oxyfluorides can form. Besides the compounds mentioned above, chromium forms two volatile oxyfluorides, $\mathrm{CrO}_{2} \mathrm{~F}_{2}$ and $\mathrm{CrOF}_{4}$ (Johnson, 1981).

Table 3-5. Selected fluorides that can be made from LWR used nuclear fuel (UNF), along with boiling temperature $\left(T_{\mathrm{b}}\right)$ and the typical amount found in LWR UNF.

\begin{tabular}{|c|c|c|c|}
\hline $\begin{array}{l}\text { Volatile } \\
\text { fluorides }\end{array}$ & $T_{\mathrm{b}}\left({ }^{\circ} \mathrm{C}\right)$ & $\begin{array}{l}\text { Typical metal element amount } \\
\text { in LWR UNF (mass\%) }\end{array}$ & Reference(s) \\
\hline $\mathrm{UF}_{6}$ & 56.5 & 94.7 & Davidson and Fried (1959) \\
\hline $\mathrm{NpF}_{6}$ & 55.2 & 0.06 & Malm et al. (1958) \\
\hline $\mathrm{PuF}_{6}$ & 65.0 & 0.94 & Malm et al. (1959) \\
\hline $\mathrm{MoF}_{6}$ & 33.8 & \multirow{2}{*}{0.40} & Nisel'son et al. (1968) \\
\hline $\mathrm{MoOF}_{4}$ & 185.8 & & Ngai and Stafford (1971) \\
\hline $\mathrm{RuF}_{6}$ & $\begin{array}{l}100.0 \\
\text { (unstable) }\end{array}$ & \multirow{3}{*}{0.28} & Rak and Lisý (1979) \\
\hline $\mathrm{RuF}_{5}$ & 226.8 & & Rak and Lisý (1979) \\
\hline $\mathrm{RuOF}_{4}$ & 186 & & Ngai and Stafford (1971) \\
\hline $\mathrm{TcF}_{6}$ & 55.3 & \multirow{3}{*}{0.09} & \multirow{3}{*}{ Simmons (1996) } \\
\hline $\mathrm{TcO}_{3} \mathrm{~F}$ & 100 & & \\
\hline $\mathrm{TcOF}_{4}$ & 165 & & \\
\hline $\mathrm{RhF}_{6}$ & 73.5 & 0.06 & Chernick et al. (1961) \\
\hline $\mathrm{TeF}_{6}$ & -36 (sublimes) & 0.06 & Prideaux, E.B.R. (1906) \\
\hline $\mathrm{IF}_{7}$ & 4.8 (sublimes) & \multirow{2}{*}{0.03} & Adams (1974) \\
\hline $\mathrm{IF}_{5}$ & 100.5 & & Rogers et al. (1954) \\
\hline $\mathrm{SeF}_{6}$ & -39 (sublimes) & 0.006 & Prideaux (1906) \\
\hline $\mathrm{BrF}_{5}$ & 40.8 & \multirow{2}{*}{0.002} & \multirow{2}{*}{$\begin{array}{l}\text { Rogers and Speirs (1956) } \\
\text { Oliver and Grisard (1952) }\end{array}$} \\
\hline $\mathrm{BrF}_{3}$ & 125.8 & & \\
\hline $\mathrm{SbF}_{5}$ & 143 & 0.001 & Shair and Schurig (1951) \\
\hline
\end{tabular}

\subsubsection{Separations Methods Based on Fluoride Volatility}

Fluoride volatility can be used to separate uranium from many of the other actinide fluorides and fission products (Campbell and Cathers, 1960). Several fluorinating agents can be used for fluoride volatility processes. The most common are $\mathrm{F}_{2}$, interhalogens (e.g., $\mathrm{ClF}_{3}, \mathrm{BrF}_{3}, \mathrm{BrF}_{5}, \mathrm{ClF}$ ), and $\mathrm{NF}_{3}$. Both $\mathrm{F}_{2}$ and $\mathrm{ClF}_{3}$ can produce $\mathrm{PuF}_{6}$ (Schmets, 1967), whereas bromine fluorides, $\mathrm{ClF}$, and $\mathrm{NF}_{3}$ will not (Scheele et al., 2012). Interhalogens can be used for low-temperature fluorination processes, even at room temperature (Schmets, 1967). Hence, in addition to the fluorinated metals, excess fluorinating agent will be present in the volatility process off-gas.

Because of its lower volatility and thermodynamic stability, plutonium is not separated using fluoride volatility. For instance, the reagent $\mathrm{NF}_{3}$ requires higher temperatures $\left(>550^{\circ} \mathrm{C}\right)$ to produce $\mathrm{UF}_{6}$ but will not produce $\mathrm{PuF}_{6}$. While moderate temperatures (e.g., $300-350^{\circ} \mathrm{C}$ ) can be used to produce $\mathrm{UF}_{6}$ with very little $\mathrm{PuF}_{6}$, much higher temperatures $\left(>600^{\circ} \mathrm{C}\right)$ are needed to increase the yield of $\mathrm{PuF}_{6}$ (Schmets, 1967; Shatalov et al.Shatalov2001, 2001). Conversely, plutonium hexafluoride and $\mathrm{NpF}_{6}$ are very strong 
fluorinating agents, and they will fluorinate uranyl fluorides (e.g., $\mathrm{UO}_{2} \mathrm{~F}_{2}, \mathrm{UOF}_{4}$ ) and lower oxidation-state uranium fluorides (e.g., $\mathrm{UF}_{4}, \mathrm{UF}_{5}$ ). An upfront trap made of uranyl (or lower) fluorides would allow recovery of plutonium produced during the volatilization process. Because it will always be mixed with uranium and neptunium, this trapping methodology could provide a degree of proliferation protection by never producing a pure stream of plutonium (Sasahira et al., 2005; Amamoto and Sato, 2007).

The other technology used for separating individual fluorides is by selective trapping (Trowbridge et al., 2004). Volatile fluorides and oxyfluorides physisorb and chemisorb on other fluorides or oxyfluorides with bonding strengths ranging from weak adsorption to forming miscible multicomponent salts. The interactions are temperature dependent, which allows control over selectivity. Several reagents have been tested at lab scale (e.g., $\mathrm{BiF}_{3}, \mathrm{CoF}_{2}, \mathrm{CoF}_{3}, \mathrm{PbF}_{2}, \mathrm{MnF}_{2}, \mathrm{SnF}_{4}, \mathrm{KF}, \mathrm{BiOF}, \mathrm{K}_{3} \mathrm{NiF}_{6}, \mathrm{Na}_{3} \mathrm{AlF}_{6}$ ). Some have been used at pilot scale (e.g., LiF), and two at industrial scale (i.e., $\mathrm{NaF}$ and $\mathrm{MgF}_{2}$ ) (Capps, 1951). Of these, $\mathrm{BiOF}$ shows promise for selectively trapping $\mathrm{HF}$ comingled with $\mathrm{UF}_{6}$ (Capps, 1951).

Magnesium fluoride (i.e., $\mathrm{MgF}_{2}$ ) in the form of porous pellets has been used at large scale for the selective trapping of volatile technetium fluorides and oxyfluorides of technetium mixed with $\mathrm{UF}_{6}$ (Golliher et al., 1963; Katz, 1964a; Simmons, 1996). Magnesium fluoride is fairly insoluble in water (i.e., $0.0076 \mathrm{~g} / 100 \mathrm{~mL}$ at $18^{\circ} \mathrm{C}$ ) (Kohlrausch, 1905), so trapped technetium can be easily removed by washing with water or dilute $\mathrm{HNO}_{3}$. The $\mathrm{MgF}_{2}$ can be reused after a drying step (Golliher et al., 1963) .

Many studies have reported the reversible sorption-desorption of $\mathrm{UF}_{6}$ in NaF (Cathers et al., 1958; Katz, 1963) including large-scale industrial use (Schultz et al., 1981). Sodium fluoride will also sorb other species such as $\mathrm{HF}$ and $\mathrm{MoF}_{6}$. Operating somewhat below $200^{\circ} \mathrm{C}$ will allow the selective trapping of $\mathrm{UF}_{6}$ while $\mathrm{MoF}_{6}$ and $\mathrm{HF}$ will bypass the trap. Uranium hexafluoride can later be desorbed at higher temperatures (Katz, 1964b; Afzal et al., 2010). Both sodium fluoride and magnesium fluoride pellets can be made by mixing the powder with water to form agglomerates that are pelletized; the pellets are then dehydrated and sintered (Richardson and McNeese, 1968) as described previously for $\mathrm{MgF}_{2}$.

Carter and Whatley (1967) have described in detail an off-gas system proposed for the MSBR fertile processing system. In this system, ${ }^{233} \mathrm{U}$ is removed from the reactor and separated from its precursor ${ }^{232} \mathrm{~Pa}$. The system is a continuous process, with volatile $\mathrm{UF}_{6}$ generated by fluorination and then separated by vacuum distillation and sorption from volatile fission products $(\mathrm{Ru}, \mathrm{Nb}, \mathrm{Mo}, \mathrm{Tc}, \mathrm{Te}, \mathrm{Br}$, and I) that are also oxidized by $\mathrm{F}_{2}$. While $\mathrm{UF}_{6}$ and $\mathrm{MoF}_{6}$ are removed on a $\mathrm{NaF}$ bed, to be later separated by thermal desorption, and technetium is removed on $\mathrm{MgF}_{2}$ bed, the rest of the fission products are transported with the $\mathrm{F}_{2}$ carrier to the off-gas system. (A second process is used to purify and recycle the $\mathrm{LiF}-\mathrm{BeF}_{2}$ carrier salt.) The $\mathrm{F}_{2}$ passes through a surge chamber with a slip stream going through an aqueous $\mathrm{KOH}$ caustic scrubber to remove fission products, as well as some $\mathrm{HF}$ and some of the $\mathrm{F}_{2}$. The $\mathrm{KOH}$ off-gas is contacted with steam to hydrolyze tellurium, the solids from which can be removed by filtration.

\subsubsection{Volatile Chlorides}

Similar to the fluoride systems, many of the fuel components, fission products, and activation products will be soluble in the chloride salt. However, the possible chloride species are listed in Table 3-6. Protactinium and uranium form chlorides (e.g., $\mathrm{PaCl}_{5}, \mathrm{UCl}_{4}$ ) that are volatile at relatively low temperature. Increasing the temperature will volatilize $\mathrm{ThCl}_{4}$, followed by $\mathrm{NpCl}_{4}$, and at even higher temperatures, $\mathrm{AmCl}_{3}$. The volatility of $\mathrm{PuCl}_{3}$ by itself is very low, but it is increased by the formation of $\mathrm{PuCl}_{4}$ in the gas phase according to Reaction (3-5) below (Hariharan et al., 1969a).

$$
2 \mathrm{PuCl}_{3}+\mathrm{Cl}_{2(\mathrm{~g})} \rightleftharpoons \mathrm{PuCl}_{4(\mathrm{~g})}
$$

Of the fission products, the rare earths and alkaline earths form nonvolatile chlorides and will remain solubilized in the salt. The fission products $\mathrm{Mo}, \mathrm{Zr}, \mathrm{Nb}, \mathrm{In}, \mathrm{I}, \mathrm{Br}, \mathrm{Cl}, \mathrm{Se}$, and $\mathrm{Te}$ form volatile chlorides and may be released along with krypton and xenon. Technetium forms volatile oxychlorides and $\mathrm{TcCl}_{4}$ (Schwochau, 2000; Johnstone et al., 2012). Cesium and ruthenium require higher volatilization temperatures. 
Very limited information is available on the topic of chloride volatility in molten salts. Olander and Camahort (1966) describe the chlorination of $\mathrm{UCl}_{4}$ dissolved in a $\mathrm{KCl}-\mathrm{LiCl}$ eutectic salt. Operating at $600^{\circ} \mathrm{C}$, about 50 mass $\%$ of the uranium volatilized in $1 \mathrm{~h}$.

Uranium forms four chlorides (i.e., $\mathrm{UCl}_{6}, \mathrm{UCl}_{5}, \mathrm{UCl}_{4}, \mathrm{UCl}_{3}$ ) and numerous oxychlorides (e.g., $\mathrm{UOCl}$, $\mathrm{UOCl}_{2}, \mathrm{UOCl}_{3}, \mathrm{UO}_{2} \mathrm{Cl}_{2}$ ). The presence of oxygen as an impurity, or from activation of the salt, can also cause the formation of oxychlorides. Typically, chlorination is done in open systems. But even under closed conditions, such as MSRE, the oxygen partial pressure measured in MSRE fuel before irradiation was $1 \times 10^{5}$ to $5 \times 10^{-4}$ bar (Briggs, 1966). This suggested that oxychlorides will be formed in the reactor salt to some extent.

Table 3-6. Summary of vapor pressures and boiling temperatures $\left(T_{\mathrm{b}}\right)$ for various chloride species.

\begin{tabular}{|c|c|c|c|c|c|}
\hline \multirow{2}{*}{ Species } & \multicolumn{3}{|c|}{ Vapor pressure (Torr) } & \multirow{2}{*}{$\begin{array}{c}T_{\mathbf{b}} \\
\left({ }^{\circ} \mathbf{C}\right)^{b}\end{array}$} & \multirow{2}{*}{ Reference } \\
\hline & $T=300^{\circ} \mathrm{C}$ & $T=500^{\circ} \mathrm{C}$ & $T=700^{\circ} \mathrm{C}$ & & \\
\hline $\mathrm{ThCl}_{4}$ & 5.9E-9 & $4.0 \mathrm{E}-3$ & 10.8 & 922 & Hariharan et al. (1969a) \\
\hline $\mathrm{PaCl}_{5}$ & 4.6 & 520 & $>760$ & 420 & Hariharan et al. (1969a) \\
\hline $\mathrm{UCl}_{3}$ & Not favored & solid & $<1$ & 1657 & Kraus (1943b) \\
\hline $\mathrm{UCl}_{4}{ }^{a}$ & 10 & $>760$ & $>760$ & dec & $\begin{array}{l}\text { Gruen and McBeth (1969) } \\
\text { Del Cul and Hunt (2019) }\end{array}$ \\
\hline $\mathrm{UCl}_{5}$ & 2.4 & 370 & $>760$ & 527 & Hariharan et al. (1969a) \\
\hline $\mathrm{UCl}_{6}$ & $>760$ & $>760$ & $>760$ & 277 & Hariharan et al. (1969a) \\
\hline $\mathrm{NpCl}_{4}$ & $3.3 \mathrm{E}-7$ & $9.3 \mathrm{E}-3$ & 0.60 & 847 & HSC Chemistry \\
\hline $\mathrm{PuCl}_{3}$ & 7.9E-5 & $2.0 \mathrm{E}-8$ & $1.1 \mathrm{E}-3$ & 1790 & Hariharan et al. (1969a) \\
\hline $\mathrm{AmCl}_{3}$ & $9.6 \mathrm{E}-12$ & $8.4 \mathrm{E}-6$ & $2.63 \mathrm{E}-2$ & 1180 & Wiegel and Schuster (1984) \\
\hline $\mathrm{ZrCl}_{4}$ & 225 & $>760$ & $>760$ & 331 & Hariharan et al. (1969a) \\
\hline $\mathrm{NbCl5}$ & $>760$ & $>760$ & $>760$ & 267 & Hariharan et al. (1969a) \\
\hline $\mathrm{MoCl}_{5}$ & $>760$ & $>760$ & $>760$ & 260 & Hariharan et al. (1969a) \\
\hline $\mathrm{MoOCl}_{4}$ & $>760$ & $>760$ & $>760$ & - & HSC Chemistry \\
\hline $\mathrm{TcCl}_{5}$ & $>760$ & $>760$ & $>760$ & 232 & HSC Chemistry \\
\hline $\mathrm{InCl}_{3}$ & $2.26 \mathrm{E}-2$ & 82 & $>760$ & 582 & HSC Chemistry \\
\hline $\mathrm{TeCl}_{4}$ & 266 & $>760$ & $>760$ & 387 & HSC Chemistry \\
\hline $\mathrm{CsCl}$ & $6.5 \mathrm{E}-8$ & $2.0 \mathrm{E}-3$ & 0.7 & 1300 & Hariharan et al. (1969a) \\
\hline $\mathrm{RuCl}_{3}$ & $3.4 \mathrm{E}-12$ & $3.1 \mathrm{E}-5$ & 0.3 & dec & Hariharan et al. (1969a) \\
\hline $\mathrm{RhCl}_{3}$ & $2.5 \mathrm{E}-17$ & $3.7 \mathrm{E}-9$ & $2.0 \mathrm{E}-4$ & dec & Hariharan et al. (1969a) \\
\hline $\mathrm{SrCl}_{2}$ & $2.3 \mathrm{E}-18$ & $2.5 \mathrm{E}-11$ & $3.5 \mathrm{E}-7$ & 2027 & Hariharan et al. (1969a) \\
\hline $\mathrm{BaCl}_{2}$ & $1.8 \mathrm{E}-16$ & $1.6 \mathrm{E}-9$ & $1.5 \mathrm{E}-5$ & 2100 & Hariharan et al. (1969a) \\
\hline $\mathrm{CeCl}_{3}$ & $1.0 \mathrm{E}-16$ & $6.8 \mathrm{E}-9$ & $1.7 \mathrm{E}-4$ & 1730 & Hariharan et al. (1969a) \\
\hline $\mathrm{GdCl}_{3}$ & $8.3 \mathrm{E}-15$ & $3.5 \mathrm{E}-7$ & $1.7 \mathrm{E}-3$ & 1580 & Hariharan et al. (1969a) \\
\hline
\end{tabular}

${ }^{a} \mathrm{UCl}_{4}$ sublimes as a $\mathrm{UCl}_{5}$ complex.

${ }^{b}$ The term "dec" denotes that the compound decomposes rather than evaporates congruently.

\subsubsection{Separations Methods Based on Chloride Volatility}

Chloride volatility processes are of interest to pyroprocessing activities and have been used to handle thorium-uranium fuels that appear amenable to chloride volatility processes. Chlorinating agents include $\mathrm{Cl}_{2}$ or $\mathrm{Cl}_{2}-\mathrm{CCl}_{4}$ gaseous mixtures, liquid $\mathrm{CCl}_{4}$ (Kraus, 1943a), $\mathrm{SOCl} 2\left(\mathrm{McBee}\right.$ et al., 1946), $\mathrm{Al}_{2} \mathrm{Cl}_{6}\left(\mathrm{Fried}_{\text {, }}\right.$ 1945; Calkins, 1958; Gruen and McBeth, 1968, 1969; Rudel and Kraus, 2017), and hexachloropropane (McBee and Evans, 1945; Patel et al., 2015). 
Early attempts to develop chloride volatility processing schemes for nuclear fuels were not very successful. The effective trapping of volatile uranium chlorides in $\mathrm{NaCl}$ suggests a strong complexation and a more difficult volatilization of uranium chlorides out of molten alkali-chloride salt. However, Warren and Ferris (1966) found that they could increase the rate of chlorination of mixed oxide fuel by pretreating the fuel with an air/oxygen mixture at temperatures of $400-600^{\circ} \mathrm{C}$ to form a very fine $\mathrm{U}_{3} \mathrm{O}_{8}$ powder. As a chlorination reagent, they used a mixture of $85 \% \mathrm{Cl}_{2}$ and $15 \% \mathrm{CCl}_{4}$. However, they could not devise a method to separate the uranium chlorides from other components. Recent developments in voloxidation using $\mathrm{NO}_{2}$ (DelCul et al., 2013) produced a $\mathrm{UO}_{3}$ powder at a lower temperature. $\mathrm{UO}_{3}$ can be chlorinated at a lower temperature and a faster rate using $\mathrm{Cl}_{2}$ or $\mathrm{Cl}_{2}-\mathrm{CCl}_{4}$ mixtures, allowing for the distillation of a pure uranium stream.

Hariharan et al. (1969a; 1969b) used a $\mathrm{Cl}_{2}-\mathrm{CCl}_{2}-\mathrm{N}_{2}$ mixture as the chlorinating reagent on powdered $\mathrm{Th} / \mathrm{U}$ and U-Pu oxide fuels. As trapping materials, they used two alumina filter beds followed by a $\mathrm{NaCl}$ bed. They generated a flowsheet with a second-stage purification for uranium and thorium products, achieving an overall decontamination factor of 10,000 . For the U-Pu fuel, they ran the chlorination process at $450^{\circ} \mathrm{C}$ on powdered fuel. The uranium was trapped in the $\mathrm{NaCl}$ along with $\mathrm{Mo}, \mathrm{Nb}$, and $\mathrm{Zr}$. The rest of the fission products remained with the plutonium in the chlorination chamber. Hariharan's laboratory did not attempt to recover and purify plutonium because they concluded that a fluoride volatility step would be more efficient. It has been speculated that conversion of fluorides to chlorides will assist in online processing of MSR salts using reagents such $\mathrm{BCl}_{3}$ or $\mathrm{AlCl}_{3}$ (Calkins, 1958). Conversely, chlorides can be transformed into fluorides using anhydrous $\mathrm{HF}$ at moderate temperatures of $250-500^{\circ} \mathrm{C}$ (Fried, 1945). Fluorinating agents such as $\mathrm{F}_{2}, \mathrm{NF}_{3}$, and $\mathrm{ClF}_{3}$ can also be used to convert chlorides to fluorides, which can then be separated by fluoride volatility processing (Matsuda et al., 2015).

For chloride-based separations, the off-gas system will need to be able to trap chlorine and chlorinating agents. As some of these can be highly toxic, such as phosgene, it is important to consider the chemical hazards as well as the radiological hazards during maintenance and end-of-life activities. 


\section{MONITORING AND DETECTION}

The MSRE fuel salt was sampled regularly through a sampler-enricher system. The samples were sent for chemical analysis. Although the data were useful in determining how the reactor had been performing after the fact, the immediacy of online monitoring can be a powerful tool for gaining in situ and real-time information on a given process or system. A variety of tools are available for characterizing a range of aspects of a given process or system, ranging from chemical composition to structural integrity. In the case of MSRs and ancillary off-gas treatment systems, the integration of online monitoring tools can (1) support informed and efficient design, (2) answer licensing challenges, and (3) support real-time process control and verification of safeguards during system operation. For the focus of this report, off-gas treatment system design, online monitoring is particularly helpful in designing and testing system performance. Furthermore, integrating online monitoring capabilities in the design stage better enables applications of these tools in deployment of MSRs and their gas treatment systems. Online measurements would need to be calibrated frequently with standard chemical analyses, because exposure to the extreme environment of a molten salt reactor core could degrade the performance of sensitive online detectors.

\subsection{Online Chemical Composition Analysis for Molten Salt Reactor Off-Gas Treatment Systems}

Of particular interest is the analysis of the chemical composition of the gas stream entering and exiting the treatment systems. This is an invaluable tool to the design of treatment systems as it allows researchers the opportunity to characterize and optimize system performance in real time. Of the tools available, optical spectroscopy represents one of the best options for characterizing the chemical compositions of a given process batch or stream. Optical spectroscopy is a mature technology that can typically provide needed data quickly. Furthermore, multiple techniques can be combined to gain a comprehensive understanding of the chemical composition of a given sample or stream. As an example, through the combination of elemental analysis techniques (e.g., laser-induced breakdown spectroscopy, LIBS) and molecular analysis approaches (e.g., Raman spectroscopy), researchers can gain a complete elemental breakdown as well as detailed insight into the molecular speciation within the system. This enables researchers to both understand how well the treatment system is working and how the system needs to be modified to enhance performance. This report section will focus on the applications of molecular and elemental optical spectroscopic techniques to the online and real-time monitoring of off-gas treatment systems, both within the gas phase and scrubber system.

\subsubsection{Molecular Analysis of Gas-Phase Species}

Molecular speciation of a given gas species can drastically impact how those species interact with and are captured by treatment systems. Characterizing this chemical speciation is essential given the potential chemical complexity of MSR off-gas streams. Many species may be present in the MSR off-gas treatment system including the gaseous species $\mathrm{Kr}, \mathrm{Xe}, \mathrm{HF}, \mathrm{H}_{2} \mathrm{O}, \mathrm{N}_{2}, \mathrm{O}_{2}, \mathrm{H}_{2}, \mathrm{~F}_{2}, \mathrm{Br}_{2}, \mathrm{I}_{2}$, and $\mathrm{Ar}$ (Riley et al., 2018a; McFarlane et al., 2019a). Volatile chloride or fluoride products can also be formed with uranium, some transuranics, and fission products (Riley et al., 2018a). Radionuclides that can be present in the gas phase and are of most concern include ${ }^{3} \mathrm{H},{ }^{14} \mathrm{C},{ }^{85} \mathrm{Kr}$, and ${ }^{129} \mathrm{I}$ (Bruffey et al., 2015; Riley et al., 2016). Iodine, for example, can form many species in molten salt systems including $\mathrm{I}^{-}$, and $\mathrm{I}_{2}$, (Bruffey et al., 2015) and mixed halide species. In molten chloride systems, $\mathrm{ICl}$ is expected to be the major form of iodine due to the excess chloride present in these systems (Burger, 1991; Burger and Sheele, 2004; Fritz and Phillips, 2013; Bruffey et al., 2015; McFarlane et al., 2018) unless $\mathrm{NaCl}$ is a constituent salt. Gaseous species are inherently more difficult to control than liquid or solid products and pose a challenge in treatment systems (Jubin et al., 2012; Jubin and Strachan, 2015). These species also tend to be present at low concentrations, making their detection and quantification even more challenging (Jubin and Strachan, 2015). 
Because molecular speciation impacts treatment system performance, analysis of these species is essential to understand what is coming out of the reactor and ensure the treatment system is appropriately designed to capture and compensate for the chemical behavior of the different species. Furthermore, under deployment scenarios the ability to identify and quantify these potential species is critical to ensure off-gas treatment systems are operating effectively and the release of potentially hazardous gaseous species is in compliance with US regulatory requirements (Jubin et al., 2012; Bruffey et al., 2015). Online monitoring not only supports informed design of treatment systems but also allows for greater insight and understanding of reactor output and treatment system performance. A variety of optical approaches are available that can provide the needed chemical speciation information. Table 4-1 lists four different optical techniques commonly available, along with examples of species which can be analyzed by each spectroscopic technique. Of the available techniques, Raman spectroscopy presents uniquely identifiable signatures for the largest number of key control species, including the diatomic gases $\mathrm{H}_{2}, \mathrm{~N}_{2}, \mathrm{O}_{2}, \mathrm{~F}_{2}, \mathrm{Br}_{2}$, $\mathrm{ICl}$, and $\mathrm{I}_{2}$, making it an invaluable tool for off-gas characterization (Holzer et al., 1970b; Fouche and Chang, 1971; Kiefer and Bernstein, 1972; Shaw III, 1981; Strauss, 1988; McFarlane et al., 2019a; Felmy et al., 2020).

Table 4-1. Optical spectroscopic techniques capable of analyzing the following examples of potential molecular off-gas species. FTIR denotes Fourier transform infrared spectroscopy.

\begin{tabular}{|c|c|c|}
\hline Technique & Species & References \\
\hline Raman & $\begin{array}{c}\mathrm{HF}, \mathrm{N}_{2}, \mathrm{H}_{2} \\
\mathrm{HI}, \\
\mathrm{H}_{2} \mathrm{O} \\
\mathrm{N}_{2}, \mathrm{O}_{2}, \\
\mathrm{~F}_{2}, \\
\mathrm{Br}_{2}, \mathrm{Cl}_{2}, \mathrm{ICl}, \mathrm{IBr}, \mathrm{BrCl} \\
\mathrm{I}_{2}, \\
\text { tritium, e.g., }{ }^{3} \mathrm{H}_{2}(\mathrm{~g}),{ }^{3} \mathrm{HH}(\mathrm{g}),{ }^{3} \mathrm{HF}(\mathrm{g}), \\
{ }^{3} \mathrm{HF}(\mathrm{l})\end{array}$ & $\begin{array}{l}\text { McFarlane et al., 2019a } \\
\text { van Straaten and Silvera, } 1987 \\
\text { Casella et al., } 2015 \\
\text { Fouche and Chang, 1971; } \\
\text { Schiferl et al., } 1987 \\
\text { Holzer et al., 1970b } \\
\text { Holzer et al., 1970b; Kiefer and } \\
\text { Bernstein, 1972; Shaw III, 1981; } \\
\text { Strauss, 1988 } \\
\text { Fischer et al., } 2011\end{array}$ \\
\hline FTIR & $\begin{array}{c}\mathrm{HF} \\
\mathrm{HI} \\
\mathrm{HCl} \\
\mathrm{HOI} \\
\mathrm{ICl} \\
\\
\mathrm{IBr}, \mathrm{BrCl}\end{array}$ & $\begin{array}{l}\text { Andrews, } 1988 \\
\text { Bulanin et al., } 2003 \\
\text { Hughey et al., } 2020 \\
\text { Barnes et al., } 1992 \\
\text { Brooks and Crawford, 1955; Hedderich } \\
\text { et al., 1992; McFarlane et al., 2019a; } \\
\text { Hughey et al., 2020 } \\
\text { McFarlane et al., 2019a }\end{array}$ \\
\hline UV-vis & $\begin{array}{c}\mathrm{I}_{2}, \mathrm{I}^{-} \\
\mathrm{HI}, \mathrm{HBr} \\
\mathrm{Br}_{2}, \mathrm{BrCl} \\
\mathrm{CH}_{3} \mathrm{I} \\
\mathrm{ICl}\end{array}$ & $\begin{array}{l}\text { Awtrey and Connick, 1951b } \\
\text { Huebert and Martin, } 1968 \\
\text { Maric et al., } 1994 \\
\text { Rattigan et al., } 1997 \\
\text { Nebeker and Pings, 1965; Hedderich et } \\
\text { al., } 1992\end{array}$ \\
\hline Luminescence & $\mathrm{I}_{2}, \mathrm{Br}_{2}, \mathrm{Cl}_{2}$ & Holzer et al., 1970b \\
\hline
\end{tabular}




\begin{tabular}{|c|c|l|}
\hline & HOI & Loomis et al., 1997 \\
ICl & Hedderich et al., 1992 \\
\hline
\end{tabular}

As an example, Raman spectroscopy has been demonstrated to be useful in the characterization of $\mathrm{I}_{2}$ (Holzer et al., 1970b; Kiefer and Bernstein, 1972; Shaw III, 1981; Strauss, 1988; Felmy et al., 2020). Figure 4-1 presents the Raman response of $I_{2(\mathrm{~g})}$ when interrogated using either a $532 \mathrm{~nm}$ or $671 \mathrm{~nm}$ excitation laser (Felmy et al., 2020). It should be noted that the spectrum contains both fluorescence (the largest response bands) and Raman (smaller bands that appear as shoulders to the fluorescence) bands. This optical signal for $I_{2(\mathrm{~g})}$ was used to construct calibration curves as a function of pressure. Figure 4-1 shows the Raman response with changing pressure of $\mathrm{I}_{2(\mathrm{~g})}$ and the resulting calibration curves used to calculate a limit of detection. The limit of detection of $\mathrm{I}_{2}$ was determined to be $6.7 \times 10^{-5}$ torr at $25^{\circ} \mathrm{C}$. It should be emphasized that this analysis approach also indicated some fingerprint dependencies on gas temperature, suggesting Raman or other vibrational approaches may be a useful tool for indirectly measuring gas temperature that does not rely on corrosion-vulnerable thermocouples.
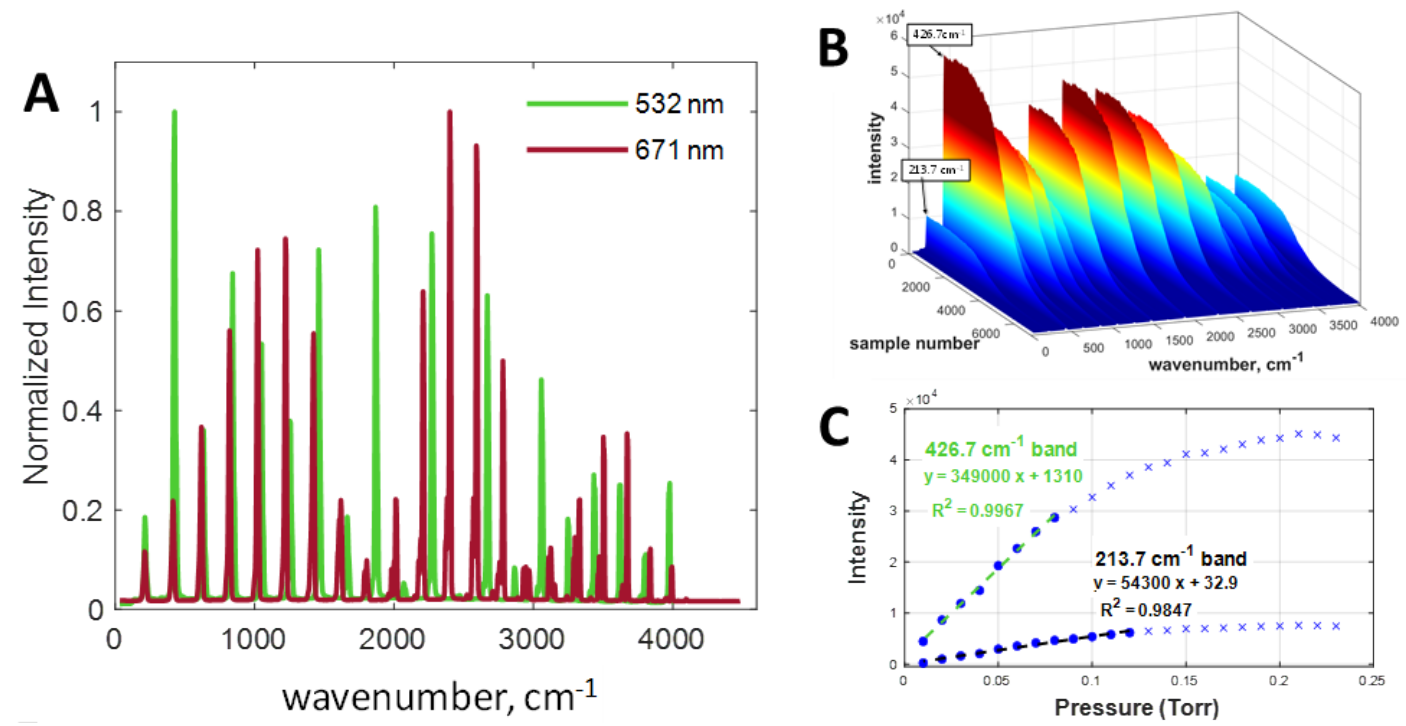

Figure 4-1. (A) Raman spectra of gaseous $I_{2(\mathrm{~g})}$ in a sealed quartz reference cell from $532 \mathrm{~nm}$ and $671 \mathrm{~nm}$ Raman systems with a 0.5 second integration time. (B) Change in the intensity of spectra with a change in pressure of $\mathrm{I}_{2(\mathrm{~g})}$ using a $532 \mathrm{~nm}$ excitation laser at $25^{\circ} \mathrm{C}$. (C) Calibration curves at $25^{\circ} \mathrm{C}$ showing the intensity of the Raman band of $\mathrm{I}_{2(\mathrm{~g})}$ at $213.7 \mathrm{~cm}^{-1}$ and the first fluorescent band at $426.7 \mathrm{~cm}^{-1}$ as a function of the pressure of $\mathrm{I}_{2(\mathrm{~g})}$ in the measurement cell using the $532 \mathrm{~nm}$ laser system. These figures were taken from Felmy et al. (2020).

Work presented by Felmy et al. (2020) also indicates advanced data analysis can be paired with Raman spectroscopy. In this case, authors explored the application of chemometric modeling to the principal component analysis of $\mathrm{I}_{2(\mathrm{~g})}$ Raman fingerprints. This supported enhanced analysis of optical characteristics but also laid the foundation necessary to begin building quantification models for iodine within the gas phase. Real-time quantification via chemometric analysis has been partnered with Raman spectroscopy within different applications in which it has been successfully utilized to characterize solutions with highly complex chemical compositions (Lines et al., 2019; Nelson et al., 2019; Lackey et al., 2020; Lines et al., 2020). Resulting real-time data output can then be used to support process control and verification of process outlet composition. Future demonstrations and developments will focus on the integration of chemometric modeling to support real-time identification and quantification of gas-phase components. Examples of initial applications are covered below. 
Raman spectroscopy has also been applied to the analysis of other gaseous species that are of interest to MSR off-gas treatment. Examples include tritium, which can be detected via Raman spectroscopy and differentiated from other isotopic species. The various isotopes and molecular combinations of hydrogen, including ${ }^{3} \mathrm{H}_{2},{ }^{3} \mathrm{H}^{2} \mathrm{H},{ }^{2} \mathrm{H}_{2},{ }^{3} \mathrm{HH}, \mathrm{H}^{2} \mathrm{H}$, and $\mathrm{H}_{2}$, all have distinct Raman bands (Fischer et al., 2011). Figure 4-2a shows an example of the different distinct Raman bands for the different possible tritium $\left({ }^{3} \mathrm{H}\right.$ or $\left.\mathrm{T}\right)$, deuterium $\left({ }^{2} \mathrm{H}\right.$ or $\left.\mathrm{D}\right)$, and hydrogen gas species. Additionally, Raman spectroscopy has been used to follow $\mathrm{HF}, \mathrm{O}_{2}, \mathrm{~N}_{2}, \mathrm{CO}_{2}$, and $\mathrm{H}_{2} \mathrm{O}$, among other chemical species of process concern within fluorination studies (Casella et al., 2019). An example of process output taken from Casella et al. (2019) can be seen in Figure 4-2b and Figure 4-2c. In this case, only qualitative data were generated, but integration of chemometric models for real-time quantification will support enhanced and potentially automated process control.
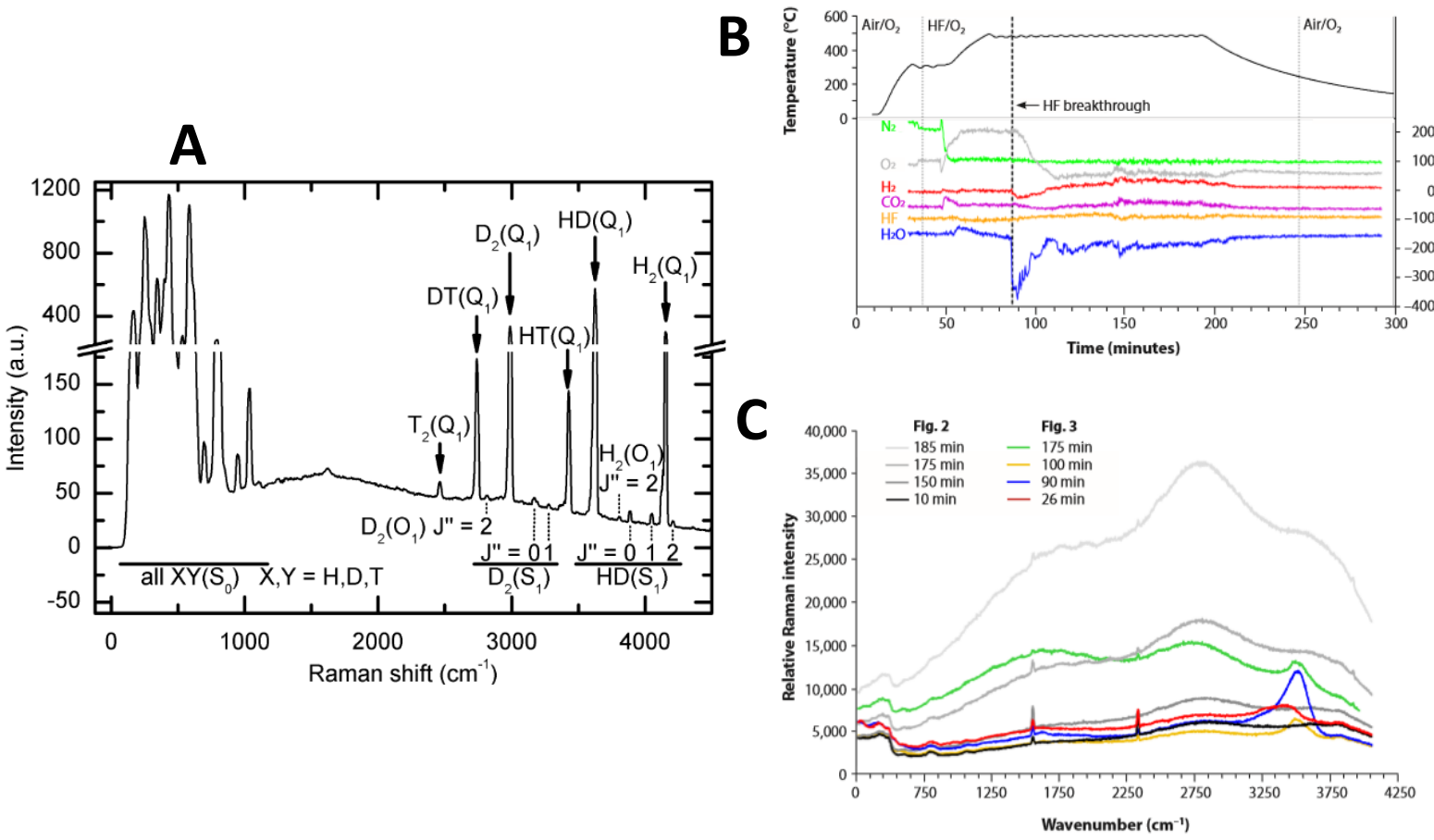

Figure 4-2. (A) Spectrum of lowly tritiated gas sample with all six hydrogen isotopologues measured (Fischer et al., 2011). (B) Peak response over time (C) of the various Raman bands of interest (Casella et al., 2019).

The work by Casella et al. (2019) also demonstrates one effective route for integrating Raman spectroscopy into a gas line. In this system, a $\mathrm{T}$ junction fitted with an optical window was inserted into the gas line (Figure 4-3a). This provided an airtight junction that held the Raman probe in the needed location. Overall, this route used already demonstrated and approved gas-line parts and a minimized space footprint. Raman spectroscopy had been applied to monitoring a variety of systems within harsh environments and was an ideal fit for the Casella et al. (2019) demonstration, which focused on monitoring a corrosive gas within a radiation area. The Raman probe and connected fiber optics are the only components of the monitoring system that are exposed to either caustic media (predominantly the probe tip and window) or the radiation environment. These components are predominantly metal and window material (optimizable for deployment needs). As demonstrated by Casella et al. (2019), the Raman probe withstood multiple runs of being exposed to $50 \%+$ streams of $\mathrm{HF}_{(\mathrm{g})}$. In other demonstrations, Raman probe materials provided viable optical data after receiving $1 \times 10^{8}$ rad of gamma dose (Lines et al., 2019). The rest of the components (instrument, operator control computer, and operator) could be located well out of the hazardous zone. 
Previous deployments have used fiber-optic cables to connect the probe in the hazardous environment to the operator and instrument located over $200 \mathrm{~m}$ away (Bryan et al., 2013).
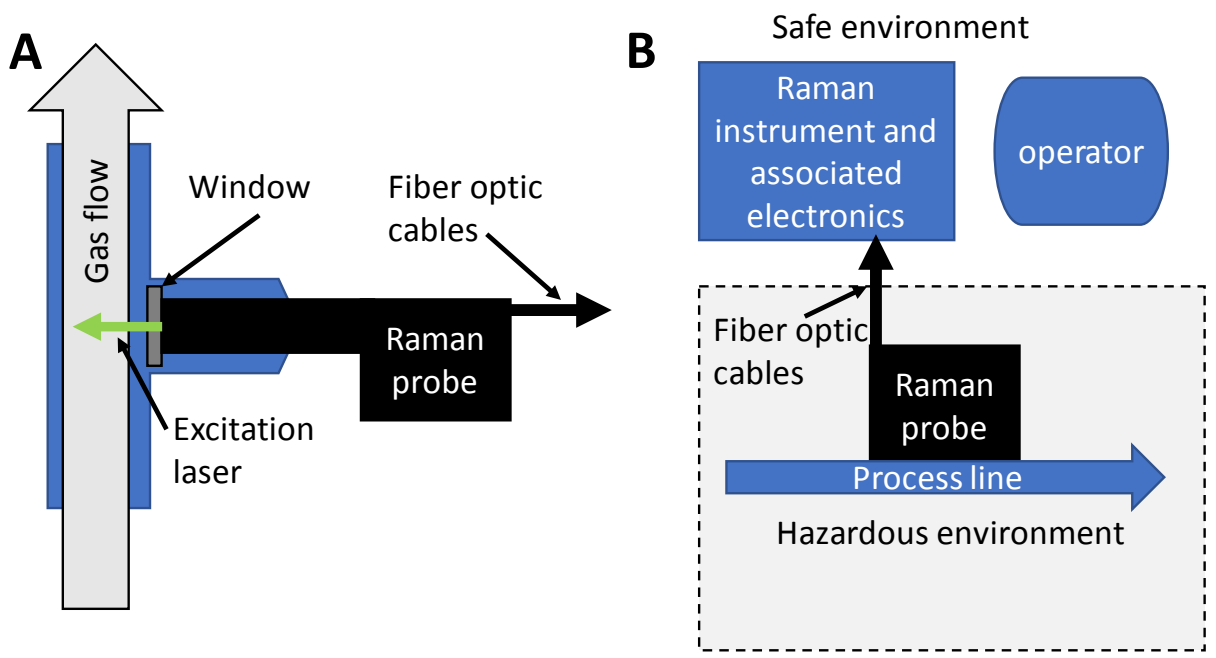

Figure 4-3. (A) Schematic of probe inserted into gas line and (B) schematic of monitoring setup maximizing distancing between probe within the hazardous environment and instrument/operator in safe environment.

As listed in Table 4-1, Fourier transform infrared (FTIR) spectroscopy is another optical spectroscopic technique capable of measuring many off-gas species of interest such as the interhalogens, including ICl, $\mathrm{IBr}$, and $\mathrm{BrCl}$ (Brooks and Crawford, 1955; Hedderich et al., 1992; McFarlane et al., 2019a). Figure 4-4(a) shows an example of the FTIR fingerprint and the resulting calibration curve for ICl gas at $25^{\circ} \mathrm{C}$ (Hughey et al., 2020). Also shown in Figure 4-4(a) (highlighted in inset) is the signal from $\mathrm{HCl}$ contamination in the $\mathrm{ICl}$ sample. Both species present uniquely identifiable fingerprints. Furthermore, $\mathrm{ICl}$ demonstrates a linear response dependence on partial pressure or concentration of $\mathrm{ICl}$ in the gas phase. The calibration curve [Figure 4-4(b)] is found by integrating the ICl band, and plotting as a function of ICl pressure shows that gaseous species such as ICl can also be quantified using optical techniques such as FTIR. Similar FTIR vapor measurements of $\mathrm{ICl}$ at $35^{\circ} \mathrm{C}, 50^{\circ} \mathrm{C}$, and $70^{\circ} \mathrm{C}$ were also collected.
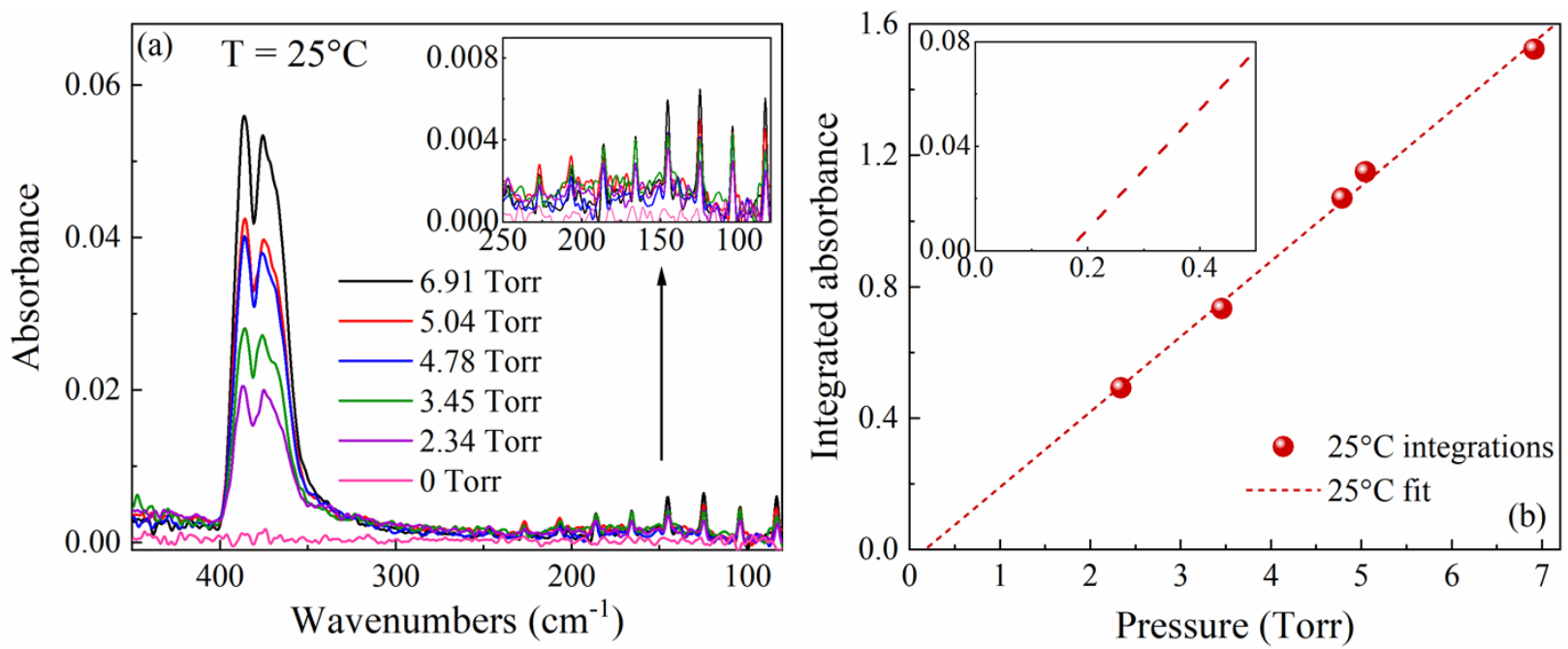

Figure 4-4. (a) Infrared spectra of $\mathrm{ICl}$ at $25^{\circ} \mathrm{C}$ and various pressures (0 to 6.91 Torr); inset: close-up view of low-frequency $\mathrm{HCl}$ features. (b) Beer's Law analysis of the integrated area of the $\mathrm{ICl}$ band as a function of pressure; inset: extrapolation of fit to zero pressure. These figures were taken from Hughey et al. (2020). 
The variable pressure data ( $\mathrm{ICl}$ at varying concentrations in the gas phase) collected for $25^{\circ} \mathrm{C}, 35^{\circ} \mathrm{C}, 50^{\circ} \mathrm{C}$, and $70^{\circ} \mathrm{C}$ were used as a training set for formulating chemometric models for pressures of $\mathrm{ICl}$ in the gas phase. These models use the spectral data and signatures to measure or calculate a given system feature, in this case pressure, of the target analyte: ICl. Figure 4-5(A-D) shows the FTIR absorbance measurements of $\mathrm{ICl}$ at variable pressures and temperatures. This training set data was used to build a partial least-squares (PLS) model for calculating ICl pressure. A parity plot demonstrating model performance is shown in Figure 4-5(E), indicating excellent alignment between the known (measured) pressure and model measurement of pressure based on spectral signals. The variable temperature data all fit within the $95 \%$ confidence interval [shown in Figure 4-5(E)].
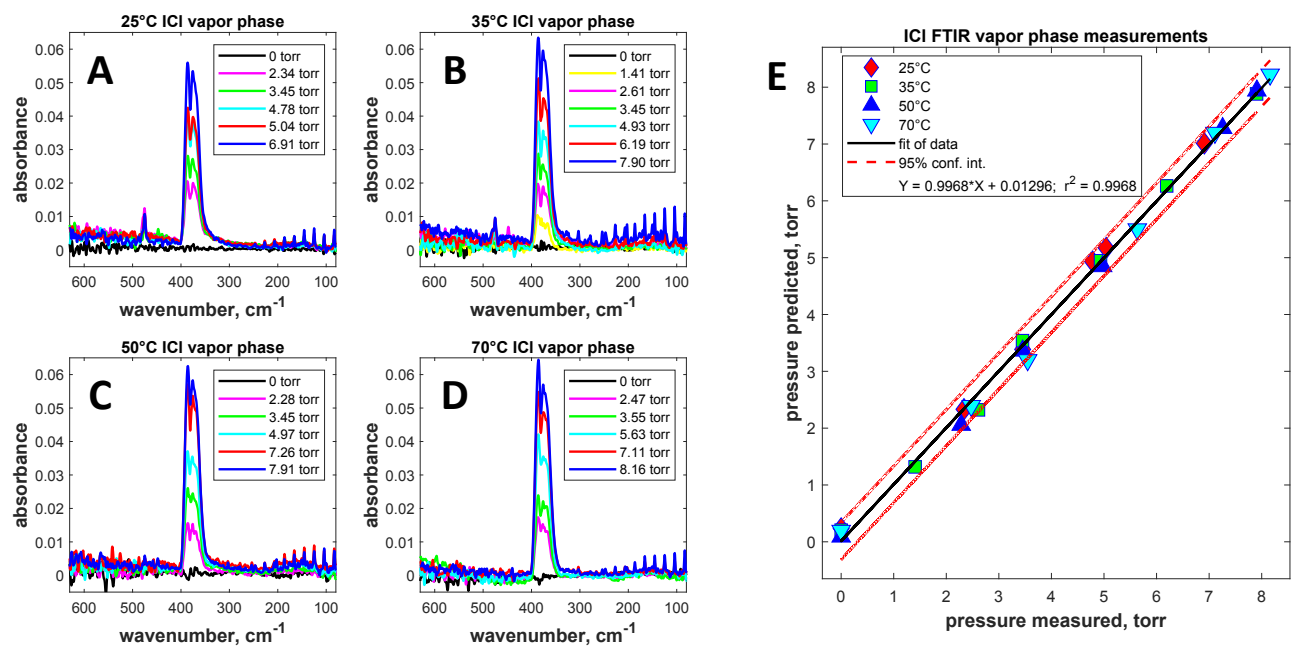

Figure 4-5. FTIR absorbance measurements of variable pressure $\mathrm{ICl}$ collected at $25^{\circ} \mathrm{C}, 35^{\circ} \mathrm{C}, 50^{\circ} \mathrm{C}$, and $70^{\circ} \mathrm{C}$ (A)-(D), respectively; (E) PLS model results for the prediction of ICl pressure based on FTIR absorbance data. Model performance metrics: root-mean-square error of calibration (RMSEC $=0.147$ ); root-mean-square error of cross validation $(\mathrm{RMSECV}=0.176) ; \mathrm{r}^{2}($ calibration $)=0.9968$.

While FTIR can provide complementary information to Raman spectroscopy as well as highlight species that are not Raman active, it presents some challenges in the integration of probes to process lines. Fiberoptic cables for transmitting FTIR signal must be limited in length (Harrington, 2000), meaning the instrument and associated electronics cannot be very far from the point of monitoring (Hartwig and Lambrecht, 2008). Infrared measurements using waveguide materials based on heavy-metal fluorides/chalcogenides, crystals/AgBrCl/sapphire, or hollow waveguide/metallic/metal-halide hollow core types all have limitations based on poor mechanical properties (brittle and added $\mathrm{dB}$ loss on bending) (Saito et al., 1990; Matsuura and Miyagi, 1992) and poor optical properties (high dB/m loss) (Gregory and Harrington, 1993), which restrict use to several meters for deployments. This can be a challenge with monitoring lines within radiation areas, where instrument electronics will be damaged by radiation dose. Some opportunities can be explored here, such as advanced shielding or careful selection of monitoring location to minimize dose to instruments.

Recent advances in long open-path measurement of atmospheric gases using mid-infrared (Griffith et al., 2006) and near-infrared (Griffith et al., 2018) absorption spectroscopy allow for the interrogation of a few hundred meters up to a $20 \mathrm{~km}$ path length for gas measurement. This has been successfully applied to gasphase measurements of urban (Platt et al., 1980a), desert (Holla et al., 2015), and arctic environments (Hausmann and Platt, 1994) where fixed-place measurements were not practical based on proximity to sample. In addition, differential optical absorption spectroscopy (DOAS), typically employing UV and visible spectroscopy, can operate over paths of several kilometers and have been used for measuring halogen-containing gaseous species such $\mathrm{ClO}, \mathrm{OClO}, \mathrm{BrO}, \mathrm{IO}, \mathrm{OBrO}, \mathrm{OIO}, \mathrm{I}_{2}, \mathrm{OIO}$, and other gases (Platt 
and Perner, 1980; Platt et al., 1980a; Platt et al., 1980b; Platt et al., 1981; Griffith et al., 2018; Nasse et al., 2019). The ability to operate UV, visible, and infrared absorption spectroscopy over an open long-path length without requiring a waveguide medium allows for the direct measurement of gaseous analytes remotely in which sensitive equipment is well removed from the environment containing the sample.

Other optical techniques available for providing molecular information include UV-vis and luminescence spectroscopy. These techniques can be used to identify and potentially quantify various decay products produced in MSRs that form volatile species. Examples of UV-vis active species include $\mathrm{I}_{2}$ and $\mathrm{I}^{-}$(Awtrey and Connick, 1951a), $\mathrm{Br}_{2}$ and $\mathrm{BrCl}$ (Maric et al., 1994), and $\mathrm{CH}_{3} \mathrm{I}$ (Rattigan et al., 1997). In all these cases, $\mathrm{UV}$-vis responses tend to be broad band unless using instruments with high resolving power (which also tend to require long collections times). This makes using UV-vis for selective identification and quantification of target analytes within the gas phase more challenging. In the case of a gas-phase absorption spectrum of molecular $\mathrm{I}_{2}$, the highly resolved spectrum contains over 14,000 assigned transitions associated with the vibrionic-rotational transitions between 450-700 nm (Gerstenkorn and Luc, 1985; Lessinger, 1994; Pursell and Doezema, 1999). Despite the fact that UV-vis can easily be integrated into online monitoring flow cells in a manner similar to Raman spectroscopy, it may not be the most sensitive tool for gas-phase characterization. Luminescence has improved potential for characterizing gas-phase systems as compared with UV-vis absorbance (Williamson, 2011). Several key species are luminescent, including $\mathrm{I}_{2}$ (Holzer et al., 1970a; Sakurai and Broida, 1970; Tellinghuisen, 2007; Williamson, 2010) and the interhalogen ICl species (Holzer et al., 1970b). With several of these actively luminescent species, high sensitivity for target analytes can be achieved. Furthermore, both monatomic and molecular species have the potential to be luminescent. This approach can also be integrated into a process line in a fashion similar to Raman spectroscopy and has significant potential to be a valuable tool for the characterization of gaseous species.

\subsubsection{Elemental Analysis of Gaseous Species}

A variety of elements across the entire Periodic Table from hydrogen through and beyond uranium may be present in MSR off-gas streams. Numerous elements will be present at the initial start of the reactor, and others will gradually build in. The former includes elements present as the cover gas (e.g., He, Ar), primary salt components (e.g., U, Cl, F, Be, $\mathrm{Li}, \mathrm{Na}, \mathrm{Mg}$ ), and impurities (e.g., O, N, trace heavy metals) in the salt from initial fuel and coolant salt production. Elements that gradually build in will originate from including fission (e.g., noble gases, I), activation (e.g., transuranics, ${ }^{3} \mathrm{H}$ ), radioactive decay (e.g., Pa), and structural material degradation (e.g., $\mathrm{Cr}, \mathrm{Ni}, \mathrm{Fe}, \mathrm{C}$ ) processes. Identification of the elements present in the off-gas is a key aspect of effective off-gas treatment system design and operation. The capability to perform elemental composition measurements online and in real time is important to both developmental and operational efforts. An important consideration is that the elements will be present as a complex and dynamic mixture of gases, vapors, and aerosols. The monitoring approach must be able to handle this complex, multicomponent stream and provide reliable analytical data. LIBS was identified as an elemental analysis technique with a high potential for enabling online identification and quantification of the large range of elements present in an MSR off-gas.

LIBS has been shown to be a robust technique for measuring elemental composition in many different circumstances, including those relevant to MSR off-gas streams. The LIBS technique involves optical emission analysis of laser-induced micro-plasmas. The plasmas are formed by focusing a pulsed laser to a achieve a power density on the order of $10 \mathrm{GW} / \mathrm{cm}^{2}$ or greater. The high-power density results in the formation of a micro-plasma with an internal temperature in excess of 23,000 K. Initially, the plasma acts as a blackbody radiation source and emits a continuum of light. As the plasma cools, quantized light emission from excited atomic and ionic species begins to dominate the optical emission. In some instances, molecular emission of diatomic molecules is also present either from elements that were bound before laser excitation or that bound during plasma cooling. Emission line position and intensity analysis is then performed on the collected optical emission spectra to identify and quantify the elements present in the ablated volume. 
LIBS analysis typically involves measuring the intensity of light in the UV-Vis-NIR (near-IR) region (nominally $200 \mathrm{~nm}$ to $1000 \mathrm{~nm}$ ). Most elements have one or more emission lines within this wavelength range that are strong enough to be detected at concentrations around or below a few parts per million in the plasma. A few notable elemental exceptions exist, including I, S, and P. Elements such as I, S, and P have weak emission signals and/or emission lines in the UV or deep UV regions. Specialized optical setups are required to perform sensitive measurements in the UV and deep UV regions that are possible in a developmental lab setting but less practical for industrial deployment. An alternative is to couple LIBS with secondary techniques such as laser absorption or fluorescence, which may be explored in future efforts.

Several examples of using LIBS for online monitoring as well as analysis of molten salt aerosols have been published and presented in recent years. Environmental monitoring of aerosols was explored by Gallou et al. (2011). Williams and Phongikaroon $(2017,2018)$ demonstrated the capability to use LIBS to monitor molten salt aerosols. The system developed passed the molten salt aerosol through a sampling chamber where the laser was fired into the aerosol stream through a sapphire optical window. The plasma region included aerosolized particles and the flow gas. This system was used to measure a $\mathrm{UCl}_{3}$ - $\mathrm{LiCl} \mathrm{KCl}$ system, and a univariate model was developed with a limit of detection of $0.065 \mathrm{wt} \% \mathrm{U}(650 \mathrm{ppm})$. Additionally, through the implementation of chemometric modelling, Williams and Phongikaroon (2018) were able to reduce the root mean squared error of cross-validation from 0.20 to $0.085 \mathrm{wt} \%$ uranium. McFarlane et al. (2019a) discussed the further development of LIBS for quantifying heavy metals in aerosol streams in a recent conference proceedings.

A fundamental requirement for performing LIBS measurements is optical access to the sample. Figure 4-6 shows a computer-aided design (CAD) drawing of a sampling chamber used to perform LIBS measurements of gaseous streams. This setup has been used in recent developmental work as presented by McFarlane et al. (2019a). Recent work has involved connecting an aerosol source, in this case a collision nebulizer, to a sampling chamber to explore real-time monitoring with LIBS of aerosolized fission products. An example plot of $\mathrm{Gd}, \mathrm{Nd}$, and $\mathrm{Sm}$ in an aqueous aerosol quantified in real time using LIBS is presented in Figure 4-7. Future work involves modification of the nebulizer and sampling chamber to be operable at high temperatures in order to measure molten salts.

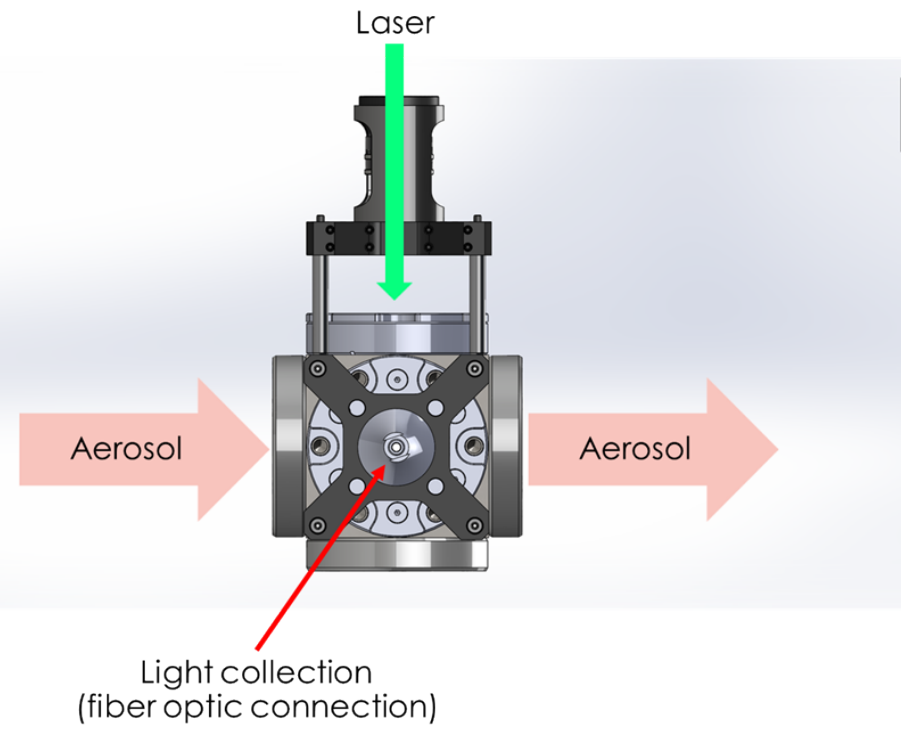

Figure 4-6. Schematic of the sampling chamber used for performing LIBS measurements on an aerosol stream such as what would be expected to be present under certain conditions in the off-gas system of MSRs. The same sampling chamber could be used to deploy other optical spectroscopy techniques, such as Raman, in tandem with LIBS (McFarlane et al., 2019a). 


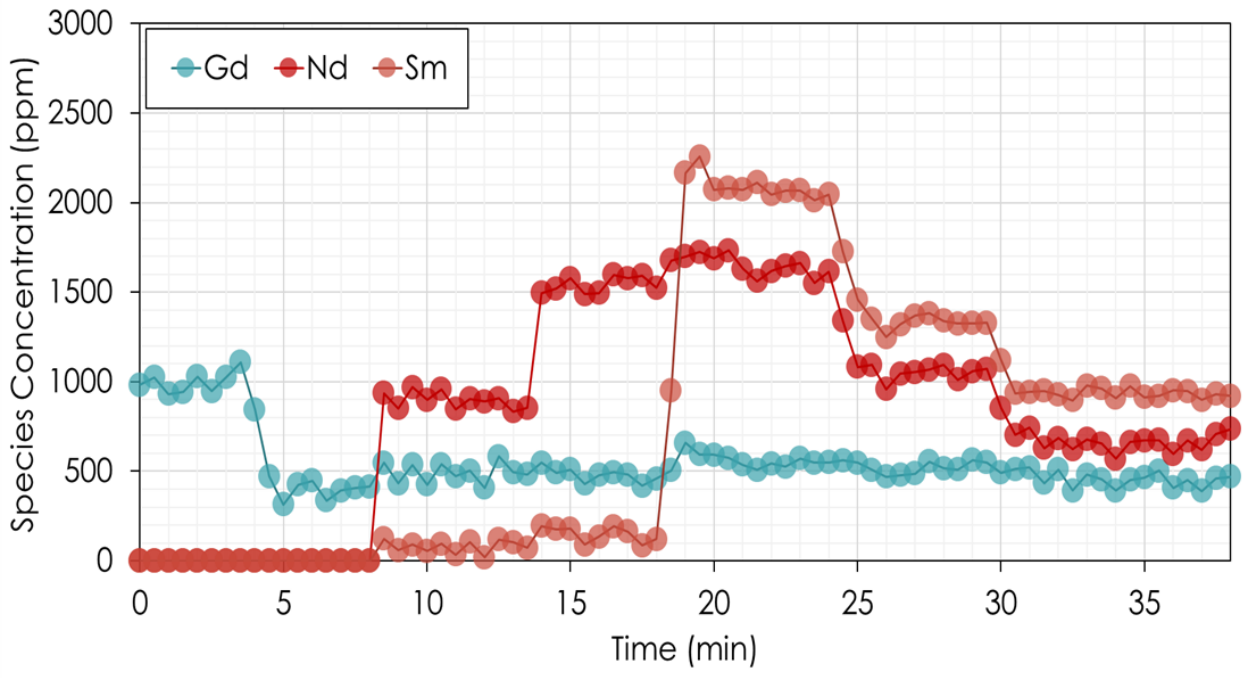

Figure 4-7. Concentration of $\mathrm{Gd}, \mathrm{Nd}$, and $\mathrm{Sm}$ as a function of time measured in real time using PLS regression analysis of LIBS data collected on a room-temperature aerosol of a water solution containing dissolved lanthanide metal salts to simulate a molten salt aerosol stream containing lanthanide fission products.

In addition to LIBS, several other elemental analysis techniques exist that could potentially be applied to MSR off-gas systems. Mass spectrometry and gamma spectroscopy are two analytical techniques that will likely be used in tandem with LIBS for elemental (and isotopic) analysis of MSR off-gas streams. Mass spectrometry would involve sub-sampling gas streams followed by ionization and electromagnetic separation of species based on charge-to-mass ratios. Various ionization approaches are possible but would have to accommodate the complex mixture of species present in the MSR off-gas. This will likely not be an issue during developmental studies when short-term operation is adequate. However, for long-term and reliable operation, the use of mass spectrometry may be difficult. Gamma spectroscopy is also possible to determine the presence of radionuclides which can be correlated to the presence of many but not all elements present in the off-gas stream. As further expounded on below, analysis via gamma spectroscopy will face the primary difficulty of a large background radiation. Sub-sampling for gamma spectroscopy, as with mass spectrometry, is possible and could circumvent this issue. Certainly, gamma spectroscopy will be used to monitor the output of the off-gas treatment system in order to quantify the release of radionuclides. As ongoing technology development efforts move forward and begin using radioactive salts to larger extents, the implementation of gamma spectroscopy for monitoring MSR off-gas streams will be further explored.

\subsubsection{Online Monitoring Applied to Non-Gas-Phase Portions of Off-Gas Treatment Systems}

The various gas treatment steps can include a molten hydroxide scrubber, as described in other sections of this report. Monitoring of the salt conditions within these systems is also crucial in determining the amount of volatile species being captured, as this determines the decontamination factor and ensures full accountancy for materials (Riley et al., 2016). Gaseous species that are expected to be trapped in the hydroxide scrubber include alkaline species, noble metals, halogens, and acidic species (Riley et al., 2018a). Various chemical species within the scrubber melt can be monitored using a variety of techniques.

The trapping of acidic species such as $\mathrm{HCl}, \mathrm{HF}$, or $\mathrm{HI}$ can cause the formation of water inside the hydroxide melt [see Equations (3-1) - (3-3)]. This change in water concentration can be monitored through conductivity measurements (Dauby et al., 1980; Tilman et al., 1984). In these studies, a linear relationship was found between the conductivity and water content of the salt which could be used to calculate the 
amount of water in the salt. This relationship between conductivity and water content was explained as an increased extent of proton transfer within the melt (Dauby et al., 1980). Using this method, the water content of the salt which could be caused by the trapping of acidic gaseous species could be monitored.

Optical spectroscopy can also be applied to molten salt systems to monitor the trapping of species within the hydroxide scrubber. With this technique, light can be directed into the molten hydroxide through either a corrosion-resistant window material or dip probe which can provide significant chemical composition data. Raman spectroscopy can be used to analyze many polyatomic molecules expected to be present in the off-gas stream. These include the halogens (i.e., $\mathrm{F}_{2}, \mathrm{Cl}_{2}, \mathrm{Br}_{2}, \mathrm{I}_{2}$ ) (Holzer et al., 1970b; Schiferl et al., 1987; McFarlane et al., 2019a) as well as acidic gases (e.g., HCl, HF, HI) (McFarlane et al., 2019a) and water (Casella et al., 2015), which would be potentially produced from trapping of these acidic species. The Raman water band can be used to monitor the concentration of water and hydroxide as the band shape changes from a sharp peak for $\mathrm{NaOH}$, for example, compared with a broad signal for water, caused by increased hydrogen bonding (Walrafen and Douglas, 2006).

Other optical techniques capable of interrogating a molten hydroxide include FTIR, UV-vis, and luminescence spectroscopy. Table 4-2 lists examples of species expected to be found in the hydroxide scrubber and the optical technique capable of analyzing each species. Gaseous species may change chemical form when dissolved in the hydroxide scrubber; therefore, information about how these speciation changes affect the optical signature within the melt is an important part of designing online monitoring techniques for these systems. Furthermore, anticipated products such as iodate or trapped species such as carbonate are also known to be Raman active (Bates et al., 1972; Gardiner et al., 1972; Lines et al., 2019). Overall, in situ optical spectroscopy, such as Raman, within the scrubber melt could provide valuable insight not only into the decontamination factor but also on the chemistry of dissolved species. That chemistry knowledge can be leveraged in the design of more efficient or effective scrubber systems.

Table 4-2. Examples of species expected to be trapped by molten hydroxide scrubber and the optical techniques capable of analysis.

\begin{tabular}{|l|c|l|}
\hline Technique & Species $^{a}$ & \multicolumn{1}{|c|}{ References } \\
\hline \multirow{3}{*}{ Raman } & $\mathrm{HF}$ & McFarlane et al., 2019a \\
& $\mathrm{HI}$ & van Straaten and Silvera, 1987 \\
& $\mathrm{F}_{2}$ & Schiferl et al., 1987 \\
& $\mathrm{Cl}_{2}, \mathrm{Br}_{2}$ & Holzer et al., 1970b \\
& $\mathrm{I}_{2}$ & Holzer et al., 1970b; Kiefer and Bernstein, \\
& $\mathrm{H}_{2} \mathrm{O}$ & Casella et al., 2015 \\
& $\mathrm{CO}_{2}$ & Child et al., 1981 \\
\hline \multirow{3}{*}{ FTIR } & $\mathrm{HF}$ & Andrews, 1988 \\
& $\mathrm{HCl}$ & Hughey et al., 2020 \\
& $\mathrm{HI}$ & Bulanin et al., 2003 \\
\hline \multirow{2}{*}{ UV-vis } & $\mathrm{I}_{2}$ & Awtrey and Connick, 1951b \\
& $\mathrm{HI}$ & Huebert and Martin, 1968 \\
& $\mathrm{Br}_{2}$ & Maric et al., 1994 \\
\hline Luminescence & $\mathrm{I}_{2}, \mathrm{Cl}_{2}, \mathrm{Br}_{2}$ & Holzer et al., 1970b \\
\hline
\end{tabular}

${ }^{a}$ Speciation changes when dissolved in the scrubber may affect optical activity. 


\subsection{Online Monitoring beyond Chemical Composition for MSR Off- Gas Treatment Systems}

MSR off-gas treatment systems can benefit from online monitoring technology that provides information in addition to the chemical composition of the treatment stream. Applications can include radiation detection to determine isotopic compositions, contamination levels on system components, as well as monitoring the temperatures, flowrates, pressures, and effectiveness of redox control in the system. In the harsh radiation environment of MSRs, remote operation of these techniques is crucial to maintaining operator safety (Holcomb et al., 2018).

Radiation detection and quantification could be a valuable tool but poses challenges in MSRs due to the high background radiation (Holcomb et al., 2018). This may make direct gamma-ray nondestructive assay (NDA) measurements more difficult, as the large quantity of fission products present in the salt will produce a high background which could produce a signal too high for the detector, and there will likely be interferents which will complicate the gamma-ray spectrum (Holcomb et al., 2018). Applications using effective shielding may provide an effective route to characterizing this aspect of the gas treatment system.

The highly radioactive environment expected in off-gas treatment systems is likely to produce a significant heat load (McFarlane et al., 2019a). Therefore, monitoring the temperature within these systems is necessary to ensure proper cooling systems are functioning. The temperature of the system will also affect the phase of off-gas products. For example, vaporized salts may condense and affect the transport of material through the off-gas treatment system (McFarlane et al., 2019a). Also influenced by the temperature of the system is the pressure. Increases in temperature and expansion of gas volume can cause local overpressurization (McFarlane et al., 2019a). Plugged gas lines may also cause overpressurization and localized heating from accumulated radioactive decay. A variety of direct and indirect temperature measurement tools are available, the most common being corrosion-resistant thermocouples.

Corrosion development, pressurization, radiation detection, and flow rates are all parameters that require monitoring throughout the reactor and the off-gas treatment system. Commercially available instrumentation requires shielding to so it can survive the radiation fields; it also needs coatings for protection against corrosion, and material alterations to withstand temperatures up to $1000^{\circ} \mathrm{C}$. Standard methods of inference through distance or non-contact measurements can be implemented but would have a direct impact on the advanced controls used within reactor operations. The closer the instrumentation is to the location of interest, the more direct and less degraded the measurement. Multiple corrosion monitoring sensors are under development but are still at a low technology readiness level. Pressure sensors and flow rate sensors that would survive all the harsh conditions do not currently exist, but some development using fiber optics within a protective housing are under development under other DOE Nuclear Energy programs. Radiation detection is the only sensor that can be easily placed in high radiation and corrosive environments; however, operation temperatures will cause degradation in sensor materials. Technological advances may be leveraged from research performed under other ongoing advanced reactor programs such as the Versatile Test Reactor and Transformational Challenge Reactor, as well as the development in technology maturation within the molten salt campaign. Understanding reactor performance can be improved through appropriately placed instrumentation coupled with neutronics modeling.

Online monitoring of the off-gas system can be understood through prototypic development in the laboratory. Development of a test-stand started in FY 2019 and carried over into FY 2020. The initial prototype was constructed of glass to better visualize the system performance, followed by the development of a molten hydroxide system operating at elevated temperatures. This non-nuclear system is outfitted with pressure, flow, and temperature sensors to monitor the performance during execution of lab demonstrations. The design went through a thorough review to maximize the capabilities and is under construction. The data collected from this test bed can be directly implemented into the off-gas system dynamic model. 
To support remote maintenance and viewing of MSR components and ancillary systems, monitoring equipment and instruments which can survive the expected harsh conditions are required (Holcomb et al., 2018). These can include imaging such as the use of radiation-hardened cameras or LiDAR (light detection and ranging), which can use laser reflection off objects to create a 3D image of its surroundings (Holcomb et al., 2018). Somewhat similar to LiDAR is ultrasonics, which uses soundwaves instead of a laser to map surfaces (Holcomb et al., 2018). With this technique, the distance to an object is measured by bouncing soundwaves off the object and measuring the time it takes for the soundwave to return. These mapping techniques can allow for the monitoring of the degradation off-gas treatment system components.

\subsection{Online Monitoring of Systems that Contribute to Off-Gas Loading}

Monitoring the molten salt conditions within the reactor itself is also vital to ensure that the reactor is operating efficiently and safely. This can include the ability to monitor and control the concentration and oxidation state of fissile materials within the salt melt, as well as the need to control the extent of corrosion of containment materials. The species being introduced to the off-gas system can be informed through monitoring the reactor salt composition and conditions. For instance, the U(III)/U(IV) ratio impacts the salt redox potential and the form of $\mathrm{T}_{2} / \mathrm{TF}$ exiting the reactor, as noted in Section 3.3.

Electrochemistry is one method of monitoring molten salt speciation using electrodes capable of withstanding the highly corrosive nature of molten salts. Electrochemistry can, for example, be used to detect species such as chromium in the salt produced by the corrosion of containment materials (Cotarta et al., 1997; Martínez et al., 2000; Uehara et al., 2009). Another important aspect of preventing corrosion in MSRs is the ability to control the $\mathrm{U}(\mathrm{III}) / \mathrm{U}(\mathrm{IV})$ ratio, which can be accomplished by electrochemical methods (Prabhakara Reddy et al., 2004; Kim et al., 2012). Figure 4-8 shows a cyclic voltammogram (CV) of uranium in a chloride molten salt (Prabhakara Reddy et al., 2004). The CV shows the current produced as the applied potential modulates the oxidation state of uranium through the $\mathrm{U}^{4+/ 3+}$ oxidation states (peak III) and $\mathrm{U}^{3+/ 0}$ (peak I). Peak II was determined to be adsorption of U(III). Using this technique, the oxidation state of uranium can be controlled. While this may not be practical within an MSR design, it is useful in the design and testing stages of lab-scale systems, as well as characterizing chemical behavior of salt systems. 


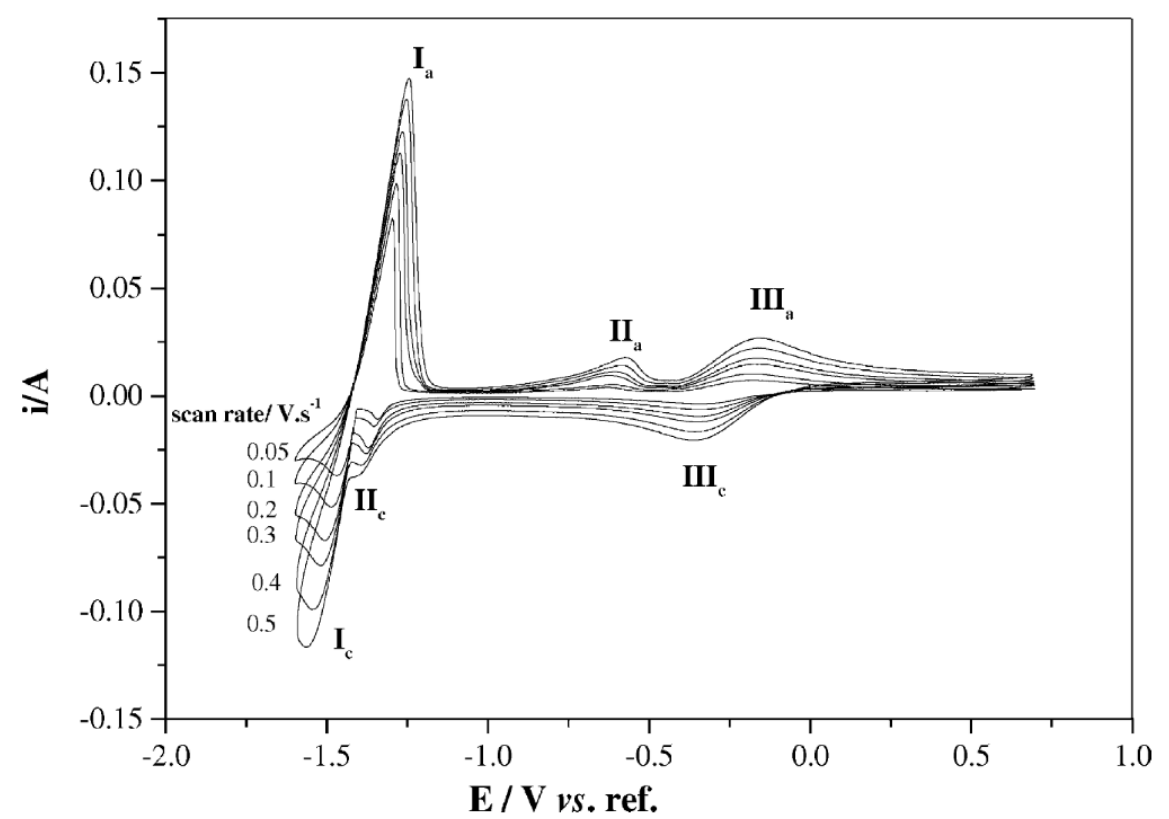

Figure 4-8. Cyclic voltammograms of $\mathrm{LiCl}-\mathrm{KCl}-\mathrm{UCl}_{3}$ at a glassy carbon electrode at $755 \mathrm{~K}$. Apparent electrode area: $0.427 \mathrm{~cm}^{2}$, concentration of $\mathrm{UCl}_{3}: 0.474 \mathrm{~mol} \%$ (Prabhakara Reddy et al., 2004).

Optical spectroscopy can also be applied to the study of molten salt systems. Techniques such as Raman and UV-vis spectroscopy offer a way to analyze species such as uranium and plutonium, as well as fission and corrosion products that are expected in MSRs. Combining spectroscopy with electrochemistry in spectroelectrochemistry is particularly valuable for the interrogation and control of conditions present in the salt. Spectroelectrochemistry has been used in molten salt systems for both its ability to determine speciation and for controlling the oxidation states of specific species within these systems (Nagai et al., 2005; Polovov et al., 2007; Volkovich et al., 2007; Polovov et al., 2008; Abramov et al., 2010; Nagai et al., 2011; Park et al., 2011; Nagai et al., 2013; Schroll et al., 2016). Corrosion products such as Cr, Fe, Ni, Mo, $\mathrm{Ti}$, and Mn have been studied using spectroelectrochemical methods (Volkovich et al., 2007; Abramov et al., 2010). These species have UV-vis optical signatures, and the presence and abundance of these products can determine the extent of corrosion in the system.

Using spectroelectrochemistry for the study of uranium (III)/(IV) oxidation states allows for the ability to not only control the oxidation state of uranium with electrochemical methods but also allows for a spectroscopic analysis of the speciation. Spectroelectrochemistry has been applied to these systems using UV-vis to observe the different optical signatures for the various oxidation states of uranium in molten salts (Nagai et al., 2005; Polovov et al., 2007; Polovov et al., 2008; Nagai et al., 2011; Park et al., 2011; Nagai et al., 2013). Figure 4-9(a) shows each $\mathrm{UV}$-vis signature for $\mathrm{UO}_{2}{ }^{2+}, \mathrm{UO}_{2}{ }^{+}, \mathrm{U}^{4+}$, and $\mathrm{U}^{3+}$ in a chloride molten salt (Nagai et al., 2013). By applying an electrochemical potential to these systems, the change in the oxidation state of uranium can be observed spectroscopically. This can be seen in Figure 4-9(b) in which the increase in U(III) signature can be observed with an applied potential as uranium metal is converted to U(III) (Park et al., 2011). These UV-vis signatures can be used to help verify the oxidation state of the uranium present, especially in systems with mixed or changing oxidation state. 

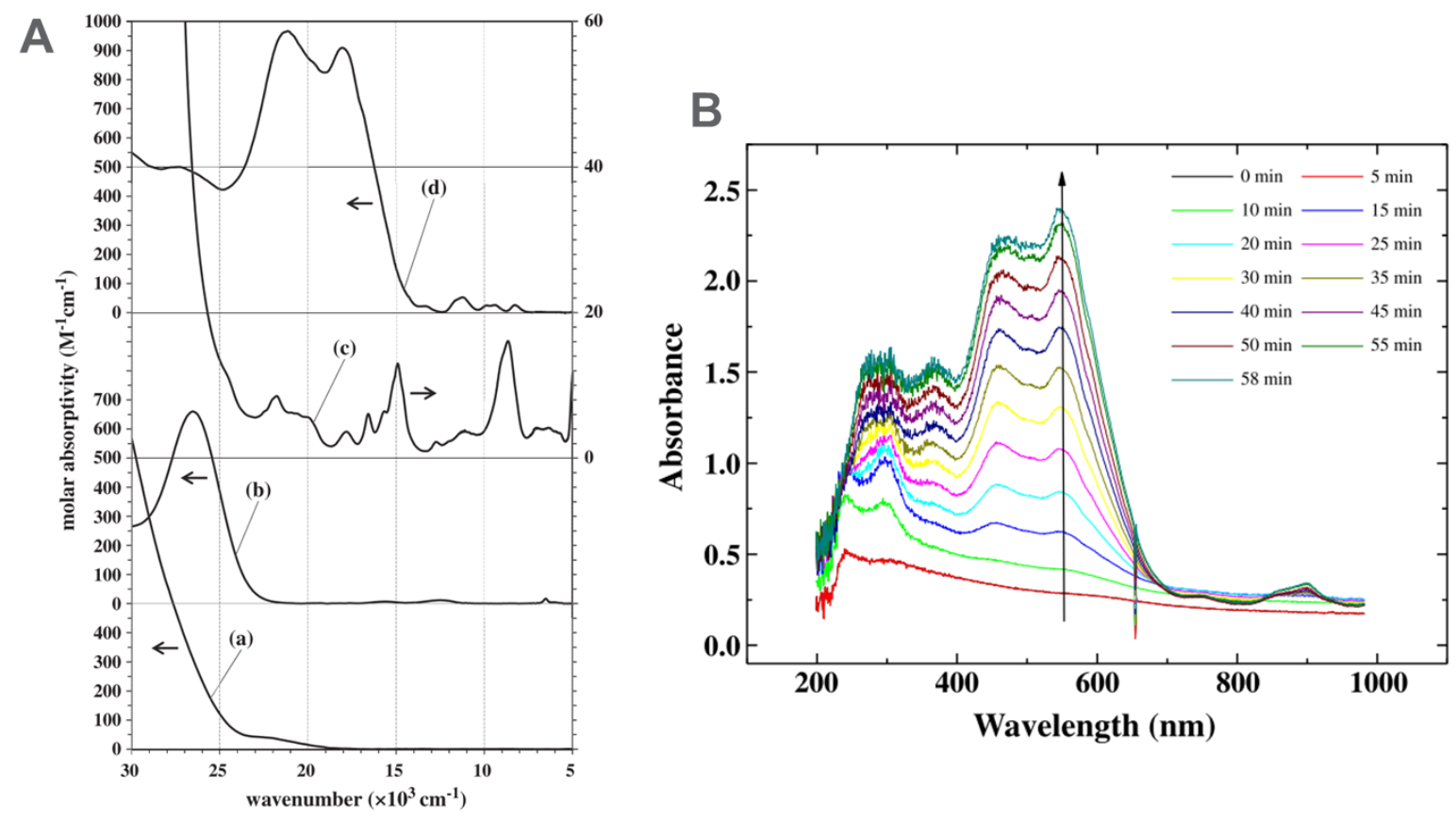

Figure 4-9. (A) The absorption spectra of (a) $\mathrm{UO}_{2}{ }^{2+}$, (b) $\mathrm{UO}_{2}{ }^{+}$, (c) $\mathrm{U}^{4+}$, (d) $\mathrm{U}^{3+}$ in LiCl-RbCl eutectic melt at $400^{\circ} \mathrm{C}$ (Nagai et al., 2013). (B) UV-vis absorption spectrum changes during the chronopotentiometry (Park et al., 2011). 


\section{AN OFF-GAS SYSTEM AND COMPUTER-AIDED DESIGN}

An off-gas system will include many of the components suggested in Sections 3 and 4, depending on the configuration of the reactor circuit. An example of processing and managing these off-gas streams is provided in Figure 5-1, including options for effluent management after these streams are removed from the headspace of an MSR. The flow diagram lays out parallel pathways targeting specific species. In this scenario, particulates are removed in a molten hydroxide scrubber. Water, containing tritium and other species, that evolves from the scrubber is condensed and drained. Residual halides, such as fission product iodine species, and chlorine or fluorine from the salt matrix, can be removed using a silver-mordenite aerogel that has been shown to effectively trap iodine. Non-fission generated gases, either contaminants in the system generated from salt activation, can be trapped cryogenically or on activated carbon and removed. Krypton and xenon can also be trapped cryogenically and stored in the case of xenon, until it has fully decayed. Figure 5-1 also provides the end state or waste form of each of the off-gas removal streams.

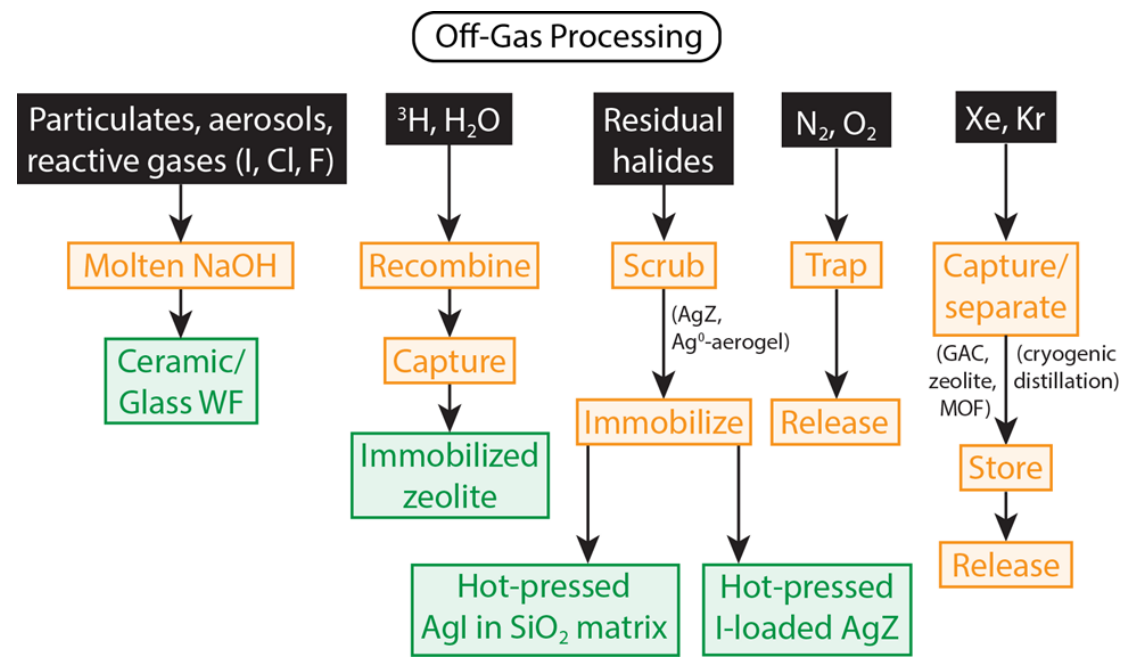

Figure 5-1. Summary of off-gas constituents and planned path forward for capture, immobilization, disposal, and/or release. "WF," "AgZ," and "Ag0-aerogel" denote waste form, silver mordenite, and silverfunctionalized silica aerogel, respectively (Riley et al., 2018).

These various components will be tested individually, but ultimately, the off-gas system will depend on each of the components mating successfully in a chain from the reactor headspace to outside containment. The coupling of such diverse system elements will require analysis of mass transfer and heat transfer for the entire system. For such a model, computer-aided design (CAD) tools will be needed to optimize the components and their integration and provide parameters for heat and mass transfer models, as discussed in Section 6.

For example, CAD can be used to create parts, assemblies, and design drawings of the molten hydroxide scrubber with Creo/Parametric 3D modeling software. Specifically, this allows each component of the molten hydroxide scrubber to be carefully considered for its individual purpose. The overall drawing for the molten hydroxide scrubber being tested at ORNL is shown in Figure 5-2. CAD can aid in determining whether each part can be an off-the-shelf item, modified off-the-shelf item, or manufactured from raw material, all while managing cost efficiency. Finally, each individual part can be integrated into an assembly to create the molten hydroxide scrubber. A CAD assembly model can have many benefits, including determining the overall footprint of the system, determining facility needs, creating design drawings for manufacturing purposes, and helping avoid design flaws that can lead to hurdles during experimentation, such as minimizing design features that make in situ changes or adjustments difficult. The assembly model can also be used to aid in the design and selection of components external to the packed bed scrubber such as a heated test loop and instrumentation for monitoring and detection, as discussed in Section 4. This also 
includes linkages upstream to the salt pot, in which fission product simulant vapors and aerosols will be generated, and linkages downstream to online monitoring. Ultimately, CAD can help design unique parts that make up individual systems or sub-assemblies that couple together and create an end-to-end off-gas monitoring system. This is not only essential to the fabrication of such a system but also to its characterization.
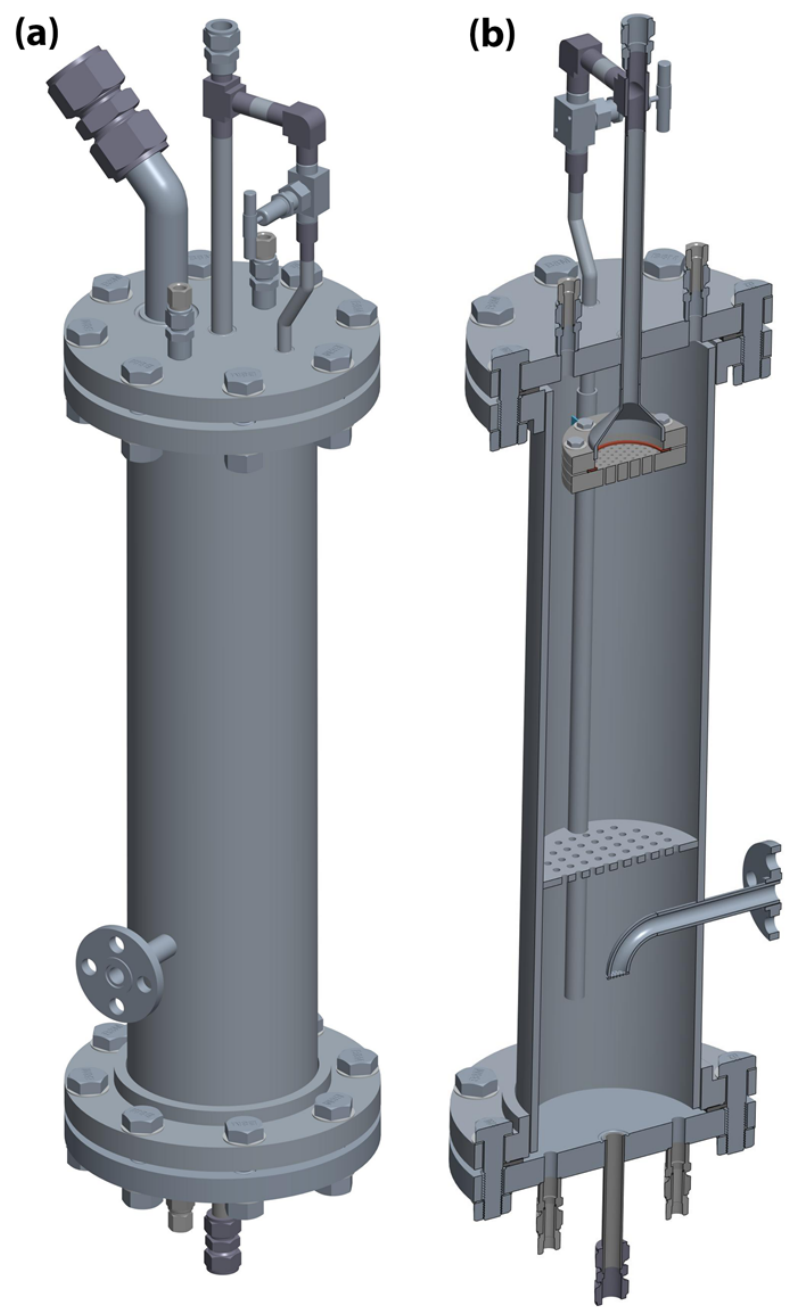

Figure 5-2. CAD drawing of molten hydroxide eutectic scrubber.

The CAD model can be imported into various computational tools for high-fidelity modeling of the process. Computational fluid dynamics of the two-phase processes (e.g. droplets, bubbles, mists, contact area) can inform and optimize the design for parameters such as residence time, turbulence, and contact area. These parameters are historically difficult to measure in-situ in aggressive fluid environments. However, localized data (e.g. inlet and outlet conditions, point temperatures, pressures) from targeted testing can be used to validate these tools. This validation basis can then be leveraged in designing of larger components or more complicated interconnected processes. Discussion of a reactor system model that includes the off-gas is provided in Section 6. 


\section{THERMAL AND MASS ACCOUNTANCY ANALYSIS INCLUDING DECAY HEAT CALCULATIONS}

The experimental program described in earlier sections will provide data for phenomenological model development for fission product release and transport. These models will be used to simulate the behavior of the off-gas system and performance against requirements for normal operating conditions, during maintenance activities, and for the potential development of a source term under selected accident conditions such as a rupture in the cover gas system.

The behavior of the chemical species in the MSR can be described using equilibrium chemical thermodynamics, as long as one is not projecting outside the bounds of a well-mixed volume. For molten salt operation, temperatures are sufficiently high that reaction rates, including recombination following radiolysis, are very rapid. For localized systems, an assumption can be made that the speciation in the salt will be governed by species stability as expressed as Gibbs free energy. The DOE-NE Advanced Reactor Campaign is creating a database of salt species, including the chlorides and fluorides of actinides, activation products, and fission products. The Molten Salt Thermodynamic Database (MSTDB) is publicly available (McMurray et al., 2019; Ard et al., 2020) but is curated by the University of South Carolina and ORNL. The database contains mathematical expressions for temperature-dependent Gibbs free energies for pure salts and binary mixtures but is not complete, particularly for chloride salt species and fission products. Data are being collected through thermochemical measurements for multicomponent systems. These include the following methods from which thermodynamic properties can be generated.

1. Vapor pressures by Knudsen effusion (McFarlane et al., 2002)

2. Transpiration or evaporation coefficients by Langmuir volatility experiments (McMurray et al., 2018)

3. Heat capacities by differential scanning and solution calorimetries

4. Salt equilibria, solubilities, and redox interactions by electrochemistry and spectroelectrochemistry

Models of solution behavior can be constructed to extend the applicability of the thermodynamic measurements, against which mixture data can be compared. This is necessary as it is not possible to measure a complete set of data that includes all fuel, fission product, and activation product species. Experimental measurements will focus on the volatile components and those that have limited solubility in the salt such as the noble metals. The former compounds are of particular importance for purposes of the off-gas system and the associated source term.

For purposes of simulation, the speciation of the salt will be computed using a Gibbs free energy minimization algorithm, an example being Thermochimica (Simunovic and Piro, 2017). Access to Thermochimica can be obtained on GitHub, and the version that interfaces with the MSTDB is available through ORNL. Alternatively, CALPHAD (Kaufman and Bernstein, 1970), or Calculation of Phase Diagrams, can take properties of individual components and calculate the phase diagram of a multicomponent system (Wilson et al., 2018). Thus, the composition of the MSR can be determined through computation.

As discussed in earlier sections, there are several ways that radioactive species can enter the off-gas system. For volatile components that partition between the solution and the vapor phase, an approach can be taken in which the model uses an evaporation coefficient to determine the rate of transfer of the volatile species through the interface between the condensed and vapor phases. This is depicted in the schematic in Figure 6-1. Movement of species i through the interface can be calculated using Gibbs free energy minimization for the condensed-phase and gas-phase species.

$$
c_{\text {salt,interface, },} \Leftrightarrow c_{\text {gas, interface, } i \text {. }}
$$


Transport within the condensed phase will be governed by diffusion as well as concentration gradients that may arise because of inhomogeneous fission, turbulence, convection because of temperature gradients, interactions with reactor surfaces, etc. Transport through the cover gas will depend on flowing cover gas, interactions with headspace surfaces, decay, mist and aerosol formation, etc.

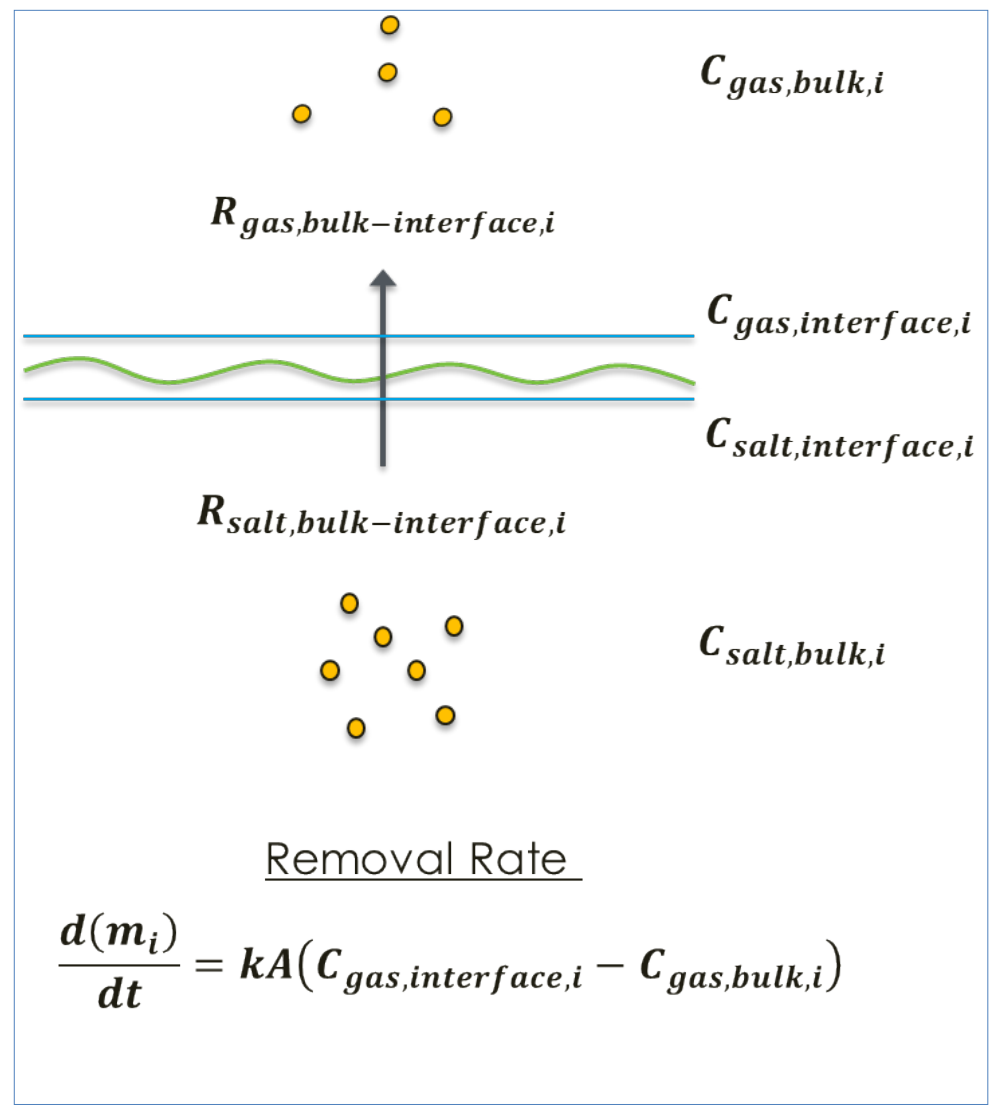

Figure 6-1. Schematic for fission product transport from the condensed molten salt phase to the cover gas with $\mathrm{R}$ referring to the first order rate equations describing transport into and out of the interface region. The transport across the interface is given by the removal rate equation at the bottom of the figure.

An effort is underway to model of the off-gas system in TRANSFORM to provide tracking of fission products (Greenwood et al., 2018), simulation of heat generation through decay, and heat removal technologies. The simulation will provide an estimate of the radionuclide release and transport for a particular set of off-gas technologies and their dependence on process conditions such as temperature, pressure, cover gas flow rate, etc. The modeling effort will start with the integration of the salt-gas interface into a previous published description of an MSR. Experimental data volatility obtained from eutectic NaF$\mathrm{LiF}-\mathrm{KF}$ will be used to generate evaporation rates as a function of temperature. The test system will be augmented with fission product compounds as more volatility data become available.

The TRANSFORM model will be developed to include components of a prototypical off-gas system, as discussed in Section 3. These could include a delay chamber, $\mathrm{NaF}$ beds at different temperatures, a caustic scrubber, and cryogenic charcoal filter beds. A schematic of such a system is shown in Figure 6-2. The TRANSFORM reactor systems simulation will not attempt to capture all of the physicochemical phenomena that may arise through the off-gas but will allow us to determine if there is a need for highfidelity modeling in certain areas. For instance, the neglect of chemical kinetics and radiolysis may not apply in the off-gas as it operates at temperatures much lower than salt melting temperatures. The rapid feedback between models and experiments is a strength of this systems modeling approach. 


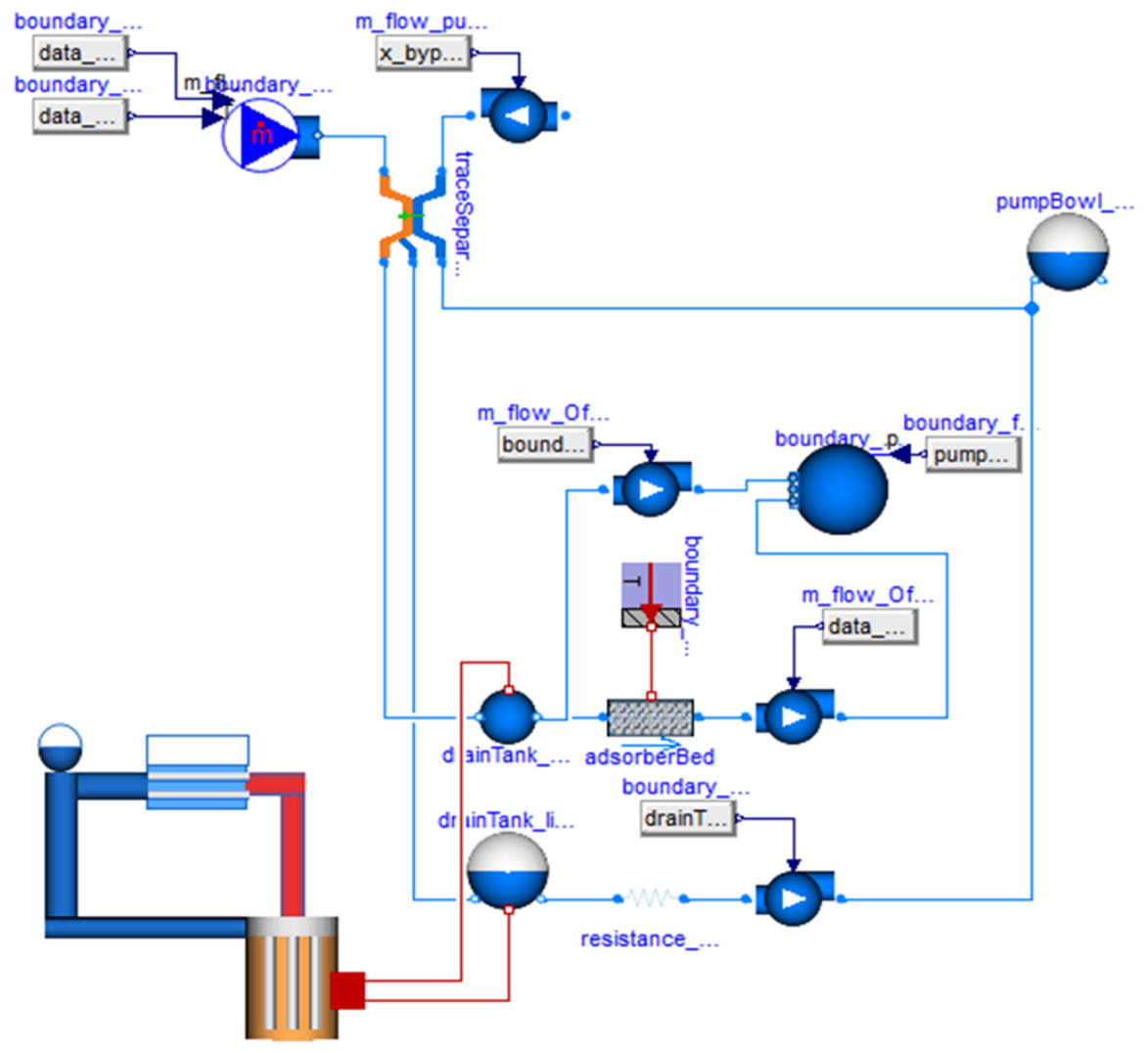

Figure 6-2. TRANSFORM platform for a reactor systems model that includes the off-gas. The reactor pump bowl is shown in the upper right-hand corner. 


\section{CONSIDERATIONS FOR NORMAL OPERATION AND MAINTENANCE, OFF-NORMAL EVENTS AND COVER GAS SYSTEM RUPTURE}

Various configurations of cover gas were discussed earlier in the introduction to Section 3. In general, the off-gas system begins at the salt-gas interface and continues through to atmospheric release outside the reactor building, with various traps or delay tanks to prevent the significant release of radionuclides to the environment. An MSR's cover gas system is directly comparable with a process line within a fuel cycle facility. The NRC regulations for fuel cycle facility safety are provided in 10 CFR 70 Subpart H, "Additional Requirements for Certain Licensees Authorized To Possess a Critical Mass of Special Nuclear Material." NUREG-1520, NRC's Standard Review Plan for Fuel Cycle Facilities License Applications, describes acceptable methods for meeting requirements of fuel cycle facilities (NRC, 2015). 10 CFR 70.61 requires each applicant to evaluate, in an integrated safety assessment [ISA] (more commonly known as process hazard assessment) performed in accordance with 10 CFR 70.62, "Safety Program and Integrated Safety Analysis," its compliance with the performance requirements in 10 CFR 70.61(b), 10 CFR 70.61(c), and 10 CFR 70.61(d). NUREG-1513 provides general guidance on acceptable methods for performing an ISA and identifies the ISA's role in facility safety. NUREG/CR-6410 provides guidance on how to calculate the characteristics of releases of radioactive materials and/or hazardous chemicals from nonreactor nuclear facilities (NUREG/CR-6410, 1998). Essential criteria for operation are that the off-gas system (1) not release radionuclides beyond system design, (2) not become plugged, (3) not overheat due to radioactive decay, and that the (4) temperatures of various components be maintained so that they continue to operate nominally, and (5) the system operate reliably (near 100\% availability) for decades. To achieve this goal, the system needs to be instrumented with sensors for flow, temperature, pressure, and radionuclide detection to ensure that it is operating according to plan. Sensors were discussed earlier in Section 4. The off-gas system is a primary source of labile radionuclides, so it requires a secondary containment to provide defense-in-depth so that if leaks occur, they are themselves confined. There also needs to be plans established to handle off-gas outages should they occur and routine maintenance procedures in place to minimize the probability of an occurrence.

In association with identifying chemical hazards for the NRC, an assessment was done on the activities involved with the operation and maintenance of generic off-gas systems for MSRs (McFarlane et al., 2019c). An off-gas system will be necessary for plant operation, thus necessitating any frequent maintenance activities to be performed online. Major maintenance/component replacement would more likely be performed during shutdowns. Online activities could include replacement of filter materials, in situ cleaning, and repair or replacement of off-gas components including sensors. The highly radioactive environment and the possibility for contamination mean that maintenance will need to be done remotely. Off-gas designs will need to accommodate robotic access with attention given to protection of electronics and other vulnerable systems. Parallel piping may be required to allow continuous operation during maintenance, with a diversionary valve used to send the flow down one channel or the other.

Monitoring of remote activities will also be important. In the safety survey, rapid measurement of radiological and process conditions (temperature, pressure, and flow rate) was identified as a way to mitigate hazards. Purge gas pressure relief (if used) and secondary containment were also included as a way to handle events such as flow restrictions and increased pressure. Auxiliary cooling may also be required, if passive heat sinks are not sufficient. Chemical hazards will include volatile fluorides and chlorides that will be highly corrosive if not scrubbed from the off-gas system early in the process. Thus, the off-gas system will require redundancy to ensure continuous operation, including secondary containment, robust online sensing, and rapid response to off-normal or rupture scenarios.

Station blackout events could mean a loss of power to the MSR off-gas, which could mean that active transport of radionuclides from the head space of the reactor would stop. However, decay and release of fission gases into the cover gas may continue, necessitating intermittent venting to the off-gas system. A 
gas accumulator could provide a backup flush of fission gases through the off-gas system. Such a scenario would need to provide an effective confinement of fission products along with passive heat removal. A secondary decay tank might be a way to provide a means to mitigate a loss-of-power event, as well as temporary storage of fission gases accumulated during maintenance outages. The design and location of the tank in the reactor building should provide sufficient passive heat removal to accommodate an indefinite power outage.

For some reactor designs, salt processing activities are planned such as fluoride volatility or electrochemical-based pyroprocessing, as discussed in Section 3.9. These activities will also require an offgas system, although it may only need to operate intermittently. Although the specific processes and conditions may differ from the reactor off-gas, these systems may be tied together at the outlet of the reactor building. Many of the same issues for off-gas safety also apply to the off-gas for salt processing. However, in this case, system failure could lead to shutdown of the salt processing, rather than scram of the reactor itself. In addition, as the salt processing need not be continuous, the system may accommodate a longer period of decay, to reduce the heat load and radionuclides in the process as well as the off-gas system. Allowing the fuel to cool for 90 days would allow much of the fission product ${ }^{133} \mathrm{Xe}$, with a half-life of 5.245 days, to decay. 


\section{LIFECYCLE OF OFF-GAS COMPONENTS AND WASTE FORMS}

\subsection{Off-Gas Components}

The lifecycle of the off-gas components will depend on several factors including the following:

- The type of scrubber system being used (e.g., molten hydroxide vs solid sorbents)

- The types of solid sorbent being used (e.g., some are more radiation tolerant than others)

- The location of the sorbent in the off-gas system (e.g., the closer in proximity to the core, the higher the fluxes)

The performance of the elements of the off-gas system can be monitored using the methods listed in Section 5. Some components will be more susceptible to degradation than others. It is likely that a scrubber system such as a molten hydroxide would function well throughout the lifecycle of the plant. However, the hydroxide will likely have to be replaced on a semiregular basis as the fission product gases build up and the acidic species start to neutralize the basic hydroxide and render the scrubber less effective. The frequency of hydroxide replenishment will vary based on several factors, the easiest to monitor being the $\mathrm{pH}$, which would be tracked using sensors present within the scrubber. Logistics for remote replenishing of the hydroxide for the scrubber has yet to be determined.

\subsection{Waste Forms and Treatment Options for Salt Streams}

The primary types of waste from an MSR are summarized in Figure 8-1 and include (1) spent fuel salt waste streams, (2) off-gas streams, (3) salt processing waste streams, (4) metal component waste streams, (5) carbon waste streams, (6) activated secondary coolant waste streams, and (7) decommissioning and decontaminating (D\&D) waste streams. Additional information can also be found for treatment and disposal options in our previous work (Riley et al., 2018b; Riley et al., 2019).

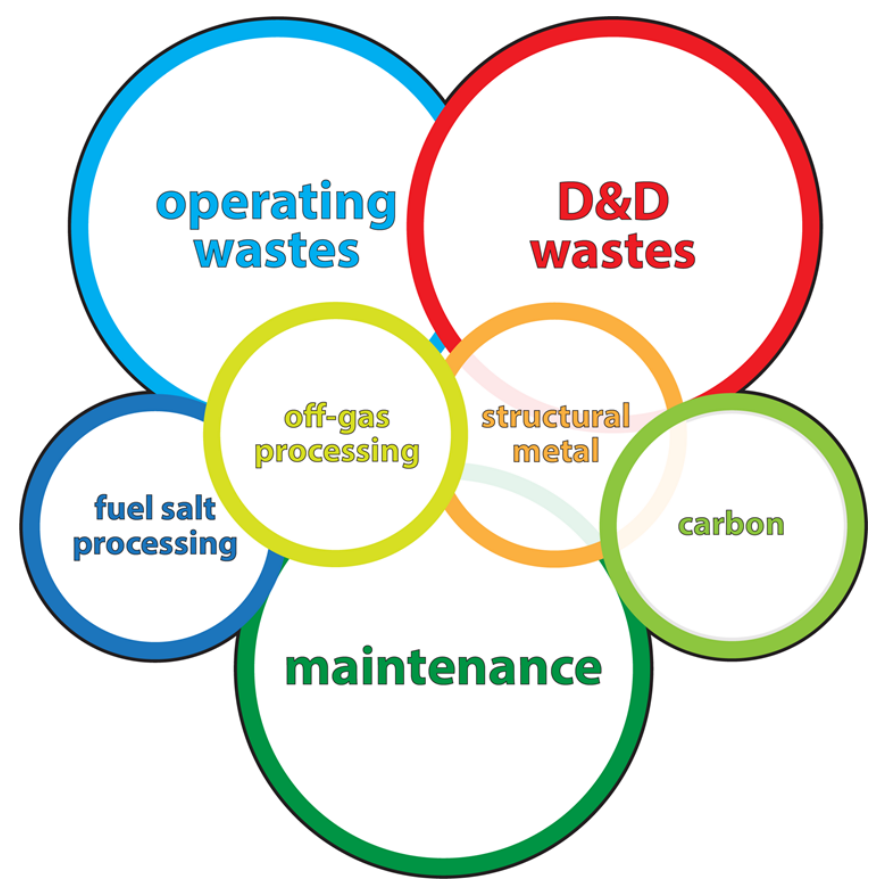

Figure 8-1. Summary of waste management categories for MSR program including the upper level (i.e., fuel salt processing, off-gas processing, structural metal, and carbon) and the lower level signifying when materials become wastes (i.e., operating wastes, D\&D wastes, and maintenance) (modified from Riley et al., 2018). 
Several waste form options and salt waste processing options exist for halide-based salt wastes. A lot of work has been done to evaluate chloride salts for the treatment of salt wastes from electrochemical reprocessing including the following, which are summarized elsewhere (Riley, 2020) and below in Figure 8-2:

- Full salt immobilization in a waste form, e.g., glass-bonded sodalite (Riley et al., 2017b), tellurite glass (Riley et al., 2012)

- $\quad$ Salt separation for waste form production and/or potential recycle of select components (Riley, 2020):

- Alkali and alkaline earths chloride removal, e.g., glass-bonded sodalite

- Chloride removal using phosphate reactions, e.g., $\mathrm{NH}_{4} \mathrm{H}_{2} \mathrm{PO}_{4},\left(\mathrm{NH}_{4}\right)_{2} \mathrm{HPO}_{4}, \mathrm{H}_{3} \mathrm{PO}_{4}$ (Donze et al., 2000; Siemer, 2012; Riley et al., 2020)

- Rare earth (RE) removal, e.g., precipitation with carbonates to form $\mathrm{REOCl}$ and/or $\mathrm{REO}_{x}$ (Bourgès et al., 2000; Caravaca et al., 2006), precipitation with $\mathrm{O}_{2(\mathrm{~g})}$ bubbling to form $\mathrm{REOCl}$ and/or $\mathrm{REO}_{x}$ (Castrillejo et al., 2002; Hayashi and Minato, 2005; Cho et al., 2006), or reactions with alkali phosphates to form $\mathrm{REPO}_{4}$ (Eun et al., 2016)

- Selective removal of specific components using vacuum distillation

- Selective removal of specific components using selective crystallization

It is unknown if these types of approaches can also be applied to fluoride salts, but it is likely that some of them can. Finding waste form options and/or salt processing options for partitioning/recycling fluoride salts remains a relatively unstudied part of this research in the literature.

(a)

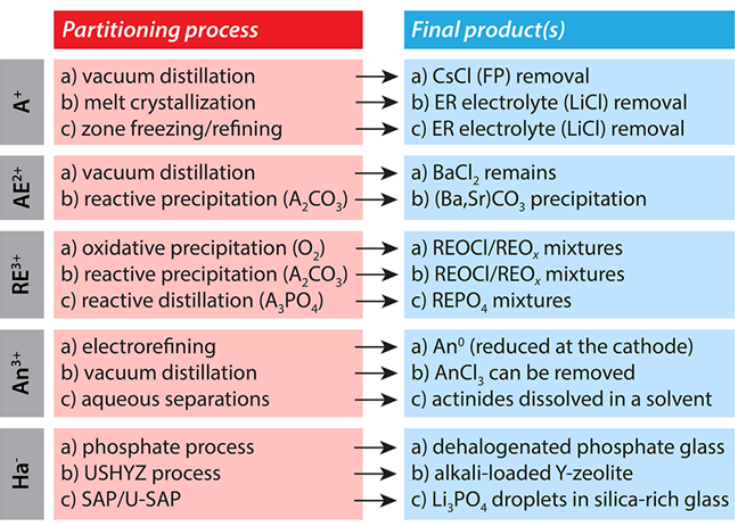

(b)

\begin{tabular}{|c|c|c|c|}
\hline 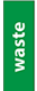 & $\begin{array}{l}\text { Unpartitioned salt } \\
\text { (e.g., } \mathrm{LiCl}+\mathrm{KCl}+ \\
\text { fission produts) }\end{array}$ & $\begin{array}{c}\text { Partially } \\
\text { dehalogenated salt } \\
\text { (e.g., REOCI) }\end{array}$ & $\begin{array}{c}\text { Fully } \\
\text { dehalogenated } \\
\text { salt (e.g., REO } \text { RE }_{x}\end{array}$ \\
\hline \multicolumn{4}{|c|}{ dehalogenation } \\
\hline ๕ัँّ & $\begin{array}{l}\text { a) phosphate process } \\
\text { b) USHYZ process } \\
\text { c) SAP/U-SAP process }\end{array}$ & $\begin{array}{l}\text { a) USHYZ process } \\
\text { b) phosphate process } \\
\text { c) LABS process }\end{array}$ & \\
\hline 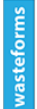 & $\begin{array}{l}\text { a) GBS } \\
\text { b) Pb-Te-O glass }\end{array}$ & $\begin{array}{l}\text { a) } P b-T e-O \text { glass } \\
\text { b) LABS glass }\end{array}$ & $\begin{array}{l}\text { a) } L A B S \text { glass } \\
\text { b) Fe-P-O glass } \\
\text { c) SAP } \\
\text { d) ZIT }\end{array}$ \\
\hline
\end{tabular}

Figure 8-2. Overview of (a) chloride salt partitioning options and final products targeting alkalis $\left(\mathrm{A}^{+}\right)$, alkaline earths $\left(\mathrm{AE}^{2+}\right)$, rare earths $\left(\mathrm{RE}^{3+}\right)$, actinides $\left(\mathrm{An}^{3+}\right)$, and halides $\left(\mathrm{Ha}^{-}\right)$where the product(s) listed are those resulting from the partitioning process (FP = fission product, USHYZ = ultrastable H-Y zeolite, SAP $=$ silica aluminophosphate). (b) Summary of chloride salt processing and waste form options for different waste streams $(\mathrm{GBS}=$ glass-bonded sodalite, $\mathrm{Pb}-\mathrm{Te}-\mathrm{O}$ is lead tellurite glass, LABS = lanthanide 
borosilicate glass, Fe-P-O is iron phosphate glass, and ZIT is zinc-in-titania). Adapted with permission from Riley (2020). Copyright 2020 American Chemical Society. 


\section{RECOMMENDATIONS ON WHAT TO DO NEXT}

\subsection{Proposed Path Forward}

- Our goal is to provide path for demonstrating technical feasibility and adequate safety of MSRs. We need to define the bounding envelope and process conditions for defining reactor operation and behavior during off-normal and accident scenarios. As stated in Section 7, the off-gas system is an integral part of the containment for MSRs. The chemistry and physics of salt components will govern the source term and release to the environment; thus, we need to continue to measure thermochemical and thermophysical property data and use these in modeling and simulation activities.

- Perform an ISA for several cover gas system design variants according to NUREG-1513 to assess the most critical components and processes and what technologies would be most beneficial to minimize the overall reactor risk.

- Develop a priority list for fission products and activation products that could contribute to the source term, with a focus on experimental efforts in volatility measurements and online detection. The priorities will be assessed on the basis of volatility, as determined by chemical thermodynamics, and dose consequence analysis.

- Initiate off-gas treatment technology testing. What are the fundamental systems that are needed for off-gas? This report provides a synopsis of the components that will be needed for the off-gas system. We need to integrate off-gas-specific technologies with test loops and larger scale release tests.

- Provide data for TRANSFORM model development and validation of off-gas components. This includes design details as well as functional requirements which can be used to mold assumptions where data is unavailable, explore design and operational parameters, and mature the off-gas design.

- Test online measurement capabilities in radioactive environments. Evaluation of online measurement techniques and components (e.g., optical windows, fibers, sampling techniques) in radiation fields will need to be performed to fully develop online measurement technologies. This will include both irradiating components followed by post-irradiation analysis as well as operating them in prototypical environments.

- In-field testing of off-gas monitoring and technologies in the off-gas of an actual research reactor.

- Evaluate/propose waste form options for fluoride salt wastes. Very little (if any) research has been done to evaluate methods for immobilizing fluoride salt wastes from MSRs, so this field remains wide open for new research. 10 CFR Part 72.128 provides criteria for high-level radioactive waste and other radioactive waste storage and handling. Primary criteria are suitability for long-term storage, minimized quantities, appropriate heat removal, and capability to test and monitor components important to safety. This research could include methods for partitioning the used salt for recycling key isotopically enriched species. 


\section{REFERENCES}

Abramov, A. V., I. B. Polovov, V. A. Volkovich, O. I. Rebrin, T. R. Griffiths, I. May, and H. Kinoshita. 2010. "Spectroelectrochemical study of stainless steel corrosion in $\mathrm{NaCl}-\mathrm{KCl}$ melt." ECS Transactions 33(7):277-85.

Adams, C. J. 1974. "Acceptor properties of iodine heptafluoride: octafluoroperiodates(VII)." Inorganic and Nuclear Chemistry Letters 10(10):831-35.

Afzal, S., A. Rahimi, M. R. Ehsani, and H. Tavakoli. 2010. "Experimental study of hydrogen fluoride adsorption on sodium fluoride." Journal of Industrial and Engineering Chemistry 16(1):147-51.

Amamoto, I. and K. Sato. 2007. "Reprocessing method by fluoride volatility process using solid-gas separation." Patent No. US7208129B2.

Andrews, L. 1988. "FTIR spectra of base - HF complexes in noble gas matrices." Journal of Molecular Structure 173:103-10.

Ard, J. C., K. E. Johnson, M. S. Christian, J. Schorne-Pinto, J. A. Yingling, T. M. Besmann, J. W. McMurray, J. Peng, and R. A. Lefebre. 2020. Molten Salt Thermodynamic Database (MSTDB). Oak Ridge National Laboratory, Oak Ridge, TN.

Awtrey, A. D. and R. E. Connick. 1951a. "The absorption spectra of $\mathrm{I}_{2}, \mathrm{I}_{3}^{-}, \mathrm{I}^{-}, \mathrm{IO}_{3}-\mathrm{S}_{4} \mathrm{O}_{6}{ }^{=}$and $\mathrm{S}_{2} \mathrm{O}_{3}{ }^{=}$. Heat of the reaction $\mathrm{I}_{3}{ }^{-}=\mathrm{I}_{2}+\mathrm{I}$." Journal of the American Chemical Society 73(4):1842-43.

Awtrey, A. D. and R. E. Connick. 1951b. "The Absorption Spectra of I2, I3-, I-, IO3-, S4O6= and S2O3=. Heat of the Reaction I3- = I2 + I-." Journal of the American Chemical Society 73(4):1842-43.

Baetsle, L. H. and J. Broothaerts. 1977. "Reprocessing Off-Gas Treatment Research in Belgium." In Seminar on Radioactive Effluents from Nuclear Fuel Reprocessing Plants, Schule für Kerntechnik Kernforschungszentrum, Karlsruhe, Germany.

Baker, F. S., C. I. Contescu, C. Tsouris, and J. McFarlane. 2007. Activated carbon composites for air separation. ORNL/TM-2007/329, Oak Ridge National Laboratory, Oak Ridge, TN.

Banerjee, D., C. M. Simon, A. M. Plonka, R. K. Motkuri, J. Liu, X. Chen, B. Smit, J. B. Parise, M. Haranczyk, and P. K. Thallapally. 2016. "Metal-organic framework with optimally selective xenon adsorption and separation." Nature Communications 7:11831-1-7.

Barnes, I., K. H. Becker, and J. Starcke. 1992. "FTIR spectroscopic observation of gaseous HOI." Chemical Physics Letters 196(6):578-82.

Bates, J. B., M. H. Brooker, A. S. Quist, and G. E. Boyd. 1972. "Raman spectra of molten alkali metal carbonates." The Journal of Physical Chemistry 76(11):1565-71.

Bazan, R. E., M. Bastos-Neto, A. Moeller, F. Dreisbach, and R. Staudt. 2011. "Adsorption equilibria of $\mathrm{O}_{2}, \mathrm{Ar}, \mathrm{Kr}$ and $\mathrm{Xe}$ on activated carbon and zeolites: single component and mixture data." Adsorption 17(2):371-83.

Bell, J. T., R. A. Strehlow, J. D. Redman, and F. J. Smith. 1979. Tritium Permeation Through Steam Generator Materials. In Proceedings of $14^{\text {th }}$ Intersociety Energy Conversion Engineering Conference. vol. 2, pp. 1577-82. 
Blander, M., Epel, L.G., Fraas, A.P., Newton, R.F. 1959. Aluminum chloride as a thermodynamic working fluid and heat transfer medium, ORNL-2677, Oak Ridge National Laboratory, Oak Ridge, TN.

Bourgès, G., A. Godot, C. Valot, and D. Devillard. 2000. Pyro-oxidation of plutonium spent salts with sodium carbonate. In Proceedings of Pyrochemical Separations - Nuclear Energy Agency.

Briggs, R. B. 1966. Molten-Salt Reactor Program Semiannual Progress Report. ORNL-3936, Oak Ridge National Laboratory, Oak Ridge, TN.

Briggs, R. B. 1972. "Tritium in molten salt reactors." Reactor Technology 14:335-42.

Briggs, R. B. and R. B. Korsmeyer. 1970. "Distrubtion of tritium in an MSBR." In Molten-Salt Reactor Program Semiannual Progress Report, ORNL-4548, eds. MW Rosenthal, RB Briggs and PR Kasten, pp. 53-57. Oak Ridge National Laboratory, Oak Ridge, TN.

Brooks, W. V. F. and B. J. Crawford. 1955. "Vibrational intensities. V. BrCl and ICl." The Journal of Chemical Physics 23(2):363-65.

Bruffey, S. H. and R. T. Jubin. 2017. "Analysis of Krypton-85 Legacy Waste Forms: Part I." Nuclear Technology 200(2):159-69.

Bruffey, S. H., R. T. Jubin, and J. A. Jordan. 2016. "Capture of Elemental and Organic Iodine from Dilute Gas Streams by Silver-exchanged Mordenite." Procedia Chemistry 21:293-99.

Bruffey, S. H., B. B. Spencer, D. M. Strachan, R. T. Jubin, N. R. Soelberg, and B. J. Riley. 2015. A Literature Survey to Identify Potentially Volatile Iodine-Bearing Species Present in Off-Gas Streams. INL/EXT-15-35609, Idaho National Laboratory, Idaho Falls, ID.

Bryan, S. A., T. G. Levitskaia, A. M. Lines, F. N. Smith, G. B. Josephson, and J. M. Bello. 2013. Dualremote Raman technology for in-situ identification of tank waste. In Proceedings of WM Symposia 2013: International Collaboration and Continuous Improvement. Pacific Northwest National Lab.(PNNL), Richland, WA (United States).

Bulanin, M. O., A. V. Domanskaya, and K. Kerl. 2003. "High-resolution FTIR measurement of the line parameters in the fundamental band of HI." Journal of Molecular Spectroscopy 218(1):75-79.

Burger, L. L. 1991. Fission product iodine during early Hanford-Site operations: Its production and behavior during fuel processing, off-gas treatment and release to the atmosphere. PNL-7210-HEDR, ON: DE91012772, Pacific Northwest Laboratory, Richland, WA.

Burger, L. L. and R. D. Sheele. 2004. HWVP Iodine Trap Evaluation. PNNL-14860, Pacific Northwest National Laboratory, Richland, WA.

Calkins, V. P. 1958. "Production of uranium tetrachloride." Patent No. US2864666A.

Campbell, D. O. and G. I. Cathers. 1960. "Processing of molten salt power reactor fuels." Industrial \& Engineering Chemistry 52(1):41-44.

Capps, R. H. 1951. Reaction of Gaseous Uranium Hexafluoride and Hydrogen Fluoride with Metallic Fluorides. K-770, Oak Ridge Gaseous Diffusion Plant, Oak Ridge, TN. 
Caravaca, C., G. De Córdoba, and L. Gutiérrez. 2006. Salt decontamination treatment from a pyrochemical spent fuel process in molten LiCl-KCl. In Proceedings of Actinide and Fission Product Partitioning and Transmutation. Nuclear Energy Agency - Organisation for Economic Co-Operation and Development.

Carter, W. L. and M. E. Whatley. 1967. Fuel and blanket processing development for molten salt breeder reactors. ORNL-TM-1852, Oak Ridge National Laboratory, Oak Ridge, TN.

Casella, A., J. Carter, A. Lines, J. Bello, S. Bryan, R. Clark, J. Corbey, C. Delegard, F. Heller, B. McNamara, and L. Sweet. 2019. "In stream monitoring of off-gasses from plutonium dioxide fluorination." Actinide Research Quarterly:31-35.

Casella, A. J., L. R. H. Ahlers, E. L. Campbell, T. G. Levitskaia, J. M. Peterson, F. N. Smith, and S. A. Bryan. 2015. "Development of online spectroscopic $\mathrm{pH}$ monitoring for nuclear fuel reprocessing plants: Weak acid schemes." Analytical Chemistry 87(10):5139-47.

Castrillejo, Y., M. R. Bermejo, R. Pardo, and A. M. Martínez. 2002. "Use of electrochemical techniques for the study of solubilization processes of cerium-oxide compounds and recovery of the metal from molten chlorides." Journal of Electroanalytical Chemistry 522(2):124-40.

Cathers, G. I., M. R. Bennett, and R. L. Jolley. 1958. "UF 6 -3NaF complex formation and decomposition." Industrial \& Engineering Chemistry 50(11):1709-10.

Chernick, C. L., H. H. Claassen, and B. Weinstock. 1961. "Rhodium hexafluoride." Journal of the American Chemical Society 83(14):3165-66.

Chesne, A., P. Miquel, J. P. Goumondy, and A. Leseur. 1977. "Progress Report on French Research and Development in the Treatment of Off-Gases from Reprocessing Plants." In Seminar on Radioactive Effluents from Nuclear Fuel Reprocessing Plants, Schule für Kerntechnik Kernforschungszentrum, Karlsruhe, Germany.

Child, W. C., G. M. Begun, and D. H. Smith. 1981. "Raman spectroscopy of oxyanions in molten salts. Part 2.-Correlation of the symmetric stretching frequency with polarizing power and polarizability of the cation." Journal of the Chemical Society, Faraday Transactions 2: Molecular and Chemical Physics 77(12):2237-47.

Cho, Y.-J., H.-C. Yang, H.-C. Eun, E.-H. Kim, and I.-T. Kim. 2006. "Characteristics of oxidation reaction of rare-earth chlorides for precipitation in LiCl-KCl molten salt by oxygen sparging." Journal of Nuclear Science and Technology 43(10):1280-86.

Collard, G. E. R., D. Hennart, J. Van Dooren, and W. R. A. Goosens. 1980. Iodine trapping and conditioning in the Mercurex process. In Proceedings of $16^{\text {th }} \mathrm{DOE}$ Nucl. Air Clean. Conf. eds. MW First, pp. 552-64, United States Nuclear Regulatory Commission, Cambridge, MA.

Compere, E. L., S. S. Kirslis, E. G. Bohlmann, F. F. Blankenship, and W. R. Grimes. 1975. Fission product behavior in the molten salt reactor experiment. ORNL-4865, Oak Ridge National Laboratory, Oak Ridge, TN.

Cotarta, A., J. Bouteillon, and J. C. Poignet. 1997. "Electrochemistry of molten $\mathrm{LiCl}-\mathrm{KCl}-\mathrm{CrCl}_{3}$ and $\mathrm{LiCl}-$ $\mathrm{KCl}-\mathrm{CrCl}_{2}$ mixtures." Journal of Applied Electrochemistry 27(6):651-58. 
Craig, B. D. and D. B. Anderson, eds. 1997. Sodium Hydroxide. in "Handbook of Corrosion Data," ASM International, Materials Park, $\mathrm{OH}$,

Daniel, C., A. Elbaraoui, S. Aguado, M.-A. Springuel-Huet, A. Nossov, J.-P. Fontaine, S. Topin, T. Taffary, L. Deliere, Y. Schuurman, and D. Farrusseng. 2013. "Xenon capture on silver-loaded zeolites: characterization of very strong adsorption sites." The Journal of Physical Chemistry C 117(29):15122-29.

Dauby, C., J. Glibert, and P. Claes. 1980. "Water and oxide ions concentration dependence of the specific mass and conductance of the molten $\mathrm{NaOH}-\mathrm{KOH}$ eutectic mixture." Electrochimica Acta 25(8):1077-81.

Davidson, N. R. and S. Fried. 1959. "Method of preparing UF." Patent No. US2910344.

Davies, M. Alloy Selection for Service in Caustic Soda, 2 $2^{\text {nd }}$ edition. 2019. Accessed at https://www.nickelinstitute.org/media/4341/nickelpub10019_causticsoda_20pg.pdf.

Del Cul, G. D. and R. D. Hunt. 2019. Chlorination scoping tests on aluminum 6061 coupons. ORNL/SPR2019/1252, Oak Ridge National Laboratory, Oak Ridge, TN.

DelCul, G. D., J. A. Johnson, B. B. Spencer, and E. D. Collins. 2013. Roadmap for development of an advanced head-end. In Proceedings of GLOBAL 2013. pp. 879-81.

Deliere, L., B. Coasne, S. Topin, C. Gréau, C. Moulin, and D. Farrusseng. 2016. "Breakthrough in xenon capture and purification using adsorbent-supported silver nanoparticles." Chemistry: A European Journal 22:9660-66.

Donze, S., L. Montagne, and G. Palavit. 2000. "Thermal conversion of heavy metal chlorides $\left(\mathrm{PbCl}_{2}\right.$, $\left.\mathrm{CdCl}_{2}\right)$ and alkaline chlorides $(\mathrm{NaCl}, \mathrm{KCl})$ into phosphate glasses." Chemistry of Materials 12(7):1921-25.

Engel, J. R., W. R. Grimes, H. F. Bauman, H. E. McCoy, J. F. Dearing, and W. A. Rhoades. 1980. Conceptual design characteristics of a denatured molten-salt reactor with once-through fueling. ORNL/TM-7207, Oak Ridge National Laboratory, Oak Ridge, TN.

Eun, H. C., J. H. Choi, I. H. Cho, T. K. Lee, T. J. Kim, J. S. Shin, H. S. Park, and D. H. Ahn. 2016. "Purification of $\mathrm{LiCl}-\mathrm{KCl}$ eutectic waste salt containing rare earth chlorides delivered from the pyrochemical process of used nuclear fuel using a reactive distillation process." Journal of Radioanalytical and Nuclear Chemistry 307:1419-27.

Felmy, H. M., A. J. Clifford, A. Schafer Medina, R. M. Cox, A. M. Lines, and S. A. Bryan. 2020. "Online Monitoring of Reactor Off-Gas: Following Iodine using Raman Spectroscopy." In preparation.

Fischer, S., M. Sturm, M. Schlösser, B. Bornschein, G. Drexlin, F. Priester, R. J. Lewis, and H. H. Telle. 2011. "Monitoring of tritium purity during long-term circulation in the KATRIN test experiment LOOPINO using laser Raman spectroscopy." Fusion Science and Technology 60(3):925-30.

Forsberg, C. W., S. Lam, D. M. Carpenter, D. G. Whyte, R. Scarlat, C. Contescu, L. Wei, J. Stempien, and E. Blandford. 2017. "Tritium control and capture in salt-cooled fission and fusion reactors: Status, challenges, and path forward." Nuclear Technology 197(2):119-39.

Fouche, D. G. and R. K. Chang. 1971. "Relative Raman cross section for $\mathrm{N}_{2}, \mathrm{O}_{2}, \mathrm{CO}, \mathrm{CO}_{2}, \mathrm{SO}_{2}$, and $\mathrm{H}_{2} \mathrm{~S}$." Applied Physics Letters 18(12):579-80. 
Fried, S. 1945. The Reaction of Uranium Compounds with Aluminum Chloride. USAEC N-2188, MUCFWHZ-152, Chicago University Metallurgical Laboratory, Oak Ridge, TN.

Fritz, B. G. and N. R. J. Phillips. 2013. "Use of CAP88 PC to infer differences in the chemical form of ${ }^{129}$ I emitted from a fuel reprocessing facility." Journal of Environmental Radioactivity 120:1-5.

Fukada, S. 2013. "Flibe-tritium research for fission or fusion reactors at Kyushu University." Journal of Plasma Fusion Research 10:22-26.

Fukada, S. and N. Mitshishi. 1988. "Hydrogen permeation through duct walls with turbulent-flow." Memoirs of the Faculty of Engineering, Kyushu University 48(1):69-83.

Gabbard, C. H. 1972. Development of a Venturi Type Bobble Generator for Use in the Molten-Salt Reactor Xenon Removal System. ORNL-TM-4122, Oak Ridge National Laboratory, Oak Ridge, TN.

Gallou, G., J. B. Sirven, C. Dutouquet, O. Le Bihan, and E. Frejafon. 2011. "Aerosols analysis by LIBS for monitoring of air pollution by industrial sources." Aerosol Science and Technology 45(8):918-26.

Gardiner, D. J., R. B. Girling, and R. E. Hester. 1972. "Vibrational spectra and force constants of chlorate, bromate and iodate ions in aqueous solution." Journal of Molecular Structure 13(1):105-14.

Gerstenkorn, S. and P. Luc. 1985. "Description of the absorption spectrum of iodine recorded by means of Fourier transform spectroscopy: the (B-X) system." Journal de Physique 46:867-81.

Golliher, W. R., R. A. LeDoux, S. Bernstein, and V. A. Smith. 1963. Separation of Technetium-99 from Uranium Hexafluoride. TID-18290, Union Carbide Nuclear Company, Paducah Plant, KY.

Greenwood, M. S., B. Betzler, and A. L. Qualls. 2018. Dynamic System Models for Informing Licensing and Safeguards Investigations of Molten Salt Reactors. ORNL/TM-2018/876, Oak Ridge National Laboratory, Oak Ridge, TN.

Gregory, C. C. and J. A. Harrington. 1993. "Attenuation, modal, and polarization properties of $\mathrm{n}<1$, hollow dielectric wave-guides." Applied Optics 32(27):5302-09.

Griffith, D. W. T., I. Jamie, M. Esler, S. R. Wilson, S. D. Parkes, C. Waring, and G. W. Bryant. 2006. "Real-time field measurements of stable isotopes in water and $\mathrm{CO}_{2}$ by Fourier transform infrared spectrometry." Isotopes in Environmental and Health Studies 42(1):9-20.

Griffith, D. W. T., D. Pohler, S. Schmitt, S. Hammer, S. N. Vardag, and U. Platt. 2018. "Long open-path measurements of greenhouse gases in air using near-infrared Fourier transform spectroscopy." Atmospheric Measurement Techniques 11(3):1549-63.

Gruen, D. M. and R. L. McBeth. 1968. "Uranium tetrachloride - aluminum trichloride vapor complex." Inorganic and Nuclear Chemistry Letters 4(5):299-303.

Gruen, D. M. and R. L. McBeth. 1969. "Vapor complexes of uranium pentachloride and uranium tetrachloride with aluminum chloride. The nature of gaseous uranium pentachloride." Inorganic Chemistry 8(12):2625-33. 
Hariharan, A. V., D. D. Sood, S. P. Sood, R. Prasad, and R. Sampathkumar. 1969a. Laboratory investigations in non-aqueous process chemistry. In Proceedings of Department of Atomic Energy, Chemistry and Metallurgy Committee. vol. 1, pp. 283-89.

Hariharan, A. V., S. P. Sood, R. Prasad, D. D. Sood, K. Rengan, P. V. Balakrishnan, and M. V. Ramaniah. 1969b. Direct chlorination volatility processing of nuclear fuels: Laboratory studies - CONF-690801. In Proceedings of Nuclear Metallurgy - Symposium on Reprocessing of Nuclear Fuels. eds. P Chiotti, vol. 15, pp. 261-77.

Harrington, J. A. 2000. "A review of IR transmitting, hollow waveguides." Fiber and Integrated Optics 19(3):211-27.

Hartwig, S. and A. Lambrecht. 2008. "Characterization of hollow fibres for compact infrared gas measurement cells." tm - Technisches Messen 75(10):555-64.

Hausmann, M. and U. Platt. 1994. "Spectroscopic measurement of bromine oxide and ozone in the high arctic during Polar Sunrise Experiment 1992." Journal of Geophysical Research-Atmospheres 99(D12):25399-413.

Hayashi, H. and K. Minato. 2005. "Stability of lanthanide oxides in LiCl-KCl eutectic melt." Journal of Physics and Chemistry of Solids 66(2-4):422-26.

Hedderich, H. G., P. F. Bernath, and G. A. McRae. 1992. "The high-resolution infrared spectrum of iodine monochloride." Journal of Molecular Spectroscopy 155(2):384-92.

Henrich, E. and R. von Ammon. 1985. "Das Konzept Der Abgasreingung in Wiederaufarbeitungsanlgen." Atomkernenergie, Kerntechnik 46(2):81-88.

Hightower, J. R. and L. E. McNeese. 1968. Measurement of the relative volatilities of fluorides of Ce, La, $\mathrm{Pr}, \mathrm{Nd}, \mathrm{Sm}, \mathrm{Eu}, \mathrm{Ba}, \mathrm{Sr}, \mathrm{Y}$ and $\mathrm{Zr}$ in mixtures of LiF and BeF . ORNL-TM-2058, Oak Ridge National Laboratory, Oak Ridge, TN.

Holcomb, D. E., C. L. Britton Jr., V. K. Varma, and L. G. Worrall. 2018. Remote Operations and Maintenance Framework for Molten Salt Reactors. ORNL/TM-2018/1107, Oak Ridge National Laboratory, Oak Ridge, TN.

Holcomb, D. E., G. F. Flanagan, G. T. Mays, W. D. Pointer, K. R. Robb, and G. L. Yoder Jr. 2013. Fluoride Salt-Cooled High-Temperature Reactor Technology Development and Demonstration Roadmap. ORNL/TM-2013/401, Oak Ridge National Laboratory, Oak Ridge, TN.

Holcomb, D. E., W. Poore III, and G. F. Flanagan. 2020. MSR Fuel Salt Qualification Methodology. ORNL/TM/1576, Oak Ridge National Laboratory, Oak Ridge, TN.

Holcomb, D. E. and D. F. Wilson. 2017. "Apparatus and Method For Stripping Tritium from Molten Salt." Patent No. US9564251B2.

Holla, R., S. Schmitt, U. Friess, D. Pohler, J. Zingler, U. Corsmeier, and U. Platt. 2015. "Vertical distribution of $\mathrm{BrO}$ in the boundary layer at the Dead Sea." Environmental Chemistry 12(4):438-60.

Holzer, W., W. F. Murphy, and H. J. Bernstein. 1970a. "Resonance fluorescence of iodine, bromine, and chlorine gases obtained with argon-ion laser excitation." Journal of Chemical Physics 52(1):469-70. 
Holzer, W., W. F. Murphy, and H. J. Bernstein. 1970b. "Resonance Raman effect and resonance fluorescence in halogen gases." Journal of Chemical Physics 52(1):399-407.

Horner, D. E., J. C. Mailen, and F. A. Posey. 1977. "Electrolytic trapping of iodine from process gas streams." United States Application No. 4004993.

HSC Chemistry, Outotec.

Huebert, B. J. and R. M. Martin. 1968. "Gas-phase far-ultraviolet absorption spectrum of hydrogen bromide and hydrogen iodide." The Journal of Physical Chemistry 72(8):3046-48.

Hughey, K. D., A. M. Bradley, H. M. Felmy, A. J. Clifford, R. M. Cox, A. M. Lines, S. A. Bryan, and T. J. Johnson. 2020. Quantitative far-infrared band strengths of iodine monochloride (ICl), a molten salt offgas product. In Proceedings of SPIE Defense + Commerical Sensing, 114160Q, doi: 10.1117/12.2557555.

Huve, J., A. Ryzhikov, H. Nouali, V. Lalia, G. Augé, and T. J. Daou. 2018. "Porous sorbents for the capture of radioactive iodine compounds: a review." RSC Advances 8(51):29248-73.

IAEA. 1987. IAEA-Technical Reports, Design of off-gas and air cleaning systems at nuclear power plants.

IAEA. 1980. IAEA-Technical Reports.

Janz, G. J. 1988. Thermodynamic and Transport Properties of Molten Salts: Correlation Equations for Critically Evaluated Density, Surface Tension, Electrical Conductance, and Viscosity Data, 17, American Chemical Society and the American Institute of Physics.

Johnson, B. M. 1981. "Chemistry of chromium oxyfluorides and group VIB perfluoroglutarates." Portland State University, M.S. Chemistry thesis.

Johnstone, E. V., F. Poineau, P. M. Forster, L. Ma, T. Hartmann, A. Cornelius, D. Antonio, A. P. Sattelberger, and K. R. Czerwinski. 2012. "Technetium tetrachloride revisited: A precursor to lower-valent binary technetium chlorides." Inorganic Chemistry 51(15):8462-67.

Jubin, R. T. 1981. Organic Iodine Removal from Simulated Dissolver off-Gas Systems Utilizing SilverExchanged Mordenite. In Proceedings of the $16^{\text {th }}$ DOE Nuclear Air Cleaning Conference, San Diego, CA, CONF-801038-1.

Jubin, R. T. 1988. Airborne Waste Management Technology Applicable for Use in Reprocessing Plants for Control of Iodine and Other Off-Gas Constituents. ORNL/TM-10477, Oak Ridge National Laboratory, Oak Ridge, TN.

Jubin, R. T. and S. H. Bruffey. 2016. Analysis of Selected Legacy ${ }^{85} \mathrm{Kr}$ Samples. FCRD-MRWFD-2016000047, FCRD-MRWFD-2016-000299, ORNL/TM-2016/350, Oak Ridge National Laboratory, Oak Ridge, TN.

Jubin, R. T., N. R. Soelberg, D. M. Strachan, and G. Ilas. 2012. Fuel age impacts on gaseous fission product capture during separations. FCRD-SWF-2012-000089, PNNL-22550, Oak Ridge National Laboratory, Oak Ridge, TN. 
Jubin, R. T. and D. Strachan. 2015. Assessments and Options for Removal and Immobilization of Volatile Radionuclides from the Processing of Used Nuclear Fuel. FCRD-MRWFD-2015-000429, ORNL-SPR2015/115, Oak Ridge National Laboratory, Oak Ridge, TN.

Katz, S. 1963. Apparatus for the gasometric study of solid-gas reactions: Sodium fluoride with hydrogen fluoride and uranium hexafluoride. ORNL-3497, Oak Ridge National Laboratory, Oak Ridge, TN.

Katz, S. 1964a. Reduction of Uranium Hexafluoride Retention on Beds of Magnesium Fluoride used for Removal of Technetium Hexafluoride. ORNL-3544, Oak Ridge National Laboratory, Oak Ridge, TN.

Katz, S. 1964b. "Use of high-surface-area sodium fluoride to prepare $\mathrm{MF}_{6}-2 \mathrm{NaF}$ complexes with uranium, tungsten, and molybdenum hexafluorides." Inorganic Chemistry 3(11):1598-600.

Kaufman, L. and H. Bernstein. 1970. Computer Calculation of Phase Diagrams, Academic Press, New York, NY, 0-12-402050-X.

Kedl, R. J. 1972. The Migration of a Class of Fission Products (Noble Metals) in the Molten Salt Reactor Experiment. ORNL-TM-3884, Oak Ridge National Laboratory, Oak Ridge, TN.

Kiefer, W. and H. J. Bernstein. 1972. "Vibrational-rotational structure in the resonance Raman effect of iodine vapor." Journal of Molecular Spectroscopy 43(3):366-81.

Kim, G.-Y., D. Yoon, S. Paek, S.-H. Kim, T.-J. Kim, and D.-H. Ahn. 2012. "A study on the electrochemical deposition behavior of uranium ion in a $\mathrm{LiCl}-\mathrm{KCl}$ molten salt on solid and liquid electrode." Journal of Electroanalytical Chemistry 682:128-35.

Kim, H. T., C. H. Jung, S. N. Oh, and K. W. Lee. 2001. "Particle efficiency of gravitational wet scrubber considering diffusion, interception, and impaction." Environmental Engineering Science 18(2):125-36.

Kohlrausch, F. 1905. "Die Löslichkeit einiger schwerlöslicher Salze im Wasser bei $18^{\circ}$ (The solubility of some sparingly soluble salts in water at 18²." Zeitschrift für Physikalische Chemie 50(1):355-56.

Korsmeyer, R. B. 1971. The Effect of Hydrogen Back-Diffusion on the Transport of Tritium in an MSBR. ORNL-CF-71-5-10, Oak Ridge National Laboratory, Oak Ridge, TN.

Kraus, C. A. 1943a. Summarizing Report of Investigations Relating to Uranium Covering the Period September 1, 1942 to April 15, 1943. A-726, Brown University, Providence, RI.

Kraus, C. A. 1943b. Summarizing Report of investigations relating to uranium covering the period September 1, 1942 to April 15, 1943. Contract OEMsr-290 Supplement 3, OEMsr-688 Supplement 1, Brown University, Providence, RI.

Lackey, H. E., G. L. Nelson, A. M. Lines, and S. A. Bryan. 2020. "Reimagining pH measurement: Utilizing Raman spectroscopy for enhanced accuracy in phosphoric acid systems." Analytical Chemistry 92(8):588289.

Laser, M., H. Beaujean, J. Bohnenstingl, P. Filss, M. Heidendael, S. Mastera, E. Merz, and H. Vygen. 1973. Off-Gas Treatment and Krypton Disposal in HTGR-Fuel Element Reprocessing. In Proceedings of Symposium on the Management of Radioactive Wastes from Fuel Reprocessing. Organisation for Economic Co-operation and Development. 
Lecocq, A. 1976. "Method for preventing tritium contamination of secondary salt and steam in a molten salt reactor." Patent No. US3963564A.

Lessinger, L. 1994. "Morse oscillators, Birge-Sponer extrapolation, and the electronic absorption spectrum of $\mathrm{I}_{2}$." Journal of Chemical Education 71(5):388-91.

Lines, A. M., G. B. Hall, S. Sinkov, T. Levitskaia, N. Gallagher, G. J. Lumetta, and S. A. Bryan. 2020. "Overcoming oxidation state-dependent spectral interferences: Online monitoring of U(VI) reduction to U(IV) via Raman and UV-vis spectroscopy." Industrial \& Engineering Chemistry Research 59(19):8894901.

Lines, A. M., P. Tse, H. M. Felmy, J. M. Wilson, J. Shafer, K. M. Denslow, A. N. Still, C. King, and S. A. Bryan. 2019. "Online, real-time analysis of highly complex processing streams: Quantification of analytes in Hanford tank sample." Industrial \& Engineering Chemistry Research 58(47):21194-200.

Liu, J., C. A. Fernandez, P. F. Martin, P. K. Thallapally, and D. M. Strachan. 2014. "A Two-Column Method for the Separation of $\mathrm{Kr}$ and Xe from Process Off-Gases." Industrial \& Engineering Chemistry Research 53(32): 12893-99.

Loomis, R. A., J. J. Klaassen, J. Lindner, P. G. Christopher, and S. R. Leone. 1997. "Fourier transform infrared emission study of the mechanism and dynamics of HOI formed in the reaction of alkyl iodides with $\mathrm{O}\left({ }^{3} P\right) . "$ The Journal of Chemical Physics 106(10):3934-47.

Lu, W., Z. Wei, Z.-Y. Gu, T.-F. Liu, J. Park, J. Park, J. Tian, M. Zhang, Q. Zhang, T. Gentle Iii, M. Bosch, and H.-C. Zhou. 2014. "Tuning the structure and function of metal-organic frameworks via linker design." Chemical Society Reviews 43(16):5561-93.

Mailen, J. C. and D. E. Horner. 1975. "Removal of radioiodine from gas streams by electrolytic scrubbing." Nuclear Technology 30:317-24.

Malm, J. G., B. Weinstock, and H. H. Claassen. 1959. "Platinum hexafluoride and method of fluorinating plutonium containing mixtures therewith." Patent No. US2893826.

Malm, J. G., B. Weinstock, and E. E. Weaver. 1958. "The Preparation and Properties of $\mathrm{NpF}_{5}$; a Comparison with $\mathrm{PuF}_{5} . "$ The Journal of Physical Chemistry 62(12):1506-08.

Maric, D., J. P. Burrows, and G. K. Moortgat. 1994. "A study of the UV-visible absorption spectra of $\mathrm{Br}_{2}$ and BrCl." Journal of Photochemistry and Photobiology A: Chemistry 83(3):179-92.

Martinez, A. M., Y. Castrillejo, B. Børresen, M. R. Bermejo, and M. Vega. 2000. "Chemical and electrochemical behaviour of chromium in molten chlorides." Journal of Electroanalytical Chemistry 493(1):1-14.

Matsuda, H., H. Habuka, Y. Ishida, and T. Ohno. 2015. "Metal fluorides produced using chlorine trifluoride gas." Journal of Surface Engineered Materials and Advanced Technology 5:228-36.

Matsuura, Y. and M. Miyagi. 1992. "Bending losses and beam profiles of zinc selenide-coated silver waveguides for carbon-dioxide laser-light." Applied Optics 31(30):6441-45.

Matyáš, J., G. E. Fryxell, B. J. Busche, K. Wallace, and L. S. Fifield. 2011a. Functionalized silica aerogels: advanced materials to capture and immobilize radioactive iodine. In Proceedings of Ceramic Materials for 
Energy Applications: Ceramic Engineering and Science. eds. H-T Lin, et al., vol. 32, pp. 23-33, WileyThe American Ceramic Society.

Matyáš, J., G. E. Fryxell, B. J. Busche, K. Wallace, and L. S. Fifield. 2011b. Functionalized silica aerogels: advanced materials to capture and immobilize radioactive iodine. In Proceedings of Ceram. Eng. Sci.: Ceram. Mater. Energy Appl. eds. H-T Lin, et al., vol. 32, pp. 23-33, Wiley-The American Ceramic Society.

McBee, E. T. and L. R. Evans. 1945. The Identification of the By-Products from the Reaction of Tuballoy Trioxide with Hexachloropropene. A-2704, Purdue University, Lafayette, IN.

McBee, E. T., D. W. Pearce, and R. Mezey. 1946. Chlorination of tuballoy U oxides with thionyl chloride. A-2706, Purdue University, Lafayette, IN.

McFarlane, J., N. D. Bull Ezell, G. Del Cul, D. E. Holcomb, K. Myhre, A. Chapel, A. Lines, S. Bryan, H. M. Felmy, and B. Riley. 2019a. Fission Product Volatility and Off-Gas Systems for Molten Salt Reactors. ORNL/TM-2019/1266, PNNL-28974, Oak Ridge National Laboratory, Oak Ridge, TN.

McFarlane, J., N. D. Bull Ezell, G. D. DelCul, D. E. Holcomb, K. Myhre, A. Lines, S. Bryan, H. M. Felmy, and B. J. Riley. 2019b. Fission Product Volatility and Off-Gas Systems for Molten Salt Reactors. ORNL/TM-2019/1266, PNNL-28974, Oak Ridge National Laboratory, Oak Ridge, TN.

McFarlane, J., P. Taylor, D. Holcomb, and W. P. Poore. 2019c. Review or Hazards Associated with Molten Salt Reactor Fuel Processing Operations. ORNL/TM-2019/1195, Oak Ridge National Laboratory, Oak Ridge, TN.

McFarlane, J., C. F. Weber, M. S. Greenwood, and A. L. Qualls. 2018. Thermochemical and transport properties important to molten salt reactor operation: Off-gas performance and the fission product mechanistic source term. ORNL/TM-2018/958, Oak Ridge National Laboratory, Oak Ridge, TN.

McFarlane, J., J. C. Wren, and R. L. Lemire. 2002. "Chemical speciation of iodine source term to containment." Nuclear Technology 138:162-78.

McMurray, J., T. Besmann, J. Ard, S. Utlak, and R. Lefebvre. 2019. Status of the Molten Salt Thermodynamic Database. MSTDB, ORNL/SPR-2019/1208, Oak Ridge National Laboratory, Oak Ridge, TN.

McMurray, J. W., B. J. Frame, and S. L. Voi. 2018. "Vaporization behavior of an alkyl diphenyl ether and a commercial lubricant." Vacuum 155(c):43-48.

McNeese, L. E. 1974. Program Plan for the Development of Molten-Salt Breeder Reactors. ORNL-5018, Oak Ridge National Laboratory, Oak Ridge, TN.

Mineo, H., M. Gotoh, M. Iizuka, S. Fujisaki, H. Hagiya, and G. Uchiyama. 2003. "Applicability of a model predicting iodine-129 profile in a silver nitrate silica-gel column for dissolver off-gas treatment of fuel reprocessing." Separation Science and Technology 38(9):1981-2001.

Mineo, H., M. Gotoh, M. Iizuka, S. Fujisaki, and G. Uchiyama. 2002. "A Simple Model Predicting Iodine Profile in a Packed Bed of Silica-Gel Impregnated with Silver Nitrate." Journal of Nuclear Science and Technology 39(3):241-47. 
Nagai, T., A. Uehara, T. Fujii, N. Sato, and H. Yamana. 2011. "Electrochemical behavior and electronic absorption spectra of uranium trivalent ions in molten $\mathrm{LiCl}-\mathrm{CsCl}$ mixtures." Journal of Nuclear Materials 414(2):226-31.

Nagai, T., A. Uehara, T. Fujii, O. Shirai, N. Sato, and H. Yamana. 2005. "Redox equilibrium of $\mathrm{U}^{4+} / \mathrm{U}^{3+}$ in molten $\mathrm{NaCl}-2 \mathrm{CsCl}$ by UV-Vis spectrophotometry and cyclic voltammetry " Journal of Nuclear Science and Technology 42(12):1025-31.

Nagai, T., A. Uehara, T. Fujii, and H. Yamana. 2013. "Reduction behavior of $\mathrm{UO}_{2}{ }^{2+}$ in molten $\mathrm{LiCl}-\mathrm{RbCl}$ and LiCl-KCl eutectics by using tungsten." Journal of Nuclear Materials 439(1):1-6.

Naito, K., T. Tsuji, T. Matsui, and K. Une. 1974. "Purification of inert gas." Journal of Nuclear Science and Technology 11(1):22-28.

Nasse, J. M., P. G. Eger, D. Pohler, S. Schmitt, U. Friess, and U. Platt. 2019. "Recent improvements of long-path DOAS measurements: impact on accuracy and stability of short-term and automated long-term observations." Atmospheric Measurement Techniques 12(8):4149-69.

Nebeker, E. B. and C. J. Pings. 1965. "The continuous absorption spectrum of iodine monochloride." The Journal of Physical Chemistry 69(7):2483-84.

Nelson, G. L., A. M. Lines, J. M. Bello, and S. A. Bryan. 2019. "Online monitoring of solutions within microfluidic chips: Simultaneous Raman and UV-Vis absorption spectroscopies." ACS Sensors 4(9):228895.

Ngai, L. H. and F. E. Stafford. 1971. "Gaseous Oxohalides, Hydroxides, and Complex Oxides of Group III and Transition Elements." In Advances in High Temperature Chemistry, ed. L Eyring, Vol 3, pp. 21370. Elsevier.

Nisel'son, L. A., R. K. Nikolaev, T. D. Sokolova, V. I. Stolyarov, and Y. M. Korolev. 1968. "Physicalchemical properties of molybdenum and tungsten hexafluorides. Separation and purification by a distillation method." Izvestiya Sibirskogo Otdeleniya Akademii Nauk SSSR, Seriya Khimicheskikh Nauk 1:109-14.

Nouar, F., J. F. Eubank, T. Bousquet, L. Wojtas, M. J. Zaworotko, and M. Eddaoudi. 2008. "Supermolecular building blocks (SBBs) for the design and synthesis of highly porous metal-organic frameworks." Journal of the American Chemical Society 130(6):1833-35.

NRC. 2015. Nuclear Regulatory Commission, Standard Review Plan for Fuel Cycle Facilities License Applications, NUREG-1520 Rev. 2, ML15176A258.

NUCON Technical Bulletin 11B10. 2012. NUCON International Inc.

NUREG/CR-6410. 1998. Science Applications International Corporation, Nuclear Fuel Cycle Facility Accident Analysis Handbook, ML072000468.

Olander, D. R. and J. L. Camahort. 1966. "Reaction of chlorine and uranium tetrachloride in the fused lithium chloride-potassium chloride eutectic." AIChE Journal 12(4):693-99.

Oliver, G. D. and J. W. Grisard. 1952. "Thermal data, vapor pressure and entropy of bromine trifluoride." Journal of the American Chemical Society 74(11):2705-07. 
Ostvald, R. V., V. V. Shagalov, I. I. Zherin, G. N. Amelina, V. F. Usov, A. I. Rudnikov, and O. B. Gromov. 2009. "Separation of system based on uranium hexafluoride and some of halogen fluorides." Journal of Fluorine Chemistry 130:108-16.

Park, Y. J., S. E. Bae, Y. H. Cho, J. Y. Kim, and K. Song. 2011. "UV-vis absorption spectroscopic study for on-line monitoring of uranium concentration in $\mathrm{LiCl}-\mathrm{KCl}$ eutectic salt." Microchemical Journal 99(2):170-73.

Patel, D., A. J. Wooles, E. Hashem, H. Omorodion, R. J. Baker, and S. T. Liddle. 2015. "Comments on reactions of oxide derivatives of uranium with hexachloropropene to give $\mathrm{UCl}_{4}$." New Journal of Chemistry 39(10):7559-62.

Petti, D. A., G. R. Smolik, M. F. Simpson, J. P. Sharpe, R. A. Anderl, S. Fukada, Y. Hatano, M. Hara, Y. Oya, T. Terai, D. K. Sze, and S. Tanaka. 2006. "JUPITER-II molten salt Flibe research: An update on tritium, mobilization and redox chemistry experiments." Fusion Engineering and Design 81(8):1439-49.

Phillips, J. E. and C. E. Easterly. 1980. Sources of Tritium. ORNL/TM-6402, Oak Ridge National Laboratory, Oak Ridge, TN.

Platt, U. and D. Perner. 1980. "Direct measurements of atmospheric $\mathrm{CH}_{2} \mathrm{O}, \mathrm{HNO}_{2}, \mathrm{O}_{3}, \mathrm{NO}_{2}$, and $\mathrm{SO}_{2}$ by differential optical-absorption in the near UV." Journal of Geophysical Research-Oceans 85(Nc12):745358.

Platt, U., D. Perner, G. W. Harris, A. M. Winer, and J. N. Pitts. 1980a. "Observations of nitrous-acid in an urban atmosphere by differential optical-absorption." Nature 285(5763):312-14.

Platt, U., D. Perner, J. Schroder, C. Kessler, and A. Toennissen. 1981. "The diurnal-variation of $\mathrm{NO}_{3} . "$ Journal of Geophysical Research-Oceans 86(Nc12):1965-70.

Platt, U., D. Perner, A. M. Winer, G. W. Harris, and J. N. Pitts. 1980b. "Detection of $\mathrm{NO}_{3}$ in the polluted troposphere by differential optical-absorption." Geophysical Research Letters 7(1):89-92.

Polovov, I. B., C. A. Sharrad, I. May, B. D. Vasin, V. A. Volkovich, and T. R. Griffiths. 2007. "Spectroelectrochemical study of ranium and neptunium in LiCl-KCl eutectic melt." ECS Transactions 3(35):503-11.

Polovov, I. B., V. A. Volkovich, J. M. Charnock, B. Kralj, R. G. Lewin, H. Kinoshita, I. May, and C. A. Sharrad. 2008. "In situ spectroscopy and spectroelectrochemistry of uranium in high-temperature alkali chloride molten salts." Inorganic Chemistry 47(17):7474-82.

Ponomarev, L. I., Y. S. Fedorov, A. E. Miroslavov, and A. M. Degtyarev. 2016. "Uranium-plutonium fuel cycle of a fast molten salt reactor." Atomic Energy 121(1):63-69.

Prabhakara Reddy, B., S. Vandarkuzhali, T. Subramanian, and P. Venkatesh. 2004. "Electrochemical studies on the redox mechanism of uranium chloride in molten LiCl- $\mathrm{KCl}$ eutectic." Electrochimica Acta 49(15):2471-78.

Prideaux, E. B. R. 1906. "XXXV.- Some reactions and new compounds of fluorine." Journal of the Chemical Society, Transactions 89(0):316-32. 
Pursell, C. J. and L. Doezema. 1999. "The electronic absorption spectrum of molecular iodine: A new fitting procedure for the physical chemistry laboratory." Journal of Chemical Education 76(6):839-41.

Rak, V. and F. Lisý. 1979. Physical and Chemical Properties of Volatile Ruthenium Fluorides. UJV 4502 - CH, Ústav Jaderného Výzkumu Řež, Řež, Czechoslovakia.

Rattigan, O. V., D. E. Shallcross, and R. Anthony Cox. 1997. "UV absorption cross-sections and atmospheric photolysis rates of $\mathrm{CF}_{3 \mathrm{I}}, \mathrm{CH}_{3} \mathrm{I}, \mathrm{C}_{2} \mathrm{H}_{5} \mathrm{I}$ and $\mathrm{CH}_{2} \mathrm{ICl}$." Journal of the Chemical Society, Faraday Transactions 93(16):2839-46.

Reshetnikov, N. A. and N. I. Vilutis. 1959. "The ternary system formed by the hydroxides of lithium, sodium, and potassium." Russian Journal of Inorganic Chemistry 4:49-53.

Richardson, E. W. and L. E. McNeese. 1968. "Process for making porous sodium fluoride pellets." Patent No. US3372004A.

Riley, B., J. McFarlane, G. Del Cul, J. D. Vienna, C. I. Contescu, L. M. Hay, A. V. Savino, and H. Adkins. 2018a. Identification of Potential Waste Processing and Waste Form Options for Molten Salt Reactors. NTRD-MSR-2018-000379, PNNL-27723, Pacific Northwest National Laboratory, Richland, WA.

Riley, B. J. 2020. "Electrochemical salt wasteform development: A review of salt treatment and immobilization options." Industrial \& Engineering Chemistry Research 59(21):9760-74.

Riley, B. J. and S. Chong. 2020. "Crystalline Aluminosilicates for Radionuclide Remediation." In $A n$ Introduction to Aluminosilicates, ed. NR Blevins, ch. 6, NOVA Science Publishers, New York.

Riley, B. J., J. Chun, J. V. Ryan, J. Matyáš, X. S. Li, D. W. Matson, S. K. Sundaram, D. M. Strachan, and J. D. Vienna. 2011. "Chalcogen-based aerogels as a multifunctional platform for remediation of radioactive iodine." RSC Advances 1:1704-15.

Riley, B. J., J. Chun, W. Um, W. C. Lepry, J. Matyáš, M. J. Olszta, X. Li, K. Polychronopoulou, and M. G. Kanatzidis. 2013a. "Chalcogen-Based Aerogels As Sorbents for Radionuclide Remediation." Environmental Science \& Technology 47(13):7540-47.

Riley, B. J., J. O. Kroll, J. A. Peterson, J. Matyáš, M. J. Olszta, X. Li, and J. D. Vienna. 2017a. "Silverloaded aluminosilicate aerogels as iodine sorbents." ACS Applied Materials \& Interfaces 9(38):32907-19.

Riley, B. J., J. McFarlane, G. D. DelCul, J. D. Vienna, C. I. Contescu, and C. W. Forsberg. 2019. "Molten salt reactor waste and effluent management strategies: A review." Nuclear Engineering and Design 345:94109.

Riley, B. J., J. McFarlane, G. D. DelCul, J. D. Vienna, C. I. Contescu, L. M. Hay, A. V. Savino, and H. E. Adkins. 2018b. Identification of Potential Waste Processing and Waste Form Options for Molten Salt Reactors. NTRD-MSR-2018-000379, PNNL-27723, Pacific Northwest National Laboratory, Richland, WA.

Riley, B. J., J. A. Peterson, J. D. Vienna, W. L. Ebert, and S. M. Frank. 2020. "Dehalogenation of electrochemical processing salt simulants with ammonium phosphates and immobilization of salt cations in an iron phosphate glass waste form." Journal of Nuclear Materials 529:151949. 
Riley, B. J., D. Pierce, A, and J. Chun. 2013b. Efforts to Consolidate Chalcogels with Adsorbed Iodine. FCRD-SWF-2013-000249, PNNL-22678, Pacific Northwest National Laboratory, Richland, WA.

Riley, B. J., D. Pierce, A, J. Chun, J. Matyáš, W. C. Lepry, T. Garn, J. Law, and M. G. Kanatzidis. 2014. "Polyacrylonitrile-chalcogel hybrid sorbents for radioiodine capture." Environmental Science \& Technology 48(10):5832-39.

Riley, B. J., D. A. Pierce, W. C. Lepry, J. O. Kroll, J. Chun, K. S. Subrahmanyam, M. G. Kanatzidis, F. K. Alblouwy, A. Bulbule, and E. M. Sabolsky. 2015. "Consolidation of Tin Sulfide Chalcogels and Xerogels with and without Adsorbed Iodine." Industrial \& Engineering Chemistry Research 54(45):11259-67.

Riley, B. J., B. T. Rieck, J. S. McCloy, J. V. Crum, S. K. Sundaram, and J. D. Vienna. 2012. "Tellurite glass as a waste form for mixed alkali-chloride waste streams: candidate materials selection and initial testing." Journal of Nuclear Materials 424(1-3):29-37.

Riley, B. J., J. D. Vienna, S. M. Frank, J. O. Kroll, J. A. Peterson, N. L. Canfield, Z. Zhu, J. Zhang, K. Kruska, and D. K. Schreiber. 2017b. "Glass binder development for a glass-bonded sodalite ceramic waste form." Journal of Nuclear Materials 489:42-63.

Riley, B. J., J. D. Vienna, D. M. Strachan, J. S. McCloy, and J. L. Jerden. 2016. "Materials and processes for the effective capture and immobilization of radioiodine: A review." Journal of Nuclear Materials 470:307-26.

Robertson, R. C. 1971a. Conceptual Design Study of a Single-Fluid Molten-Salt Breeder Reactor. ORNL4541, Oak Ridge National Laboratory, Oak Ridge, TN.

Robertson, R. C. 1965. MSRE Design and operations Report. ORNL-TM-728, Oak Ridge National Laboratory, Oak Ridge, TN.

Robertson, R. C. 1971b. Estimating Cost of Adding a Third Salt-Circulating System for Controlling Tritium Migration in the 1000-MW(e) MSBR. ORNL-TM-3428, Oak Ridge National Laboratory, Oak Ridge, TN.

Robertson, R. C. E. 1971c. Conceptual Design Study of a Single-Fluid Molten-Salt Breeder Reactor. ORNL-4541, Oak Ridge National Laboratory, Oak Ridge, TN.

Rogers, M. T. and J. L. Speirs. 1956. "Bromine pentafluoride. Freezing and boiling points, heat of vaporization and vapor pressure-temperature relations." The Journal of Physical Chemistry 60(10):146263.

Rogers, M. T., J. L. Speirs, H. B. Thompson, and M. B. Panish. 1954. "Iodine pentafluoride, freezing and boiling point, heat of vaporization and vapor pressure-temperature relations." Journal of the American Chemical Society 76(19):4843-44.

Rosenthal, M. W., P. N. Haubenreich, and R. B. Briggs. 1972. Molten Salt Reactor Program, The Development Status of Molten Salt Breeder Reactors. ORNL-4812, Oak Ridge National Laboratory, Oak Ridge, TN.

Rudel, S. S. and F. Kraus. 2017. "Facile syntheses of pure uranium halides: $\mathrm{UCl}_{4}, \mathrm{UBr}_{4}$ and $\mathrm{UI}_{4}$." Dalton Transactions 46(18):5835-42. 
Saito, M., Y. Matsuura, M. Kawamura, and M. Miyagi. 1990. "Bending losses of incoherent-light in circular hollow wave-guides." Journal of the Optical Society of America A-Optics Image Science and Vision 7(11):2063-68.

Sakurai, K. and H. P. Broida. 1970. "Iodine fluorescence excited by He-Ne 6328-Å laser." Journal of Chemical Physics 53(4):1615-16.

Sasahira, A., Y. Kani, F. Kawamura, K. Hoshino, V. N. Prusakov, and O. Amano. 2005. Adsorption of plutonium fluoride with uranyl fluoride trap. In Proceedings of Global 2005. pp. 395.

Sava, D. F., K. W. Chapman, M. A. Rodriguez, J. A. Greathouse, P. S. Crozier, H. Zhao, P. J. Chupas, and T. M. Nenoff. 2013. "Competitive $\mathrm{I}_{2}$ Sorption by $\mathrm{Cu}-\mathrm{BTC}$ from Humid Gas Streams." Chemistry of Materials 25(13):2591-96.

Sava, D. F., T. J. Garino, and T. M. Nenoff. 2012. "Iodine confinement into metal-organic frameworks (MOFs): low-temperature sintering glasses to form novel glass composite material (GCM) alternative waste forms." Industrial \& Engineering Chemistry Research 51(2):614-20.

Sava, D. F., M. A. Rodriguez, K. W. Chapman, P. J. Chupas, J. A. Greathouse, P. S. Crozier, and T. M. Nenoff. 2011. "Capture of volatile iodine, a gaseous fission product, by zeolitic imidazolate framework8." Journal of the American Chemical Society 133(32):12398-401.

Scheele, R., B. McNamara, A. M. Casella, and A. Kozelisky. 2012. "On the use of thermal $\mathrm{NF}_{3}$ as the fluorination and oxidation agent in treatment of used nuclear fuels." Journal of Nuclear Materials 424(1):224-36.

Schiferl, D., S. Kinkead, R. C. Hanson, and D. A. Pinnick. 1987. "Raman spectra and phase diagram of fluorine at pressures up to $6 \mathrm{GPa}$ and temperatures between 10 and $320 \mathrm{~K}$." The Journal of Chemical Physics 87(5):3016-21.

Schmets, J. J. 1967. Review of Halide Volatility Processes. in "Reprocessing of fuel from present and future power reactors." KR-126, Centre d'Etude de l'Energie Nucléaire, Mol, Belgium.

Schmidt, A. S., F. Verfuss, and E. Wicke. 1985. "Studies on the permeation of hydrogen and tritium through heat-resistant alloys." Journal of Nuclear Materials 131(2):247-60.

Schroll, C. A., S. Chatterjee, T. Levitskaia, W. R. Heineman, and S. A. Bryan. 2016. "Spectroelectrochemistry of $\mathrm{EuCl}_{3}$ in four molten salt eutectics; $3 \mathrm{LiCl}-\mathrm{NaCl}, 3 \mathrm{LiCl}-2 \mathrm{KCl}, \mathrm{LiCl}-\mathrm{RbCl}$, and $3 \mathrm{LiCl}-2 \mathrm{CsCl}$; at $873 \mathrm{~K} . "$ Electroanalysis 28(9):2158-65.

Schultz, R. M., W. E. Hobbs, J. L. Norton, and M. J. Stephenson. 1981. Sorbent Selection and Design Considerations for Uranium Trapping. K/ET-5025, Union Carbide Corporation, Oak Ridge, TN.

Schwochau, K. 2000. Technetium: Chemistry and radiopharmaceutical applications, Wiley-VCH Verlag GmbH, Weinheim, Germany.

Scott, S. M., T. Hu, T. Yao, G. Xin, and J. Lian. 2015. "Graphene-based sorbents for iodine-129 capture and sequestration." Carbon 90:1-8. 
Sierchula, J., Weissbach, D., Huke, A., Ruprecht, G. Czerski, K., Dabrowski, M.P. 2019. Determination of the liquid eutectic metal fuel duel fluid reactor (DFRm) design - steady state calculations, Int. J. Energy Res. 43(8), 3692-3701.

Seregin, M. B., A. P. Parshin, A. Y. Kuznetsov, L. I. Ponomarev, and S. A. Mel'nikov. 2011. "Solubility of $\mathrm{UF}_{4}, \mathrm{ThF}_{4}$, and $\mathrm{CeF}_{3}$ in the $\mathrm{NaF}_{-} \mathrm{ZrF}_{4}$ melt." Radiochemistry 53(1):69-72.

Shair, R. C. and W. F. Schurig. 1951. "Vapor-liquid equilibrium of antimony pentafluoride-hydrogen fluoride." Industrial \& Engineering Chemistry 43(7):1624-27.

Shatalov, V. V., M. B. Seregin, V. F. Kharin, and L. A. Ponomarev. 2001. "Gas-fluoride technology for processing spent oxide fuel." Atomic Energy 90(3):224-34.

Shaw III, C. F. 1981. "Resonance fluorescence and resonance Raman spectroscopy of bromine and iodine vapor." Journal of Chemical Education 58(4):343.

Sherman, S. R. and T. M. Adams. 2008. Tritium Barrier Materials and Separation Systems for the NGNP. WSRC-STI-2008-00358, Rev. 1, Savannah River Nuclear Solutions LLC, Savannah River National Laboratory, Aiken, SC.

Siemer, D. D. 2012. "Improving the integral fast reactor's proposed salt waste management system." Nuclear Technology 178(3):341-52.

Simmons, D. 1996. An Introduction to Technetium in the Gaseous Diffusion Cascades. KTSO-39, Lockheed Martin Energy Systems, Inc., Oak Ridge, TN.

Simpson, M. F., G. R. Smolik, J. P. Sharpe, R. A. Anderl, D. A. Petti, Y. Hatano, M. Hara, Y. Oya, S. Fukada, S. Tanaka, T. Terai, and D.-K. Sze. 2006. "Quantitative measurement of beryllium-controlled redox of hydrogen fluoride in molten Flibe." Fusion Engineering and Design 81(1):541-47.

Simunovic, S. and M. H. A. Piro. 2017. Thermochimica. Vers. 00. USDOE. , https://www.osti.gov//servlets/purl/1419419.

Smith, A. N. 1971. "Reactor Off-Gas System." In Conceptual Design Study of a Single-Fluid Molten-Salt Breeder Reactor, ed. RC Robertson, ch. 7; ORNL-4541.

Smith, A. N. and M. Bell. 1969. "Distribution of Decay Heat in the MSBR Off-Gas System." In MoltenSalt Reactor Program Semiannual Progress Report for Period Ending February 28, ORNL-4396, pp. 9495.

Smith, G. P. 1956. Corrosion of Materials in Fused Hydroxides. ORNL-2048, Oak Ridge National Laboratory, Oak Ridge, TN.

Stockinger, S. L. 2012. Nuclear Power Plant Gaseous Waste Treatment System Design Prepared for the American Society of Mechanical Engineers American Society of Mechanical Engineers - Radioactive Waste Systems Committee.

Strauss, H. L. 1988. "The resonance Raman spectrum of $\mathrm{I}_{2}$ in solution." Journal of the Indian Institute of Science 68:493-504. 
Subrahmanyam, K. S., I. Spanopoulos, J. Chun, B. J. Riley, P. K. Thallapally, P. N. Trikalitis, and M. G. Kanatzidis. 2017. "Chalcogenide aerogels as sorbents for noble gases (Xe, Kr)." ACS Applied Materials \& Interfaces 9(39):33389-94.

Tanabe, H., T. Sakuragi, K. Yamaguchi, T. Sato, and H. Owada. 2010. "Development of new waste forms to immobilize iodine-129 released from a spent fuel reprocessing plant." Adv. Sci. Technol. (Stafa-Zuerich, Switz.) 73(B):158-70.

Tellinghuisen, J. 2007. "Laser-induced fluorescence in gaseous $\mathrm{I}_{2}$ excited with a green laser pointer." Journal of Chemical Education 84(2):336-41.

Thoma, R. E. 1971. Molten-salt reactor program. ORNL-4658, Oak Ridge National Laboratory, Oak Ridge, TN.

Thomas, T. R., B. A. Staples, and L. P. Murphy. 1978. The Development of $\mathrm{Ag}^{\circ} \mathrm{Z}$ for Bulk ${ }^{129} \mathrm{I}$ Removal from Nuclear Fuel Reprocessing Plants and PbX for ${ }^{129}$ I Storage. In Proceedings of $15^{\text {th }}$ DOE/NRC Nucl. Air Cleaning Treat. Conf., CONF-780819. eds. MW First, vol. 1, pp. 394-415, The Harvard Air Cleaning Laboratory, Cambridge, MA.

Tilman, P., J. P. Wiaux, C. Dauby, J. Glibert, and P. Claes. 1984. "Electrochemical determination of water and oxide ions in $\mathrm{NaOH}+49 \mathrm{~mol} \% \mathrm{KOH}$ eutectic melts." Journal of Electroanalytical Chemistry and Interfacial Electrochemistry 167(1):117-25.

Trevorrow, L. E., V. N. Kolba, G. F. Vandergrift, and M. J. Steindler. 1983a. Compatibility of Technologies with Regulations in the Waste Management of H-3, I-129, C-14, and Kr-85. Part II. Analysis. ANL-83-57-Pt.2, Argonne National Laboratory, Argonne, IL.

Trevorrow, L. E., G. F. Vandegrift, V. M. Kolba, and M. J. Steindler. 1983b. Compatibility of Technologies with regulations in the waste management of $\mathrm{H}-3, \mathrm{I}-129, \mathrm{C}-14$, and $\mathrm{Kr}-85$. Part I. Initial information base. ANL-83-57, Argonne National Laboratory Argonne, IL.

Trowbridge, L. D., G. D. DelCul, B. B. Spencer, and E. D. Collins. 2004. Advanced Spent Fuel Processing Based on Fluorination and Volatility of Fluoride Species: The "Trufluor" Concept". In Proceedings of American Nuclear Society. vol. 90, pp. 81.

Uehara, A., O. Shirai, T. Nagai, T. Fujii, and H. Yamana. 2009. "Electrochemical redox reactions of chromium and iron ions in molten $\mathrm{NaCl}-2 \mathrm{CsCl}$ eutectic for pyro-reprocessing of nuclear fuels." Journal of Applied Electrochemistry 39(6):827-35.

van Mal, H. H. 1976. "Stability of Ternary Hydrides and Some Applications." Delft University of Technology, Netherlands: Department of Applied Physics. Ph.D. dissertation.

van Straaten, J. and I. F. Silvera. 1987. "Vibrational mode frequencies, phase diagram, and optical transmission of solid hydrogen iodide to 25 GPa." Physical Review B 36(17):9253-62.

Vienna, J. D., E. D. Collins, J. V. Crum, W. L. Ebert, S. M. Frank, T. G. Garn, D. Gombert, R. Jones, R. T. Jubin, V. C. Maio, J. C. Marra, J. Matyas, T. M. Nenoff, B. J. Riley, G. J. Sevigny, N. R. Soelberg, D. M. Strachan, P. K. Thallapally, and J. H. Westsik. 2015. Closed Fuel Cycle Waste Treatment Strategy. FCRDMRWFD-2015-000674, PNNL-24114, Pacific Northwest National Laboratory, Richland, WA. 
Volkovich, V. A., D. A. Danilov, I. B. Polovov, B. D. Vasin, T. R. Griffiths, D. E. Aleksandrov, O. A. Tropin, and D. V. Tsarevskii. 2007. "Speciation of molybdenum and tungsten in molten chlorides: a spectroelectrochemical study." ECS Transactions 3(35):555-66.

Walrafen, G. E. and R. T. W. Douglas. 2006. "Raman spectra from very concentrated aqueous NaOH and from wet and dry, solid, and anhydrous molten, $\mathrm{LiOH}, \mathrm{NaOH}$, and $\mathrm{KOH}$." The Journal of Chemical Physics 124(11):114504.

Wang, C., D. Liu, and W. Lin. 2013. "Metal-organic frameworks as a tunable platform for designing functional molecular materials." Journal of the American Chemical Society 135(36):13222-34.

Wang, Z., G. Feng, M. Wang, and Y. Hong. 2017. Effect of gas flow rate on titanium sponge reaction. In Proceedings of AIP. vol. 1864, pp. 020077-1-5, American Institute of Physics.

Warren, K. S. and L. M. Ferris. 1966. Oxidation and Chlorination of $\mathrm{UO}_{2}-\mathrm{PuO} \mathrm{O}_{2}$. ORNL-3977, Oak Ridge National Laboratory, Oak Ridge, TN.

Wiegel, F. and W. Schuster. 1984. "The vapor pressure of americium trichloride." Inorganic Chimica Acta 94(1-3):111.

Wilhelm, J. and L. Puppe. 1989. "Process for removal of iodine and iodine compounds from gases and vapours with silver containing zeolite X." Patent No. US5075084A.

Williamson, J. C. 2010. "Molecular iodine fluorescence spectra generated with helium-neon lasers for spectrometer calibration." Applied Spectroscopy 64(12):1419-22.

Williamson, J. C. 2011. "Molecular iodine fluorescence using a green helium-neon laser." Journal of Chemical Education 88(6):816-18.

Wilson, T. L., E. E. Moore, D. A. Lopes, V. Kocevski, E. S. Wood, J. T. White, A. T. Nelson, J. W. McMurray, S. C. Middleburg, P. Xu, and T. M. Besmann. 2018. "Uranium nitride-silicide advanced nuclear fuel: higher efficiency and greater safety." Advances in Applied Ceramics: Structural, Functional, and Bioceramics 117(sup1):S76-S81.

Yarbro, O. O., J. C. Mailen, and M. J. Stephenson. 1977. Retention of Gaseous Isotopes, International Atomic Energy Agency, Vienna, Austria.

Zagnit'ko, A. V. and Y. D. Chuvilin. 2009. "Nanoaerosols formation during the bubbling of lithium and beryllium fluorides molten salt to produce reactor radioisotopes." Nanotechnologies in Russia 4(1112):851-56.

Zhang, J. 2014. "Electrochemistry of actinides and fission products in molten salts - Data review." Journal of Nuclear Materials 447(1-3):271-84. 


\section{APPENDIX A}

\section{MSR OFF-GAS SYSTEM PROTOTYPE}

The appendix provides a diagram for the context for the molten hydroxide scrubber in the complete off-gas system. The expected oxygen levels are in the parts-per-million range and should not affect the charcoal beds. The charcoal beds could serve as secondary halide traps. The amount of water should also be very low. If there is no interest in collecting the tritium upfront (for usage), the off-gas system could be rearranged, as shown in the below figure. The main advantage of this approach is that the traps are located after the decay bed, so the radiation field should be highly diminished; this would facilitate the maintenance and replacement of the trapping media.

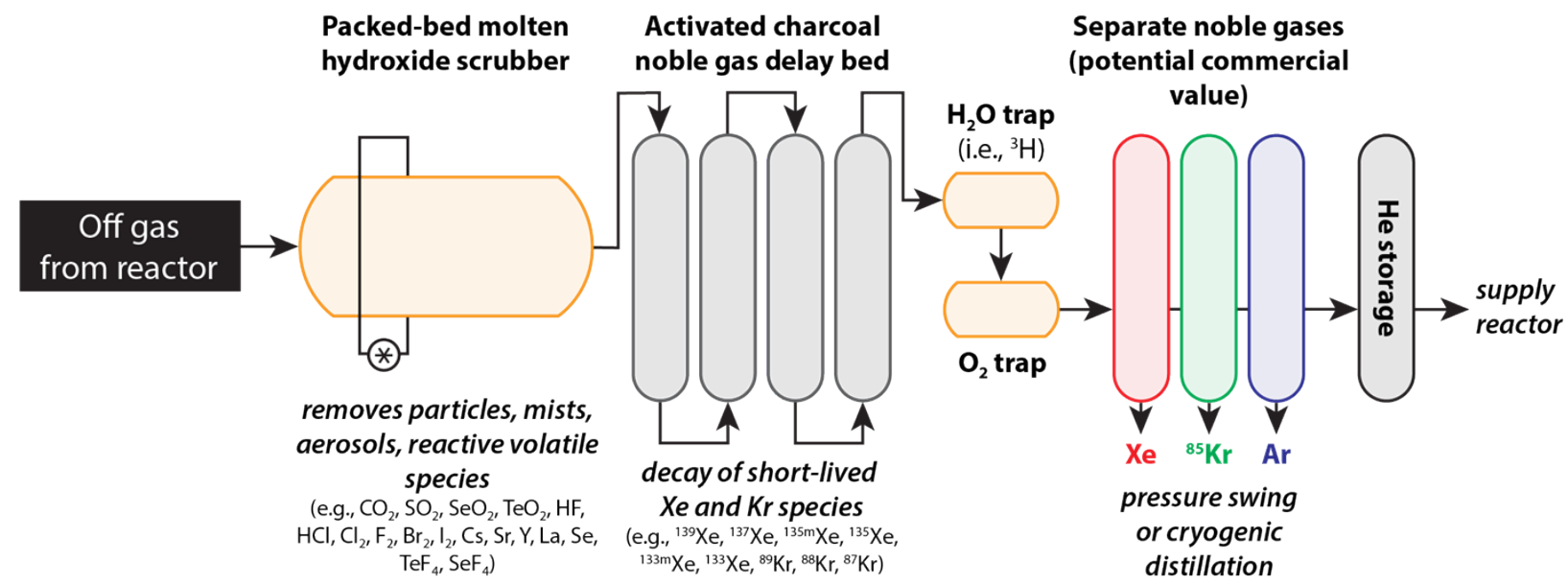

Figure A1. Modified schematic (from Figure 3-3 in Section 3.7) of the overall off-gas system for a commercial MSR based on the MSRE experience. All the components shown here except the molten hydroxide packed-bed scrubber are commercially available (Riley et al. 2018a). 